\title{
WestVirginiaUniversity
}

THE RESEARCH REPOSITORY @ WVU

Graduate Theses, Dissertations, and Problem Reports

2006

\section{Impact of optimally placed VAR support on electricity spot pricing}

Ramesh Kumar V. Khajjayam

West Virginia University

Follow this and additional works at: https://researchrepository.wvu.edu/etd

\section{Recommended Citation}

Khajjayam, Ramesh Kumar V., "Impact of optimally placed VAR support on electricity spot pricing" (2006). Graduate Theses, Dissertations, and Problem Reports. 1774.

https://researchrepository.wvu.edu/etd/1774

This Thesis is protected by copyright and/or related rights. It has been brought to you by the The Research Repository @ WVU with permission from the rights-holder(s). You are free to use this Thesis in any way that is permitted by the copyright and related rights legislation that applies to your use. For other uses you must obtain permission from the rights-holder(s) directly, unless additional rights are indicated by a Creative Commons license in the record and/ or on the work itself. This Thesis has been accepted for inclusion in WVU Graduate Theses, Dissertations, and Problem Reports collection by an authorized administrator of The Research Repository @ WVU. For more information, please contact researchrepository@mail.wvu.edu. 


\title{
Impact of Optimally Placed VAR Support on Electricity Spot Pricing
}

\author{
by \\ Ramesh Kumar V. Khajjayam \\ Thesis submitted to the \\ College of Engineering and Mineral Resources \\ at West Virginia University \\ in partial fulfillment of the requirements \\ for the degree of \\ Master of Science \\ in \\ Electrical Engineering \\ Professor Muhammad A. Choudhry, Ph.D. \\ Professor Powsiri Klinkhachorn, Ph.D. \\ Professor Ali Feliachi, Ph.D., Chair \\ Lane Department of Computer Science and Electrical Engineering \\ Morgantown, West Virginia \\ 2006
}

Keywords: Electricity pricing, VAR support, cost benefit analysis, spot prices, N-1 contingency criterion, voltage stability constrained $\mathrm{OPF}$, transmission pricing 


\author{
Abstract \\ Impact of Optimally Placed VAR Support on Electricity Spot Pricing \\ by \\ Ramesh Kumar V. Khajjayam \\ Master of Science in Electrical Engineering \\ West Virginia University \\ Professor Ali Feliachi, Ph.D., Chair
}

In view of deregulation and privatization processes, electricity pricing becomes one of the most important issues. The increases in power flows and environmental constraints are forcing electricity utilities to install new VAR equipment to enhance network operation. In this thesis a nonlinear multi-objective optimization problem has been formulated to maximize both social welfare and the maximum distance to collapse point in an open power market using reactive support like Static Var Compensator (SVC). The production and consumption costs of reactive power are intended to provide proper market signals to the electricity market agents. They are included in the multi-objective Optimal Power Flow (OPF) coupled with an (N-1) contingency criterion which is based on power flow sensitivity analysis.

Considering the cost associated with the investment of VAR support, placing them at the optimal location in the network is an important issue. An index to find the optimal site for VAR support considering various technical and economical parameters based on Cost Benefit Analysis (CBA) is proposed. The weights for these parameters are computed through an Analytic Hierarchy Process (AHP). A new approach of transmission pricing calculation taking VSC-OPF based multi-objective maximization as the objective and studied the impact of SVC on it. The integrated approach is illustrated on a 6-bus and a standard IEEE 14-bus test systems and shows promising results 


\section{Acknowledgement}

First of all, I would like to thank the Transcendental Lord Sri Krsna who is beyond mundane sense perception, for giving me strength and intelligence to complete this work. I would like to express my profound gratitude to my advisor Dr. Ali Feliachi for his invaluable advice and continuous encouragement throughout this work. I would also like to thank Dr. Muhammad Choudhry for his suggestions and providing the opportunity to instruct Electromechanics lab.

I am also thankful to my committee member Dr. Powsiri Klinkhachorn for his support throughout my graduate education. I would also like to thank Dr. Federico Milano, from University of Castilla-La Mancha, Spain, for providing the PSAT software and suggestions. Thanks to Dr. Karl Schoder for his valuable suggestions and discussions.

A special thank to the students of lab 1001: Talpasai, Silpa, Ram Praveen, Pradeep, Anisha, Ali at APERC. I enjoyed every moment working togather in the lab. Many thanks to my Morgantown and Vijayawada friends for their encouragement.

It is impossible to find the right words to thank my beloved parents, uncle and sister for their love and encouragement. Without it, this thesis would not be completed. 


\section{Contents}

Abstract $\quad$ ii

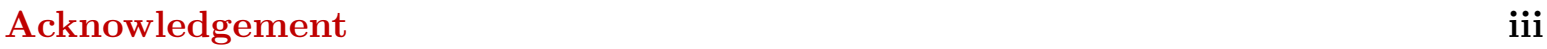

List of Figures $\quad$ vii

List of Tables $\quad$ viii

$\begin{array}{ll}\text { Notation and Acronyms } & \text { ix }\end{array}$

1 Introduction 1

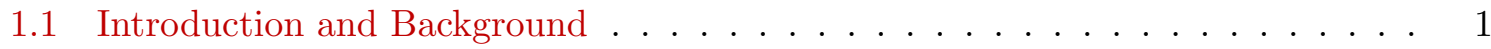

1.1 .1 Energy Pricing . . . . . . . . . . . . . . . . . 3

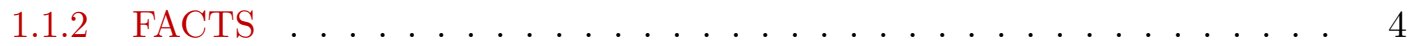

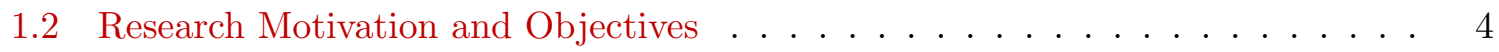

1.3 Outline of the Thesis . . . . . . . . . . . . . . 6

2 Literature Review $\quad 8$

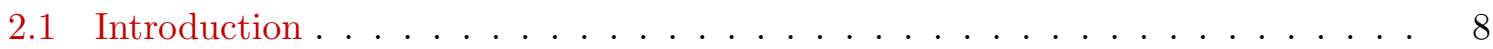

2.2 Electricity Markets Introduction _. . . . . . . . . . . . . . . . . . 9

2.2.1 Various Entities in Deregulated Electricity Market . . . . . . . . . . . 10

2.2.2 Market Clearing Mechanism . . . . . . . . . . . . . . . . . . 11

2.3 Optimal Power Flow . . . . . . . . . . . . . . . . . . . . . 15

2.3.1 OPF with VAR Support Devices . . . . . . . . . . . . . . 17

2.3 .2 Location of VAR Support . . . . . . . . . . . . . . . . . . . . . . . . . . . . . . .

2.4 Power System Analysis Toolbox (PSAT) . . . . . . . . . . . . . . 20

3 Standard OPF Model, Pricing and Tools $\quad 21$

3.1 Introduction . . . . . . . . . . . . . . . . . . . 21

3.2 Security Constrained OPF Market Model . . . . . . . . . . . . . . . 22

3.2 .1 Spot Pricing . . . . . . . . . . . . . . . . . 26

3.2 .2 Nodal Congestion Pricing . . . . . . . . . . . . . . . . . . 27

3.3 Transmission Pricing . . . . . . . . . . . . . . . . . . . . . . . . . . . . . . . . . . .

3.3.1 Wheeling Charges Method . . . . . . . . . . . . . . 29

3.4 Software Tools . . . . . . . . . . . . . . . . . . . . . 29

3.4 .1 PSAT-GAMS . . . . . . . . . . . . . . . . 29 
3.5 Summary . . . . . . . . . . . . . . . . . . . . 31

4 Voltage Stability Constrained OPF $\quad 32$

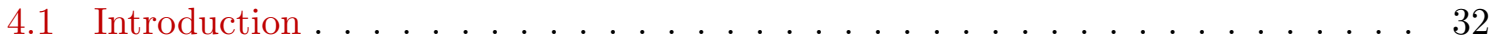

4.1 .1 Voltage Stability . . . . . . . . . . . . . . . 32

4.2 Bifurcation Analysis and Methods . . . . . . . . . . . . . . 33

4.2 .1 Direct Methods . . . . . . . . . . . . . . . . . . . 34

4.2.2 Continuation Methods . . . . . . . . . . . . . . 35

4.3 Multi Objective VSC-OPF Market model . . . . . . . . . . . . . . . . . 39

4.3.1 Spot Pricing and Nodal Congestion Pricing . . . . . . . . . . . . . . 41

4.3.2 Maximum Transfer Capability and Available Transfer Capability . . . . 43

$4.4 \mathrm{~N}-1$ Contingency Criterion . . . . . . . . . . . . . . . . . 43

4.4.1 VSC-OPF with Critical Line Contingency . . . . . . . . . . . . . . . 44

4.4 .2 Contingency Ranking with VSC-OPF . . . . . . . . . . . . 45

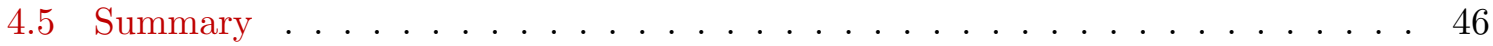

$\begin{array}{lll}5 & \text { VAR Support and Pricing } & 47\end{array}$

5.1 Introduction . . . . . . . . . . . . . . . . . . . 47

5.2 SVC Investment Costs . . . . . . . . . . . . . . . . . . . 47

5.2.1 Equipment Costs and Infrastructure Costs . . . . . . . . . . . . . . 48

5.3 Optimal Placement of VAR Support Devices . . . . . . . . . . . . . . 50

5.3 .1 Cost Benefit Analysis . . . . . . . . . . . . . . . 50

5.3 .2 Analytic Hierarchy Process . . . . . . . . . . . . . . . 54

5.3 .3 Pricing VAR Support Services . . . . . . . . . . . . . 58

5.3 .4 Analysis of Reactive Power Pricing . . . . . . . . . . . . . . . . 59

5.4 VSC-OPF with SVC and N-1 contingency criterion . . . . . . . . . . . . 60

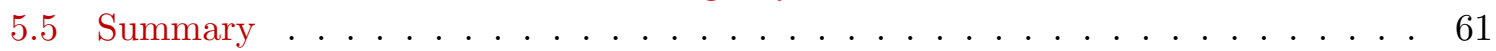

6 System Studies and Discussion $\quad 62$

6.1 Test Systems Description . . . . . . . . . . . . . . . . . . 62

6.26 -Bus Test System . . . . . . . . . . . . . . . . . 63

6.2.1 Results and Discussion . . . . . . . . . . . . . . 65

6.3 IEEE 14-Bus Test System . . . . . . . . . . . . . . . . . 76

6.3.1 Results and Discussion . . . . . . . . . . . . . . . 77

6.4 Summary . . . . . . . . . . . . . . . . . . . 89

7 Conclusions and Future Work $\quad 90$

7.1 Principal Contributions . . . . . . . . . . . . . . . . . 90

7.2 Possible Future Directions . . . . . . . . . . . . . . . . . . . 91

$\begin{array}{ll}\text { APPENDIX } & 92\end{array}$

$\begin{array}{ll}\text { A APPENDIX A } & 92\end{array}$

A.1 Network and Market Data . . . . . . . . . . . . . . . . . . . . 92

A.1.1 PSAT Data Format . . . . . . . . . . . . . . . . 92 
A.1.2 6-Bus Test System ． . . . . . . . . . . . . . . . . . . 96

A.1.3 IEEE 14-Bus Test System . . . . . . . . . . . . . . . . 96

References 


\section{List of Figures}

2.1 Supply and Demand Curve $[98] \ldots \ldots \ldots \ldots$

2.2 Double-sided auction markets . . . . . . . . . . . . . . . . . . 12

3.1 Structure of the PSAT-GAMS interface $[62] \ldots \ldots \ldots \ldots$

4.1 One Step of the Continuation method . . . . . . . . . . . . . 36

4.2 Predictor and Corrector Steps in Continuation power flow . . . . . . . . . . . 38

5.1 SVC Investment costs . . . . . . . . . . . . . . . . . . . . . . 48

5.2 Typical Investemnt Costs for SVC / STATCOM [39] . . . . . . . . . . . . . . 49

5.3 Hierarchy model for optimal placement of SVC . . . . . . . . . . . . . . . 56

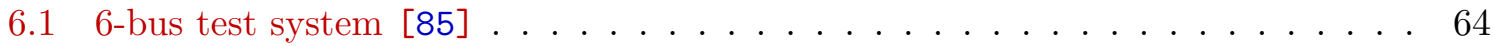

6.2 Loading Margin Vs SVC Capacity for six-bus test system . . . . . . . . . . . 69

6.3 LMPs for the six-bus system . . . . . . . . . . . . . . . . 71

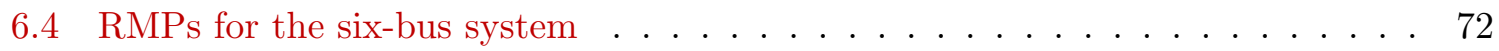

6.5 NCPs for the six-bus system . . . . . . . . . . . . . . . 72

6.6 Total transaction level for the six-bus system . . . . . . . . . . . . 73

6.7 Loading margin for the six-bus system . . . . . . . . . . . . . . 73

6.8 Congestion Cost for the six-bus system . . . . . . . . . . . . . . . . 74

6.9 LMPs for the six-bus system . . . . . . . . . . . . . . . 75

6.10 Single-line daiagram of the IEEE 14-bus test system [94] . . . . . . . . . . 76

6.11 Loading Margin Vs SVC Capacity for IEEE 14-bus test system . . . . . . . . . 82

6.12 LMPs for the IEEE 14-bus system . . . . . . . . . . . . . . . . . . . . 84

6.13 RMPs for the IEEE 14-bus system . . . . . . . . . . . . . . . . . 85

6.14 NCPs for the IEEE 14-bus system . . . . . . . . . . . . . . . . 86

6.15 RMPs for the IEEE 14-bus system . . . . . . . . . . . . . . . 87

6.16 Reactive Power output of generators for IEEE 14-bus system . . . . . . . . . 88

6.17 Bus Voltages for IEEE 14-bus system . . . . . . . . . . . . . . . . . 88 


\section{List of Tables}

2.1 Comparison of MATLAB-based packages for power system analysis . . . . . . . 20

5.1 Set of average stochastic consistency indices RI . . . . . . . . . . . 56

5.2 Weighting Scale for "More Important Than" . . . . . . . . . . . . . . . 57

5.3 Weighting Scale for "Less Important Than" . . . . . . . . . . . . . . . 57

6.1 Six-bus test system: OPF with offline power flow limits . . . . . . . . . . 65

6.2 Six-bus test system: VSC-OPF w/o contingencies . . . . . . . . . . . . 66

6.3 Six-bus test system: Sensitivity coefficients Phk and ATC (N-1) . . . . . . . 66

6.4 Six-bus test system: VSC-OPF w/ contingency on line $2-4 \ldots \ldots$. . . . . . . 67

6.5 Weighting factors for six-bus test system . . . . . . . . . . . 68

6.6 Weak bus ranking for six-bus test system using CBA . . . . . . . . . . 68

6.7 Six-bus test system: VSC-OPF w/ contingency on line 2-4 and with SVC at

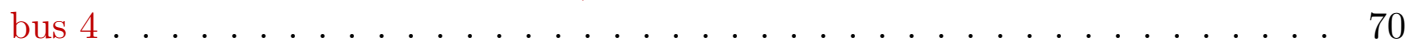

6.8 Benefit factors before and after SVC is installed . . . . . . . . . . 70

6.9 Wheeling rates for a few selected buses w.r.t. generator buses $(\$ / \mathrm{MWh}) \ldots 75$

6.10 IEEE 14-bus test system: OPF with offline power flow limits . . . . . . . . 77

6.11 IEEE 14-bus test system: VSC-OPF w/o contingencies . . . . . . . . . . 78

6.12 IEEE 14-bus test system: Sensitivity coefficients Phk and ATC (N-1) . . . . . 79

6.13 Weighting factors for IEEE 14 -bus test system . . . . . . . . . . . . . 80

6.14 Weak bus ranking for IEEE 14-bus test system . . . . . . . . . . . . . 81

6.15 Single hierarchical ranking of VAR support buses for IEEE 14-bus test system . 81

6.16 IEEE 14-bus test system: VSC-OPF w/ contingency on line 1-2 and SVC on

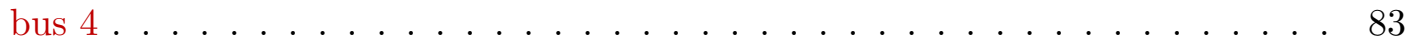

6.17 Wheeling rates for a few selected buses w.r.t. generator buses $(\$ / M W h) \ldots 6$

A.1 Bus Data Format (Bus.con) _ . . . . . . . . . . . . . . . . 92

A.2 $\mathrm{PQ}$ Data Format $(\mathrm{PQ} . \mathrm{con}) \ldots \ldots \ldots \ldots \ldots \ldots$

A.3 PV Data Format (PV.con) . . . . . . . . . . . . . . . 93

A.4 Shunt Data Format (Shunt.con) . . . . . . . . . . . . . . . 93

A.5 SW Data Format (SW.con) . . . . . . . . . . . . . . . . . 94

A.6 Line Data Format (Line.con) . . . . . . . . . . . . . . . . . 94

A.7 Demand Data Format (Demand.con) . . . . . . . . . . . . . . . 95

A.8 Supply Data Format (Supply.con) . . . . . . . . . . . . . . . . 95 


\section{Notation and Acronyms}

Notation

\section{Acronyms}

$\begin{aligned} \text { ATC } & \text { Available Transfer Capability } \\ \text { AHP } & \text { Analytic Hierarchy Process } \\ \text { CBA } & \text { Cost Benefit Analysis } \\ \text { CC } & \text { Congestion Cost } \\ \text { CPF } & \text { Continuation Power Flow } \\ \text { DISCO } & \text { Distribution Company } \\ \text { EPRI } & \text { Electric Power Research Institute } \\ \text { FACTS } & \text { Flexible AC Transmission Systems } \\ \text { GAMS } & \text { General Algebraic Modeling System } \\ \text { GENCO } & \text { Generator Company } \\ \text { IEEE } & \text { Institute of Electrical and Electronics Engineers } \\ \text { ISO } & \text { Independent System Operator } \\ \text { LMP } & \text { Locational Marginal Price } \\ \text { MCP } & \text { Market Clearing Price } \\ \text { MLC } & \text { Maximum Loading Condition } \\ \text { NCP } & \text { Nodal Congestion Price } \\ \text { OPF } & \text { Optimal Power Flow } \\ \text { PAT } & \text { Power Analysis Toolbox } \\ & \quad \text { continued on next page }\end{aligned}$


continued from previous page

\begin{aligned} \hline PF & Power Flow \\ PSAT & Power System Analysis Toolbox \\ RMP & Reactive Power Marginal Price \\ SVC & Static Var Compensator \\ TRANSCO & Transmission Company \\ VAR & Volt-Amperes Reactive \\ VSC-OPF & Voltage Stability Constrained Optimal Power Flow \end{aligned}




\section{CHAPter \\ 1 \\ Introduction}

\subsection{Introduction and Background}

During the last two decades, almost all the electric power systems around the world have been experiencing significant changes due to the privatization and deregulation process. Utilities are now integrated into decentralized environments in which the planning and operation are based on the economic principles of open-access markets. In the deregulated environment, electricity markets are basically competitive and the objective of introducing competition is to make them more efficient. The basic idea is that if fair and equitable market structures are established to give all market participants incentives to maximize their own indivual welfare, then the market as a whole will behave in a manner which maximizes welfare for everyone in the market [88].

Thus, it is clear that in the competitive market the top most economical aspect is social welfare where the market suppliers and the consumers supply bids to the market operator. Consumers should pay the lowest prices for their purchased powers whereas suppliers try to obtain maximum prices for the supplied energy. The prices should be defined on a fair basis and the transactions are limited only by the transmission line limits or power exchange policies. The supply and demand of power should be balanced in real time by dispatching 
the generation in the most economic way possible by respecting all the physical constraints. The pool or independent system/market operator determines these results by optimizing the overall system operation. Spot pricing theory based method is most widely used to dispatch generation and load in the most economic manner.

In competitive markets the primal focus of market and/or system operators is to maintain system security since the power transactions and the construction of new transmission lines are inherently associated with it. Transmission congestion occurs when there is insufficient energy to meet the demands of all customers. System congestion occured due to the thermal limits on transmission lines or voltage levels may not cause emergency conditions promptly but should be avoided and therefore by taking this practical consideration, optimization methods proposed in literature or applied in real time prefers computational efficiency to security constraints. Voltage collapse have severe and immedeate consequences on system stability and it is mandatory to avoid congestions associated with it, but voltage collpase issues are rarely associated with the competitive market studies [19]. Voltage instability may arise following a trip of a line or a generator, or a combination of eqipment outages. However, an unsually high load peak or lesser disturbances can cause voltage to fall. If ample reactive power is not available when voltage falls, reactive reserves are quickly exhausted, and voltage fall further, possibly collapsing completely.

Voltage Collapse has the following charateristics[62]:

- It is a catastrophic and sudden phenomenon and has typically severe effects on some network areas and, sometimes, even on the entire grid. Thus precise information about the proximity to voltage collapse is needed.

- It is generally induced by heavy loading conditions and/or outages which limit the power transfer capability. Hence the need for N-1 contingency criteria.

- A detailed nonlinear analytical model of power system is required to properly study voltage collapse phenomena. This is in contrast with the need of computational efficiency of methods accounting for security and economic dispatch 


\subsubsection{Energy Pricing}

In the deregulated power systems, the desired objective to achieve a more efficient power system is facilitated by competition. In order to achieve proper and efficient competition, how to establish a good pricing scheme becomes a key issue. Thus it is clear that a simple, unambiguous and a transparent pricing scheme is required so that the right market signals can be conveyed to all market pariticipants. Correct price signals will facilitate transmission access and improve economic efficiency. A good pricing scheme should consist of at least the following two aspects. First, it should be fair not only to power consumers but also to power suppliers. In addition, it should he able to stimulate new constructions through providing proper incentives[47].

Pricing energy on the basis of the location of its withdrawal or injection in a network proposed in [81] appears to have a universal following in the evolving deregulated electric power industry. Nodal Pricing is a method of determining prices in which market clearing prices (MCP) are calculated for a number of locations on the transmission grid called nodes. Each node represents the physical location on the transmission system where energy is injected by generators or withdrawn by loads. Price at each node represents the locational value of energy, which includes the cost of the energy and the cost of delivering it, i.e., losses and congestion. In all deregulated markets Independent System Operator (ISO) publishes MCP in real time in the energy market for information purposes, they are often referred to as shadow prices.

According to PJM: Locatioanal Marginal Price (LMP) or Nodal Marginal Price is the cost to serve the next $M W$ of load at a specific location, using the lowest production cost of all available generation, while observing all transmission limits.

The marginal cost to provide energy at a specific location depends on:

- Marginal cost to operate generation

- Total load (demand)

- Cost of delivery on transmission system

- Impact of losses on the interface points 


\subsubsection{FACTS}

In the present day scenario,unplanned power transactions are rapidly increasing due to the competition among utilities to meet the increasing demands and to contracts concluded directly between producers and consumers. But the power flows should follow the Kirchoff's laws and if the transactions are not properly controlled, transmission lines are often operated and stressed to the limit and beyond the performance capability of their original design and sometimes overloaded which is termed congestion and thus the full capacity of transmission interconnections could not be utilized.

Voltage stability, however, is now a major concern in planning and operation electric power systems. Voltage instability and collapse have resulted in several major system blackouts. One reason is the need for more intensive use of available transmission facilities. The increased use of existing transmission is made possible, in part, by reactive power compensation. To ensure that under these conditions the economical, reliable and secure operation of the grid are maintained, the need for various aspects of power flow management within the power system is becoming increasingly evident.

The concept of FACTS and FACTS controllers was first defined by Hingorani in 1988 [43], [44], [45]. They are high power electronics devices used to control the power flow and enhance stability, have become, not only common words in the power industry, but they have started replacing many mechanical control devices. They are certainly playing an important and a major role in the operation and control of modem power systems. FACTS devices provide new control facilities, both in steady state power flow and dynamic stability control [35]. These devices have the capability to improve line flows or loadability, contractual requirement fulfilled, decrease losses, improve voltage profile, increase social benefit, decrease congestion cost etc, without violating specified power dispatch. Because of their considerable costs it is important to ascertain the location for placement of these devices.

\subsection{Research Motivation and Objectives}

Many of today's power networks are operating close to their stability limits due to economical reasons; this inturn, has lead to system collapse problems. For heavy loaded systems, when the operating point approaches the maximum loading point on the $\mathrm{P}-\mathrm{V}$ curve, the region of 
attraction is very small; consequently, perturbations cannot be withstanded by the system. Typically, voltage stability problems are associated with system bifurcations, i.e. saddle-node or limit induced bifurcations, that lead to voltage collapse [51]. Therefore it is evident that additional controllers should be added to enhance the overall stability of systems.

Identification of weak buses is an important issue while placing VAR support. An index to place VAR support based on Cost Benefit Analysis (CBA) is proposed considering social welfare, congestion cost and maximum loading condition of the system. N-1 contingency should be considered while chosing the citation for VAR support and the critical line is found through real power flow sensitivity analysis. To properly include the system security in the operations of decentralized electricity markets, Voltage Stability Constrained OPF (VSCOPF) based market model [62] is chosen for the study with the inclusion of reactive power production and consumption costs. This multi objective OPF maximizes social welfare and the distance to maximum loading condition based on the chosen weights. It is demonstrated that through use of VAR device makes the system more efficient and escalates competition in the market. The objectives of this work are summarized as follows:

1. Develop an OPF based market model with supply and demand bids for active and also for reactive powers.

2. Identify weak nodes for the placement of new VAr support, considering both the technical and economical aspects based on Cost Benefit Analysis (CBA) coupled with N-1 contingency criterion.

3. A method to compute the weights for various parameters of the index which rank optimal VAr sites.

4. Study the effect of VAr support/SVC on power dispatch and spot prices.

5. Calculate wheeling charges and an analysis of reactive power pricing based on marginal cost theory. 


\subsection{Outline of the Thesis}

This section briefly gives an outline of the remaining chapters of this thesis as follows:

- Chapter 2: Literature Survey

This chapter gives an overview of the research background (Section 2.1) and basics of electricity markets (Section 2.2) and different entities in it. The literature work on various indices for optimal placement of VAR support devices in the OPF framework (Section 2.3) and a brief description of power system analysis toolbox (Section 2.4) are presented.

- Chapter 3: Standard OPF Model, Pricing and Tools

This chapter presents a brief introduction of OPF based market models (Section 3.1) and explains in detail about the security constrained OPF (Section 3.2) in the deregulated electricity market. Transmission pricing (Section 3.3) based on wheeling charges method and software tools (Section 3.4) used in this thesis and a summary (Section 3.5) are given.

- Chapter 4: Voltage Stability Constrained OPF

The importance of voltage stability (Section 4.1), theory of bifurcation analysis and methods (Section 4.2) are explained. The modified multi-objective OPF market model, electricity and nodal congestion pricing details (Section 4.3) coupled with N-1 contingency criterion (Section 4.4) methods based on available transfer capability (ATC) and a summary (Section 4.5) are presented.

- Chapter 5: VAR Support and Pricing

This chapter explains the necessity of VAR support (Section 5.1), the investment costs (Section 5.2) associated with it and the index for optimal placement of FACTS (Section $5.3)$ devices. The concept of VAR pricing based on marginal theory and effect of load power factor on reactive power marginal prices (Section 5.3.4) with a brief summary (Section 5.5) are discussed.

- Chapter 6: System Studies

The test systems description (Section 6.1), results and discussions for 6-bus (Section 6.2), IEEE 14-bus (Section 6.3) are summarized (Section 6.4).

- Chapter 7: Conclusions an Future Work 
This chapter presents principal contributions (Section 7.1) and possible future directions (Section 7.2).

In Appendix A.1 the network and market data of the 6-bus (A.1.2) and IEEE 14-bus (A.1.3) are given. 


\section{CHAPter}

2

\section{Literature Review}

\section{$2.1 \quad$ Introduction}

Deregulation is defined as the process by which governments remove restrictions on business and individuals in order to (in theory) encourage the efficient operation of markets. Due to the recent transition from government controlled to deregulated electricity markets, the relationship between power system controllers and electricity markets has added a new dimension, as the effect of these controllers on the overall power system stability has to be seen from an economic point of view [50]. Transmission systems are being required to provide increased power transfer capability and to accommodate a much wider range of possible generation patterns. Environmental, right-of-way, and cost problems are major hurdles for power transmission network expansion. Hence, there is an interest in better utilization of available power system capacities by installing new devices such as FACTS.

This thesis mainly focuses on the voltage stability constrained optimal power flow approach to properly include security constraints in the competitive electricity markets. The effect of VAR support such as FACTS device/SVC on power dispatch and electricity market prices is the main concern. Transmission pricing is an important issue in view of increased deregulation. FACTS devices had the ability to reduce the overall operating cost and their 


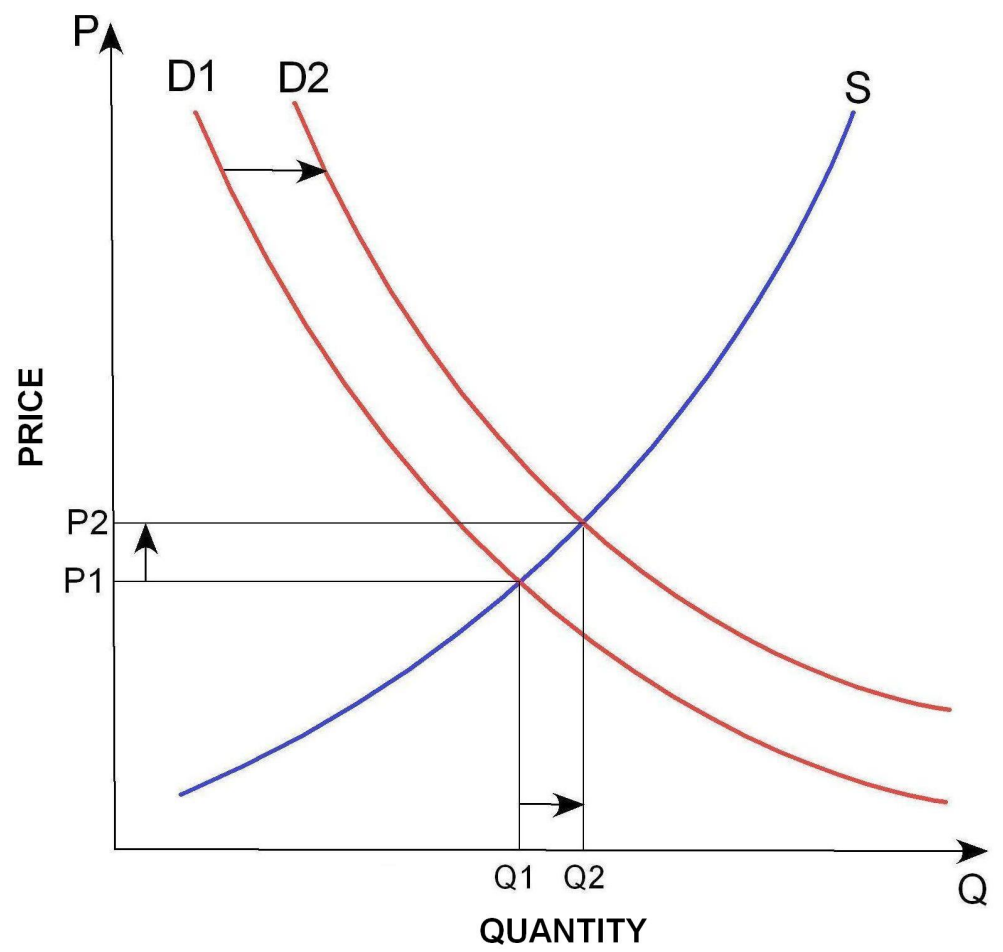

Figure 2.1: Supply and Demand Curve [98]

impact on transmission pricing. A detailed literature survey on various techniques used for finding optimal location for the placement of VAR support and effect of load power factor on reactive power marginal prices is presented in the following sections.

\subsection{Electricity Markets Introduction}

Market is a place where buyers and sellers meet to exchange goods and services. An electricity market is a system for effecting the purchase and sale of electricity using supply and demand to set the price. The theory of supply and demand describes how prices vary as a result of a balance between product availability at each price (supply) and the desires of those with purchasing power at each price (demand). The graph 2.1 depicts an increase in demand from D1 to D2 along with the consequent increase in price and quantity required to reach a new market-clearing equilibrium point on the supply curve $(\mathrm{S})$. The slope of the demand curve (downward to the right) indicates that a greater quantity will be demanded when the price is 
lower. On the other hand, the slope of the supply curve (upward to the right) tells us that as the price goes up, producers are willing to produce more goods. The point at which these curves intersect is the equilibrium point.

Electricity is by its nature difficult to store and the supply and demand has to be balanced in realtime. Unlike other products, it is not possible, under normal operating conditions, to keep it in stock. Demand and supply vary continuously. In the past, the electric power industry has been vertically integrated, meaning that a central authority monitored and controlled all the activities in generation, transmission, and distribution. For the last decade or so, the electric power industry has been undergoing a process of transition and restructuring, in particular the separation of transmission from generation activities. There is therefore a physical requirement for a controlling agency, the power system operator, to coordinate the dispatch of generating units to meet the expected demand of the system across the transmission grid. This system operator must never be involved in the market competition, and is usually called the Independent System Operator (ISO)

\subsubsection{Various Entities in Deregulated Electricity Market}

Many new entities were introduced in the new restructured market. The usual separation of the electric power industry distinguishes among generation, transmission and distribution.

Generation Companies: GENCOs

Operates and maintains existing generating plants. The Gencos interact with the short term market acting on behalf of the plant owners to bid into the short-term power pool for economic dispatch. There are many participants with existing plants and no barriers to entry for construction of new plants.

$\underline{\text { Transmission Companies: TRANSCOs }}$

This segment is regulated to provide open access, comparable service and cost recovery. Constructs and maintains the network of transmission wires. This entity should ensure the availability of the transmission system to all the entities in the system.

$\underline{\text { Distribution Companies: DISCOs }}$

They own and operate local distribution companies. This entity purchases electricity in the 
wholesale market and supply it to the final customers.

Energy Services Companies: ESCOs

These may be large industrial customers, customer pools or private companies, and their main goal is to purchase power at the least cost for their customers from GENCOs. They participate in the market like DISCOs, except that they do not own or operate the local distribution companies.

\section{$\underline{\text { Customers }}$}

These are the consumers of electricity. Depending on the market structure, the customers have various options for purchasing electricity. They can choose to purchase electricity from the spot-market by bidding for purchase, or buy directly from a GENCO, a DISCO or an ESCO.

Independent System Operator: ISO

An entity that will monitor the reliability of the power system and coordinate the supply of electricity around the state. ISO is a non-profit corporation that uses governance models developed by the Federal Energy Regulatory Commission. In the electricity market deregulation it also acts as a marketplace in wholesale power. Regional Transmission Operators (RTOs) such as the Pennsylvania-New Jersey-Maryland Interconnection (PJM) have the same function and responsibility but operate within more than one U.S. state.

\subsubsection{Market Clearing Mechanism}

In most markets, both GENCOs and ESCOs bid in the market. A market clearing price (MCP) is obtained, as illustrated in Figure 2.2, by stacking the supply bids in order of increasing prices and the demand bids in order of decreasing prices. The MCP and the amount of energy cleared for trading are obtained from the intersecting point of these curves. This market clearing process is referred to as double-sided auction power pools [85].

However, the load in most markets does not actively bid, i.e. the load is inelastic. In this case, the system price is cleared by matching the supply curve with a forecast of undispatchable load. Typically, only GENCOs submit bids that are stacked in increasing order of prices, The highest priced bid to intersect with the system demand forecast determines the MCP and such 


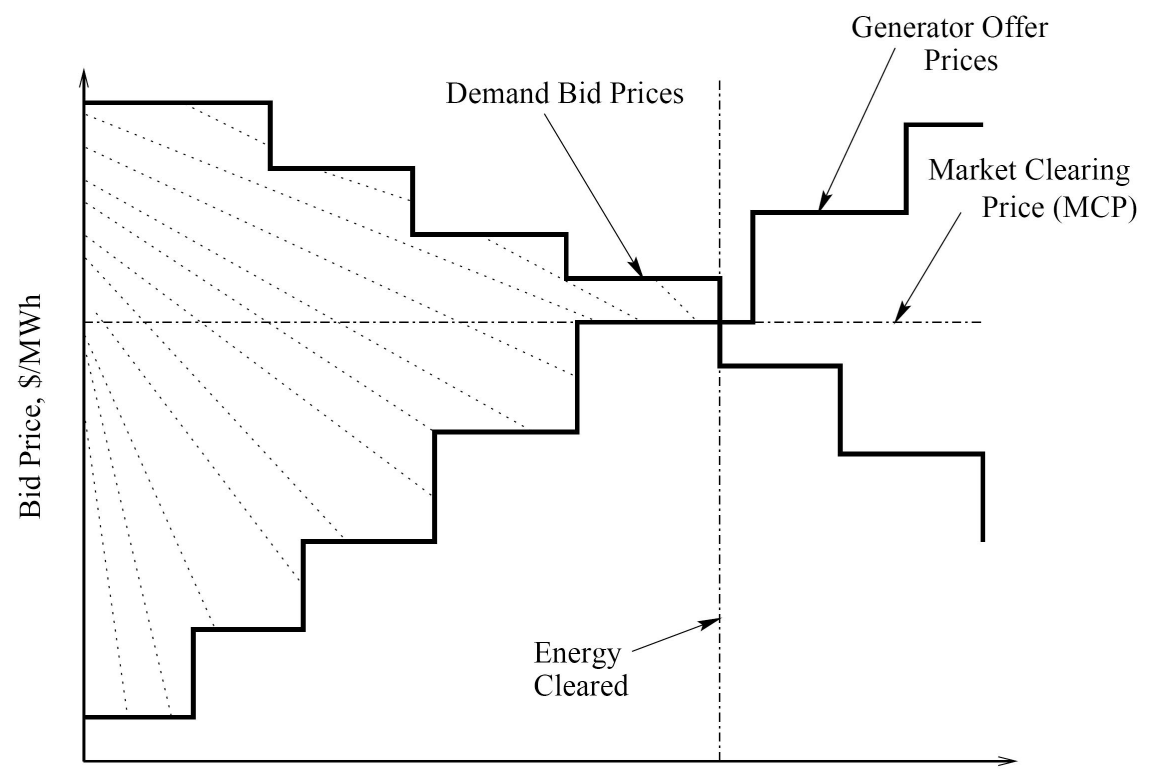

Energy Bid, MWh per h

Figure 2.2: Double-sided auction markets 
a market model is known as a single or one-sided auction power pool.

Double-sided auctions are a better setting for thinking about price formation than onesided auctions, both because they are often a better match to reality, and especially because they capture the essential problems of trade better than one-sided auctions. In this thesis, we use double-sided auctions.

UK Power Market [93]:

UK was one of the first nations to embark upon widespread privatization of its power industry. In 1987 fall, UK authority started to privatize its electric utilities, and separate generation, transmission and distribution sectors. The Electricity Pool of England and Wales has been in operation since 1990, where competition was only introduced into generation sector. In the beginning, UK power market was a "single buyer" which bought all electricity from generation companies through a spot market, and then sold directly to customers at an uniform system price. UK pool is a single commodity market where only energy is traded, and virtually all energy transactions must go through the pool.

As a means of controlling price volatility, a hedging market called "contract for differences" (CFD) market allows for bilateral contracts to be negotiated between generators and consumers. However, CFD are purely financial contracts without exposition to public. Recently UK power market has undergone a significant reform. A series of markets: a futures market, a short-run bilateral market and so on, have been setup in order to enhance competition in local distribution, simplify pricing mechanism and strengthen market transparency and liquidity.

\section{California Power Market [14]:}

In December, 1995, the California Utility Commission (CPUC) issued its policy on electric industry restructuring to replace administrative regulation with competitive market forces, and AB 1890 was signed in 1996, which called for the deregulation of Californias investor owned electric utilities (IOUS). The law established an Oversight Board, an Independent System Operator (IS0), and a Power Exchange (PX). On April 1, 1998, the power industry in California began a phased-in process of deregulation.

The ISO controls power dispatch and transmission system, but it owns no transmission, generation, or distribution facilities and has no financial interest in the PX, or in any generation 
or load. The ISO also manages transmission congestion, procures ancillary service through a market.

The PX is mandatory for utility generation and procurement by the IOUS, but voluntary for all other market participants. The PX is an independent entity that provides a forward competitive spot market for electric power, conducts day-ahead and hour-ahead auctions of generation and demand, ensures non-discriminatory, transparent bidding interface and protocols. The PX also develops balanced generation and load schedules for transmittal to the IS0.

California power market is a "wholesale" market, and allows flow based bilateral transactions to coexist with the PX spot market. Bilateral contracts and the voluntary PX are operated in parallel.

\section{Nordic Power Market [69]}

The Norwegian market was effectively deregulated in 1991, with Sweden joining as a full-fledged member in 1996, Finland in 1998, and Denmark recently. These three countries constitute one closely integrated power market where power is traded via bilateral contracts and on a common spot market exchange (Nerd Pool). The system operator in each county is respectively in charge of its system security and coordinate cross-country trading with each other. The Nordic power market is a "retail competition" market where end-customers have full freedom to select power suppliers.

The Nordic power market is mainly based on bilateral contracts, and generation reserve is not much of a problem because the system is predominantly hydro. In addition, besides a spot market, two financial markets: futures market (Eltermin) and options market (Elopticm) were developed for price hedging and risk management.

\section{PJM Power Market [76]}

PJM's markets are "wholesale markets" involving only purchase and sale of power for resale. All buyers, sellers, transmission users and transmission owners within the PJM control region must be members of PJM. Sellers and buyers located outside of PJM may buy and sell power into and out of PJM, are not required to be members, but must obtain transmission service under different tariffs. Sellers may choose to self supply, sell into PJM auction markets or privately through bilateral contracts with buyers. Buyers may choose to self supply, buy 
from PJM auction markets or through bilateral contracts with sellers (either generators or resellers of generation). End users do not participate directly and are served by resellers.

It consists of Energy Markets (Day ahead, real time (balancing) markets), Ancillary Services, Unforced Capacity Obligation (UCAP). Energy, Ancillary Services and UCAP may be bought at auction, bilaterally or self supplied. PJM constantly calculates the least cost generation mix solution to serve instantaneous load, constrained by system security limits. PJM redispatches generation, as necessary, to serve load. Generation is paid its bus price (bid based price, not cost based). Load pays for MW consumed at its bus, plus the difference between source and sink prices.

Day Ahead Market - Sellers and Buyers bid into each hour of the 24 hour day ahead period bids are stacked for each hour lowest marginal price which supplies all demand sets LMP for that hour.

Real Time Market Uncommitted Buyers and Sellers may self schedule (accept real time price), but successful day ahead bidders must honor their bids or cover from spot market at their own expense.

\subsection{Optimal Power Flow}

In view of deregulation, it is important for the independent system operator to operate power system in a more reliable and economical way. This involves a lot of decision making process and the softwares used to simulate and analyze the electricity market behavior are mostly based on OPF algorithms. The optimal power flow (OPF) is an important software in the energy management system (EMS). OPF was born in 1962 [22] and took a long time to become a successful algorithm that could be applied in every days use. The OPF-based approach is basically a nonlinear constrained optimization problem, and consists of a scalar objective function and a set of equality and inequality constraints [3], [66], [91]. The objective function varies from one system operator to another and also with the necessity. In [48] the autors classified the optimal power flow methods based on the choice of optimization techniques. The security constrained optimal power flow [59] implemented by many researchers is to minimize the cost of generation or dispatch while satisfying set of constraints such as power flow equations, active and reactive power bounds on generators, voltages at all nodes and thermal/active power limits on transmission lines. 
Non-linear optimization techniques are shown to be adequate for maximization of the loading parameter in voltage collapse studies as discussed in [16], [18], [19], [49], [80], [99]. In this thesis a modified multi-objective approach [61] is chosen to properly represent security in on-line market computations so that social welfare and the distance to collapse point are maximized at the same time. The problem is formulated as a mixed integer non-linear programming (MINLP) and is solved using General Algebraic Modeling System (GAMS) [12]. In this thesis contingencies are included using methods based on what proposed in [63] and further extended to a multi-objective optimization as cited in [61].

Optimal power flow based models are widely used for market solutions because the dual variables associated with power flow constraints gives the shadow prices which are then used in spot pricing [31] with least computational effort. Spot pricing was originally defined for active power transactions, considering only congestion alleviations [78], [81] and then extended to account for different price components, such as reactive pricing and ancillary services [10], [32]. In [41] authors detail the use of the reactive power services and demonstrate that the reactive power production costs should be included in the formulations for the calculation of the reactive power cost prices. A formulation for the reactive power production cost calculation is proposed by Lamont and FU [54] and the concept of opportunity cost is introduced. In this work for the sake of simplicity the cost of producing reactive power from generators is taken as percentage of real power generation cost without losing any generality. The active power dispatch minimizes losses as long as the system is not congested. However if the transmission system is congested losses are not equally distributed among the generators.

Some of the objectives of the OPF are:

- Minimize system real \& reactive power losses

- Minimize generation fuel costs

- Optimize power exchange with other systems (on-site generation, utilities, IPP's, \& power grids)

- Control generator's MW (governor) \& MVAR (AVR) settings within the specified limits

- Maximize voltage \& flow security indices

- Minimize load shedding 
- Maximize Social Welfare

- Minimize generator fuel cost or heat rate with different cost models \& fuel profiles

\subsubsection{OPF with VAR Support Devices}

The possibility of operating the power system at the minimal cost while satisfying specified transmission constraints and security constraints is one of main current issues in stretching transmission capacity by the use of controllable FACTS. The conventional OPF program must undergo some changes such as inclusion of new control variables belonging to FACTS devices and the corresponding load flow solutions to deal with the above said problem. In [40] presented a review literature, which addresses the application of FACTS, concepts for the improvement of power system utilization and performance.

The four typical FACTS devices that are used in general with OPF are Static Var Compensator (SVC) [5], [17], [37], [46], [74] Thyristor Controlled Series Capacitor (TCSC) [17], [33], [46], Thyristor Controlled Phase Angle Regulator (TCPAR) [34], [71], [79] , Unified Power Flow Controller (UPFC) [6], [7], [23], [38], [42], [70], [74]. The reactance of the line can be changed by TCSC . TCPAR varies the phase angle between the two terminal voltages and SVC can be used to control the reactive compensation. The UPFC is the most powerful and versatile FACTS device due to the fact that the line impedance, terminal voltages, and the voltage angle can be controlled by one and the same device.

The power flow $P_{i j}$ through the transmission line $i-j$ is a function of the line reactance $X_{i j}$, the voltage magnitude $V_{i}, V_{j}$ and the phase angle between the sending and recieving end voltages $\delta_{i}-\delta_{j}$ as shown in equation 2.1.

$$
P_{i j}=\frac{V_{i} V_{j}}{X_{i j}} \sin \left(\delta_{i}-\delta_{j}\right)
$$

The above-mentioned FACTS devices can be used to control the power flow by changing the transmission line parameters so that the power flow can be optimized. The reactive power compensation of AC transmission systems using fixed series or shunt capacitors can solve some of the above associated problems with AC networks. However the slow nature of control using mechanical switches (circuit breaker) and limits on the frequency of switching imply that faster dynamic controls are required to overcome the above mentioned problems [1]. 
Several algorithms have been proposed in literature to solve power flow and optimal power with different FACTS devices. New control variables and control objective equations are usually added in conventional power flow equations. Singinificant number of efforts have been made to study the impact of FACTS on electricity prices. The purpose of pricing is to recover cost of transmission and to encourage efficient use and investment. OPF based spot pricing is an important method. In [27] Choi presented theory and simulation results of real time pricing of real and reactive powers that maximizes social benefit. In [72], authors have shown the ability of FACTS devices to change the production cost and their impact on transmission charges. FACTS devices had the ability to reduce the overall operating cost and their impact on transmission pricing. In [90] SVC and TCSC are considered to show the above mentioned benefits of FACTS. But the optimal placement of FACTS is found through trial and error method. Most of the literature [11], [29], [56], [74], [86] are either based on minimum price dispatch algorithm or maximum social welfare [88], [89], [90], [95]. Optimization has been performed with the system operating constraints.

These market models consider the offline power flow limits and the security is simply represented by voltage limits which gives higher congestion prices and spot prices are heterogeneous [61], [65]. To properly include the security costs in the market prices the multi-objective optimal power flow which maximized both social welfare and loadability point is considered in this research. To best utilize the benefits of sources, optimal allocation of FACTS should be performed. A brief literature suvey on optimal locatin is presented in the following section.

\subsubsection{Location of VAR Support}

Congestion in a transmission system, whether vertically organized or unbundled, cannot be permitted except for a very short duration, for fear of cascade outages with uncontrolled loss of load. The role of FACTS in the open power market is to manage the congestion, enhancing security, reliability, increasing loadability or available capability, controlled flow of power, and other system performances. It is important to ascertain the location of these devices because of their significant costs.

Optimal placement of FACTS using Genetic Algorithms (GA's) is implemented in [55], [73], [75]. In [36], authors used system loadability as the index but they didnot consider the cost of FACTS devices and their impact on generation profile. Optimal location considering 
the generation cost of the power plants and investment cost of the devices is employed in [13] to evaluate the power system performance. The location of FACTS devices for reactive compensation is performed according to reactive marginal cost criterion in [74]. In [57], [72] the optimal location of FACTS devices are obtained by solving the economic dispatch problem plus the cost of these devices making the assumption that all lines initially have these devices. In [89] the optimal placement of a prefixed amount of FACTS devices is developed in an electricity market having pool and contractual dispatches by a two-step procedure. First, by using a sensitivity-based approach the few locations of FACTS devices is decided and then the optimal dispatch problem is solved to select the optimal location and parameter settings. In [67] a parallel tabu search based method, for determining the optimal allocation of UPFC devices is proposed.

Location of TCSC is taken as the best when it achieves the maximum social benefit in [88] and used a real power flow sensitivity as an index in [95]. In [21] SVC is placed where it improves the maximum loadability of the system as well as the voltage profiles at the most remote load buses. In [53], VAR support at the pilot bus improves overall system voltage profile and loading margin. The authors considered N-1 criterion but they didnot consider various costs associated with the generation. Chattopadhyay et al presented [24] an integral framework for optimal reactive power planning and its spot pricing in which the selection of VAR source sites is based only on the real power generation operation benefit-to cost ratio for a capacitor on load node. The authors considered the cost of VAR support in the objective and the approach is superior to traditional heuristic methods in which the location of new VAR devices are either simply estimated or directly assumed. However, it neglects the benefits of decrease in congestion cost and increase in system loadability in the selection of weak buses.

In this thesis, a multi-objective market model [61] that maximizes the social welfare as well as distance to collapse point is adopted. The influence of any of these terms on market prices can be studied by adjusting the corresponding weight allocated to it. A new index which considers the social welfare, congestion cost and maximum loadability coupled with N1 contingency criterion for identifying the weak candidate buses based on Cost Benefit Analysis $(\mathrm{CBA})$ is proposed in this thesis. All BCRs reflect the improvement of the systems operation state after the VAR support service is provided. The relative weights for each parameter are computed using analytic hierarchical process(AHP). The index and the methodology are 
explained in section 5.3.

\subsection{Power System Analysis Toolbox (PSAT)}

The power system analysis toolbox (PSAT) [77] is a MATLAB based toolbox for static and dynamic analysis of electric power systems. PSAT includes power flow, continuation power flow, optimal power flow, small signal stability analysis and time domain simulation. All functions can be accessed by means of graphical user interfaces (GUIs) and a Simulink-based library which provides an user friendly tool for network design.

\begin{tabular}{c|c|c|c|c|c|c}
\hline Package & PF & CPF & OPF & SSSA & TDS & GUI \\
\hline \hline EST [96] & $\sqrt{ }$ & & & $\sqrt{ }$ & $\sqrt{ }$ & \\
\hline MatEMTP [60] & & & & & $\sqrt{ }$ & $\sqrt{ }$ \\
\hline Matpower [100] & $\sqrt{ }$ & & $\sqrt{ }$ & & & \\
\hline PAT [82] & $\sqrt{ }$ & & $\sqrt{ }$ & $\sqrt{ }$ & $\sqrt{ }$ & \\
\hline PSAT [77] & $\sqrt{ }$ & $\sqrt{ }$ & $\sqrt{ }$ & $\sqrt{ }$ & $\sqrt{ }$ & $\sqrt{ }$ \\
\hline PST [28] & $\sqrt{ }$ & & & $\sqrt{ }$ & $\sqrt{ }$ & \\
\hline SPS [92] & $\sqrt{ }$ & & & $\sqrt{ }$ & $\sqrt{ }$ & $\sqrt{ }$ \\
\hline VST [26] & $\sqrt{ }$ & $\sqrt{ }$ & & $\sqrt{ }$ & $\sqrt{ }$ & $\sqrt{ }$ \\
\hline
\end{tabular}

Table 2.1: Comparison of MATLAB-based packages for power system analysis [77]

Table (2.1) depicts a brief comparison of the existing MATLAB-based packages for power system analysis. The features illustrated in the table are power flow $(\mathrm{PF})$, continuation power flow (CPF), optimal power flow (OPF), small signal stability analysis (SSSA), time domain simulation (TDS) along with features such as graphical user interface (GUI). 


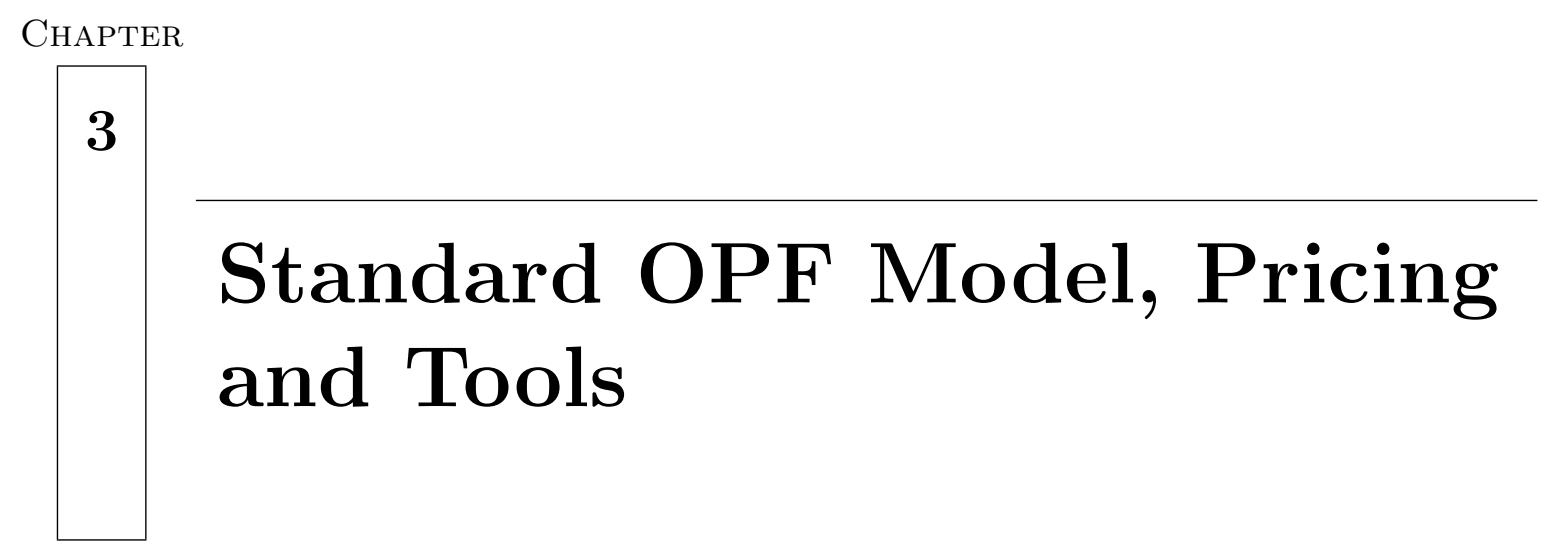

\subsection{Introduction}

A concept of electricity energy market, which reflects the generation cost on the price of electricity, is suggested to replace conventional load management strategy. This market takes charge of transmission and distribution of electricity and decides the price of electricity so as to balance the demand and supply of electricity. Participants participate in this market by selling and buying electricity. Electricity auction problem can be solved by two approaches, merit order or single-price auctions and OPF-based power markets. Though the market clearing mechanisms applied by different competitive pool-based electricity markets significantly varies, there are some common characteristics. The main drawback of the first approach is, there is a need of separate procedure to take into account congestions and in general, non linear constraints. Therefore we will concentrate only on OPF based hybrid markets. As a matter of fact, OPF methods have been used in regulated power systems to schedule power generations in order to minimize cost productions and losses in transmission lines. OPF main characteristics are as follows:

- Precise power system models can be represented in OPF by including variety of (non- 
linear) constraints.

- Having complex and unclear solution process OPF is not very popular among market operators.

- System losses and transmission congestions are taken into consideration without any additional procedures.

- The existing solvers for Nonlinear Programming and Mixed Integer Nonlinear Programming are less efficient which is a critical issue for on-line applications.

The OPF based approach to maximize the social welfare is explained in the next section.

\subsection{Security Constrained OPF Market Model}

The objective of pricing policy is to maximize the benefit of all the participants, that is, to maximize the consumers and producers surplus, subject to operational constraints. This is accomplished by setting the prices of real and reactive powers at each bus at a particular time equal to the marginal values of supplying and consuming real and reactive power at the same bus and at the same time, where the marginal values are determined by maximizing total surplus of utilities and consumers, subject to the operational constraints. The social welfare in equation 3.2 ensures that generators get the maximum income for their power production and consumers or wholesale retailers pay the cheapest prices for their power purchase as follows:

$$
\begin{aligned}
\operatorname{Max} . S w & =\sum_{j \in \mathcal{J}} B_{P_{j}}\left(P_{D_{j}}\right)+B_{Q_{j}}\left(Q_{D_{j}}\right)-\sum_{i \in \mathcal{I}} C_{P_{i}}\left(P_{S_{i}}\right)-C_{Q_{i}}\left(Q_{G_{i}}\right) \\
Q_{D_{j}} & =P_{D_{j}} \tan \left(\phi_{D_{i}}\right)
\end{aligned}
$$

where

$\mathcal{I}$ is set of pool supplier buses;

$\mathcal{J}$ is set of pool load buses;

$P_{S_{i}}$ is active power of pool supplier- $i$;

$Q_{G_{i}}$ is reactive power of pool generator- $i$;

$C_{P_{i}}$ is real power bid price of pool supplier- $i$ in $\$ / M W h$;

$C_{Q_{i}}$ is reative power bid price of pool generator- $i$ in $\$ / M V A r h$; 
$P_{D_{j}}$ is active power of pool load- $j$;

$Q_{D_{j}}$ is reactive power of pool load- $j$;

$B_{P_{j}}$ is real power bid price of pool load $j$ in $\$ / M W h$;

$B_{Q_{j}}$ is reactive power bid price of pool load- $j$ in $\$ / M V A r h$;

The objective function of this $\mathrm{OPF}$ is to maximize the net social welfare which is the difference between the total consumer benefit and cost of generation.

The operating constraints are as follows:

1) Equality Constraints:

Power flow equations corresponding to both real and reactive power balance equations are the equality constraints that can be written, for all the buses.

$$
\begin{aligned}
P_{h} & =V_{h}^{2}\left(g_{h}+g_{h 0}\right)-V_{h} \sum_{l \neq h}^{n_{l}} V_{l}\left(g_{h l} \cos \left(\theta_{h}-\theta_{l}\right)+b_{h l} \sin \left(\theta_{h}-\theta_{l}\right)\right) \quad \forall h \in \mathcal{B} \\
Q_{h} & =-V_{h}^{2}\left(b_{h}+b_{h 0}\right)+V_{h} \sum_{l \neq h}^{n_{l}} V_{l}\left(g_{h l} \sin \left(\theta_{h}-\theta_{l}\right)-b_{h l} \cos \left(\theta_{h}-\theta_{l}\right)\right) \quad \forall h \in \mathcal{B}
\end{aligned}
$$

where $P_{h}$ and $Q_{h}$ are the real and reactive powers injected at bus $h, V_{h}$ and $\theta_{h}$ are the voltages and phasor angles at bus $h, \mathcal{B}$ is the set of indexes for network buses, $n_{l}$ is the number of connections departing from bus $h$ and $g_{h}, g_{h 0}, b_{h}, b_{h 0}, g_{h l}$ and $b_{h l}$ are line parameters, namely conductances and succeptances, as commonly defined in literature.

In the following, power injections are modeled as the sum of generator and load powers connected to the bus $h$, as follows:

$$
\begin{gathered}
P_{h}=\sum_{i \in \mathcal{I}_{h}}\left(P_{G_{i 0}}+P_{S_{i}}\right)-\sum_{j \in \mathcal{J}_{h}}\left(P_{L_{0 j}}+P_{D_{j}}\right) \quad \forall h \in \mathcal{B} \\
Q_{h}=\sum_{i \in \mathcal{I}_{h}} Q_{G_{i}}-\sum_{j \in \mathcal{J}_{h}}\left(P_{L_{0 j}}+P_{D_{j}}\right) \tan \left(\phi_{D_{i}}\right) \quad \forall h \in \mathcal{B} \\
Q_{L}=P_{L} \tan \left(\phi_{L}\right)
\end{gathered}
$$

where $\mathcal{I}_{h}$ and $\mathcal{J}_{h}$ are the sub-sets of generators and loads connected to bus $h$, respectively. $P_{G_{0}}$ and $P_{L_{0}}$ are fixed power amount defining the base case condition and $P_{S}$ and $P_{D}$ are variable powers, which will be called power supply and power demand bids respectively. In all 
test cases used in this thesis, load reactive powers are assumed to be dependent on the real powers by a constant power factor $\phi_{L}$, thus leading to:

$$
y \triangleq f(x, p)=f\left(V, \theta, P_{G}, Q_{G}, P_{L}, Q_{L}\right)
$$

where $x$ is a vector of dependent variables and $p$ is a vector of independent or control variables. In a standard single slack bus power flow formulation, dependent variables are voltage magnitudes $V$ and phases $\theta$ at the load buses, generator reactive powers $Q_{G}$ and voltage phases at the generator buses, while control variables are generator active powers $P_{G}$, load powers $P_{L}$ and $Q_{L}$ and the slack bus voltage. In distributed slack bus voltage models, $y$ includes also an additional variable, say $k_{G}$, which forces all generators to share losses [9].

$$
P_{G}=\left(1+k_{G}\right)\left(P_{G_{0}}+P_{s}\right)
$$

Equations 3.3 are for single slack bus model, and do not include slack bus real power which is actually a dependent variable, while for the distributed slack bus model where as equation 3.6 is valid for all generators, including the reference phase angle generator. The distributed slack bus model will be used in this thesis in OPF problems since it allows a fair and reasonable distribution of transmission losses among all market suppliers. Firstly the active and reactive power balance is ensured, then transmission losses are accurately modeled and taken into account.

2) Inequality Constraints:

1. Supply Bid Blocks:

$$
P_{S_{\min _{i}}} \leq P_{S_{i}} \leq P_{S_{\max _{i}}} \quad \forall i \in \mathcal{I}
$$

where $P_{S_{m_{i n}}}$ and $P_{S_{m a x}}$ are the minimum and maximum bids of real power offered by unit $i$, respectively and $\mathcal{I}$ is the set of indexes of generating units.

2. Demand Bid Blocks:

$$
P_{D_{\min _{j}}} \leq P_{D_{j}} \leq P_{D_{\max _{j}}} \quad \forall j \in \mathcal{J}
$$

where $P_{D_{\text {min }_{j}}}$ and $P_{D_{\max _{j}}}$ are the minimum and maximum bids of real power demanded by consumer $j$, respectively and $\mathcal{J}$ is the set of indexes of consumers. 
3. Generator Reactive Power Support:

$$
Q_{G_{\min _{i}}} \leq Q_{G_{i}} \leq Q_{G_{\max _{i}}} \quad \forall i \in \mathcal{I}
$$

where $Q_{G_{m_{i n}}}$ and $Q_{G_{m a x_{i}}}$ are the minimum and maximum limits of the reactive power support available at unit $i$, respectively and $\mathcal{I}$ is the set of indexes of generating units.

4. Voltage "Security" Limits:

$$
V_{\min _{h}} \leq V_{h} \leq V_{\max _{h}} \quad \forall h \in \mathcal{B}
$$

where $V_{\text {min }_{h}}$ and $V_{\text {max }_{h}}$ are the minimum and maximum allowed voltage magnitues at bus $h$, respectively and $\mathcal{B}$ is the set of indexes of network buses.

5. Thermal Limits:

$$
\begin{array}{ll}
I_{h k}(\theta, V) \leq I_{h k_{\max }} & \forall(h, k) \in \mathcal{N} \\
I_{k h}(\theta, V) \leq I_{k h_{\max }} &
\end{array}
$$

where $I_{h k}$ and $I_{k h}$ are the line currents and are used to model system security by limiting transmission line flows, respectively and $\mathcal{N}$ is the set of indexes of transmission lines. All electric lines produce heat and therefore have a limit on the amount of power they can carry to prevent overheating. The actual temperatures occurring in the transmission line equipment depend on the current, that is the rate of flow of the electrons, and also on ambient weather conditions, such as temperature, wind speed, and wind direction, because the weather effects the dissipation of the heat into the air.

The thermal ratings for transmission lines, however, are usually expressed in terms of current flows, rather than actual temperatures for ease of measurement. A "normal" thermal rating for a line is the current flow level it can support indefinitely. Emergency ratings are levels the line can support for specific periods, for example, several hours.

\section{Power Limits:}

In common practice [97], the inclusion of system congestions in the OPF problem is obtained by imposing transmission capacity constraints on the real power flows, as follows:

$$
\begin{array}{ll}
\left|P_{h k}(\theta, V)\right| \leq P_{h k_{\max }} & \forall(h, k) \in \mathcal{N} \\
\left|P_{k h}(\theta, V)\right| \leq P_{k h_{\max }} &
\end{array}
$$


where $P_{h k}$ and $P_{k h}$ are obtained by means of off-line angle and/or voltage stability studies. Hence, these limits do not actually represent the actual stability conditions of the resulting OPF problem solution, which may lead in some cases to insecure solutions and/or inadequate price signals, as demonstrated in [62].

Summarizing and dropping the index notation, the standard security constrained single period OPF-based market model can be formulated as below 3.13:

$$
\begin{array}{cl}
\text { Max. } \quad B_{P}^{T} P_{D}+B_{Q}^{T} P_{D} \tan \left(\phi_{D}\right)-C_{P}^{T} P_{S}-C_{Q}^{T} Q_{G} & \rightarrow \text { SocialWelfare } \\
\text { s.t. } & \rightarrow \text { PF equations } \\
P_{S_{\min }} \leq P_{S} \leq P_{S_{\max }} & \rightarrow \text { Supply bid blocks } \\
P_{D_{\min }} \leq P_{D} \leq P_{D_{\max }} & \rightarrow \text { Demand bid blocks } \\
I_{h k}(\theta, V) \leq I_{h k_{\max }} & \rightarrow \text { Thermal limits } \\
I_{k h}(\theta, V) \leq I_{k h_{\max }} & \\
\left|P_{h k}(\theta, V)\right| \leq P_{h k_{\max }} & \rightarrow \text { Power/Congestion limits } \\
\left|P_{k h}(\theta, V)\right| \leq P_{k h_{\max }} & \\
Q_{G_{\min }} \leq Q_{G} \leq Q_{G_{\max }} & \rightarrow \text { Generator Q limits } \\
V_{\min } \leq V \leq V_{\max } & \rightarrow \text { Voltage "security" limits }
\end{array}
$$

The Congestion Costs $(\mathrm{CC})$ are defined as:

$$
C C=\sum\left(L M P_{i} P_{d_{i}}+R M P_{i} P_{d_{i}} \tan \left(\phi_{d_{i}}\right)\right)-\sum\left(L M P_{j} P_{s_{j}}+R M P_{j} Q_{g_{j}}\right)
$$

\subsubsection{Spot Pricing}

It is widely recognized that spot pricing through marginal costs can provide reliable pricing indicators [97]. OPF-based market models have the advantage of producing not only the optimal generation schedule, but also a variety of dual variables through the Lagrangian multipliers, which can be associated with Locational Marginal Prices (LMPs) and Reactive Power Marginal Prices (RMPs) at each node. The shadow prices for active and reactive powers at bus $h$ are the marginal cost associated with the equality constraints 3.3. 
The Lagrangian function for 3.13 is as follows :

$$
\begin{aligned}
& \text { Min. } \mathcal{L}=S w-\rho^{T} f\left(\theta, V, Q_{G}, Q_{D}, P_{S}, P_{D}\right) \\
& -\mu_{P_{S_{\max }}^{T}}^{T}\left(P_{S_{\max }}-P_{S}\right) \\
& \text { - } \mu_{P_{S_{\text {min }}}^{T}}^{T}\left(P_{S}-P_{S_{\text {min }}}\right) \\
& \text { - } \mu_{P_{D_{\max }}^{T}}^{T}\left(P_{D_{\max }}-P_{D}\right) \\
& \text { - } \mu_{P_{D_{\text {min }}}^{T}}^{T}\left(P_{D}-P_{D_{\text {min }}}\right) \\
& \text { - } \mu_{I_{h k \max }}^{T}\left(I_{\max }-I_{h k}\right) \\
& \text { - } \mu_{I_{\text {hhmax }}^{T}}^{T}\left(I_{\text {max }}-I_{k h}\right) \\
& \text { - } \mu_{P_{h k \max }}^{T}\left(P_{\max }-P_{h k}\right) \\
& \text { - } \mu_{P_{k h \max }}^{T}\left(P_{\max }-P_{k h}\right) \\
& \text { - } \mu_{Q_{G_{\max }}^{T}}^{T}\left(Q_{G_{\max }}-Q_{G}\right) \\
& \text { - } \mu_{Q_{G_{m i n}}^{T}}^{T}\left(Q_{G}-Q_{G_{m i n}}\right) \\
& \text { - } \mu_{V_{\max }}^{T}\left(V_{\max }-V\right) \\
& \text { - } \mu_{V_{\text {min }}}^{T}\left(V-V_{\text {min }}\right)
\end{aligned}
$$

At a particular instant, real time price of real power and reactive power at bus- $h$ can be given by 3.16, A more detailed information can be deduced from the KKT optimality condition

$$
\begin{aligned}
& L M P_{h}=\frac{\partial L}{\partial P_{h}}=\rho_{P_{h}} \\
& R M P_{h}=\frac{\partial L}{\partial Q_{h}}=\rho_{Q_{h}}
\end{aligned}
$$

applied to the OPF problem.

\subsubsection{Nodal Congestion Pricing}

Using the decomposition formula proposed in [97] for LMPs one can define a vector of active and reactive Nodal Congestion Prices (NCPs) as follows:

$$
\mathrm{NCP}=\left(\frac{\partial f^{T}}{\partial x}\right)^{-1} \frac{\partial H^{T}}{\partial x}\left(\mu_{\max }-\mu_{\min }\right)
$$

where $x=(\theta, V)$ are voltage phases and magnitudes, $\mathrm{H}$ represents the inequality constraint functions (e.g. transmission line powers and currents), and $\mu_{\max }$ and $\mu_{\min }$ are the dual 
variables or shadow prices associated to inequality constraints.

Equation (3.17) for the standard security constrained OPF (3.13) becomes:

$\mathrm{NCP}=\left[D_{x} f\right]^{-1}\left[\frac{\partial I_{h k}}{\partial x}\left(\mu_{I_{h k \max }}-\mu_{I_{h k \min }}\right)+\frac{\partial P_{h k}}{\partial x}\left(\mu_{P_{h k m a x}}-\mu_{P_{h k m i n}}\right)+\left(\begin{array}{c}0 \\ \mu_{V_{\max }}-\mu_{V_{\min }}\end{array}\right)\right]$

NCP for real power injection $h$ can be conveniently written as:

$$
\begin{aligned}
\mathrm{NCP}_{h} & =\sum_{k=1}^{l_{k}}\left(\mu_{I_{h k m a x}}-\mu_{I_{h k m i n}}\right) \frac{\partial I_{h k}}{\partial P_{h}} \\
& +\sum_{k=1}^{l_{k}}\left(\mu_{P_{h k m a x}}-\mu_{P_{h k m i n}}\right) \frac{\partial P_{h k}}{\partial P_{h}}
\end{aligned}
$$

where $l_{k}$ is the number of lines departing from bus $h$. Observe that in (3.18) dual variables or shadow prices $\mu_{P_{h k m a x}}$ and $\mu_{P_{h k m i n}}$ directly affect NCPs, which is the main drawback of transmission congestion limits $P_{h k m a x}$ computed off-line.

\subsection{Transmission Pricing}

The transmission of electricity differs from transportation of any typical commodity by some inherent aspects such as; production needs to match the consumption at the same time; system control is not an easy task; the electricity flows donot usually follow the economic law. The last aspect is normally observed when transmission systems are included in an economic dispatch

problem. Transmission is therefore the main concern in the establishment of real competition in the electricity market.

Transmission pricing has been an important issue on the ongoing debate about power system restructuring and deregulation. The purpose of pricing is to recover cost of transmission and to encourage efficient use and investment. The effect of FACTS devices on transmission charge varies according to the pricing methodology adopted. FACTS devices had the ability to reduce the overall operating cost and their impact on transmission pricing. Impact of FACTS on wheeling charges is being addressed in this thesis. This is becoming an important issue when transmission open access schemes are introduced. Investments on both transmission and generation sides are really changed by these charges. 
Pricing methods based on incremental cost and embedded cost methods [87] can be used to assess the impact of FACTS devices on transmission charges. The incremental cost methods are based on the variation of system total costs when a wheeling transaction is accomodated. The marginal cost is an example of this technique. This method is adopted in this thesis.

\subsubsection{Wheeling Charges Method}

According to economic theory, pricing transmission service by marginal cost is most acceptable. If $M C_{p B}$ and $M C_{q B}$ are the marginal costs of real and reactive powers at a buyer bus while $M C_{p S}$ and $M C_{q S}$ are at a seller bus, wheeling rate for real power is given by,

$$
W_{p}=M C_{p B}-M C_{p S}
$$

Similarly wheeling rate for reactive power is given by,

$$
W_{q}=M C_{q B}-M C_{q S}
$$

Total wheeling charges for the purchase of real power $\left(P_{B}\right)$ and reactive power $\left(Q_{B}\right)$ are given as,

$$
\begin{aligned}
& W C_{p}=P_{B} \times W_{p} \\
& W C_{q}=Q_{B} \times W_{q}
\end{aligned}
$$

\subsection{Software Tools}

The electricity market structure with both supply and demand side bidding is considered in the OPF framework. It is assumed that each generation bus or GENCO and load bus or ESCO supply their bids to the operator in $\$ / M W h$. The maket bids and limitations of transmission lines and restrictions on voltage limits and maximum power output of different sources are forumulated in a OPF structure. The problem is formulated as a Mixed Integer Nonlinear Programming and is solved by General Algebraic Modeling Systems (GAMS).

\subsubsection{PSAT-GAMS}

In the field of general purpose optimization techniques, one of researcher's favourite choice is the General Algebraic Modeling Systems (GAMS). GAMS is a highlevel modeling system 


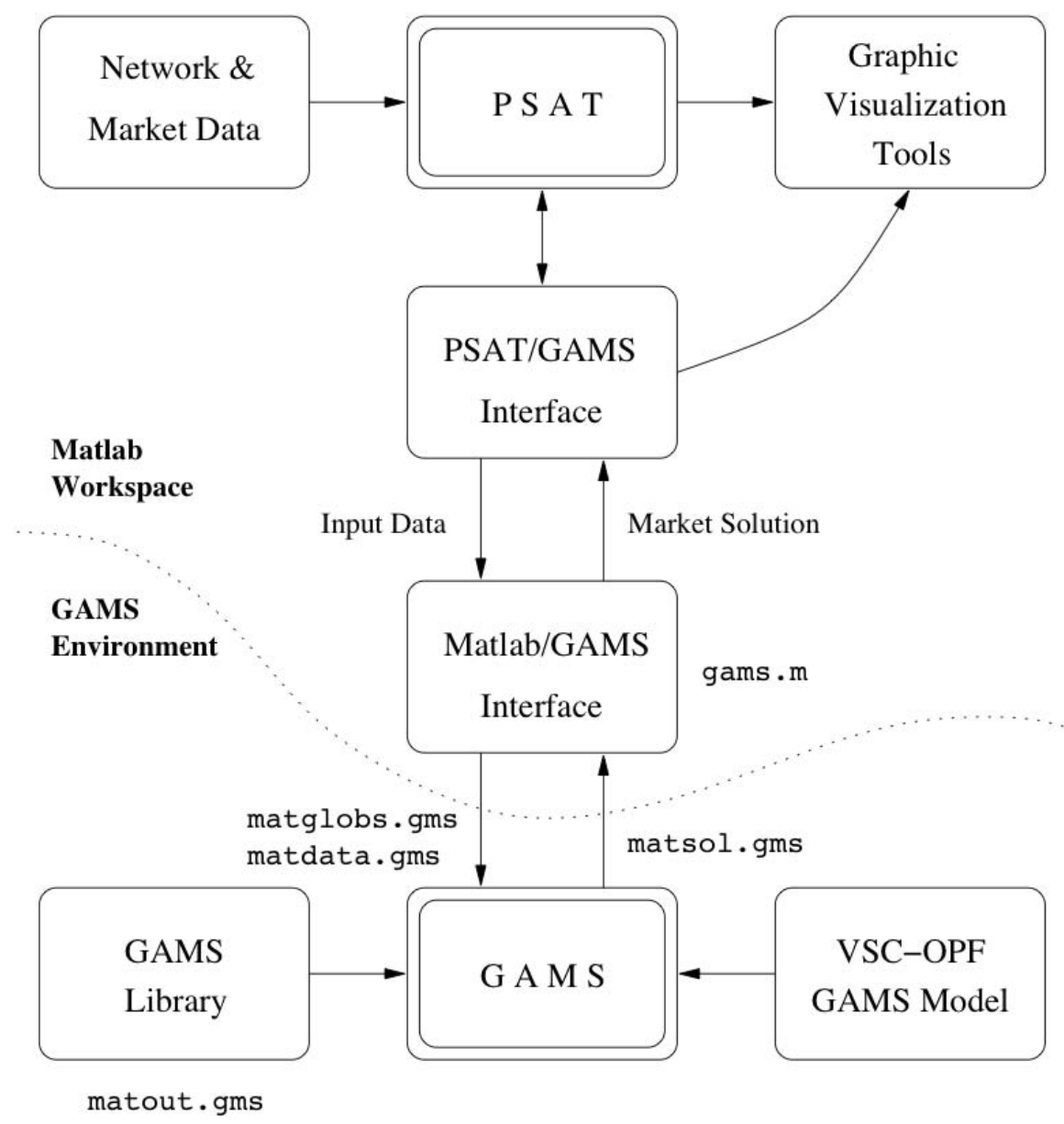

Figure 3.1: Structure of the PSAT-GAMS interface [62]

for mathematical programming problems. It consists of a language compiler and a variety of integrated high-performance solvers. GAMS is specifically designed for large and complex scale problems, and allows creating and maintaining models for a wide variety of applications and disciplines [12]. GAMS is able to formulate models in many different types of problem classes, such as linear programming (LP), nonlinear programming (NLP), mixed-integer linear programming (MILP) and mixed-integer nonlinear programming (MINLP).

The existing PSAT-GAMS interface has been used to solve the market problem. Before the interface can be used, one has to create data file describing the system. At this aim the user can use the PSAT-Simulink interface and draw the on-line diagram of the network or load a predefined test network which is provided within the PSAT main distribution. The second step is solving the power flow. At this point, the PSAT-GAMS interface can be opened and 
the GAMS solvers launched. Observe in figure 3.1 that only networks for which market data have been defined can be used with the PSAT-GAMS interface. If no market data has been defined, the interface simply terminates with a warning message. A command line version of PSAT is also provided to make it feasible to use it inside the matlab applications.

The interface works as follows: the system information are "translated" into a GAMS file (psatdata.gms). User settings (e.g. the market clearing model) and global variables (e.g. the number of bus) are also written to a GAMS script file (psatglobs.gms). The advantage of writing data files is that one could use PSAT to export the GAMS data, and then use GAMS from scripting without the use of Matlab. This feature can be useful in case of "heavy" applications, where all computer resource are needed. Once the data files have been written, GAMS is launched from within Matlab and the market clearing procedure solved. The routines (fm_gams.gms) for solving the market clearing problems have been designed to be as general as possible, with no limit in the network size or in the number of market participants. Limits are only the computer memory and GAMS solvers' capabilities.

Finally, when the GAMS solver has terminated, the GAMS output (psatsol.m) is passed back to Matlab, so that GAMS results can be displayed using the graphical capabilities of Matlab or used for further analyses using PSAT routines.

\subsection{Summary}

This chapter presented standard OPF based market clearing mechanism considering real and reactive power bids for suppliers and consumers. Technique to solve the optimization problem has been discussed along with electricity spot prices i.e. LMPs, RPMPs and security i.e. NCPs. A method to price transmission service based on wheeling charges and the software tools used in this thesis are discussed. 


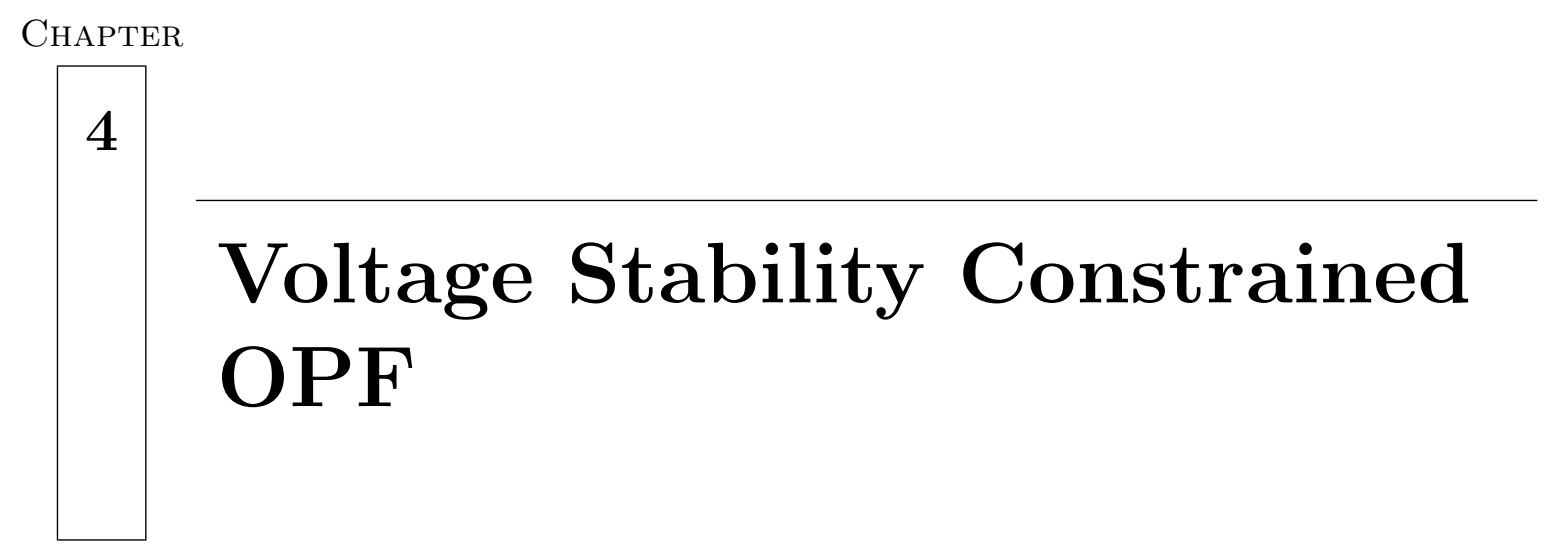

\subsection{Introduction}

This chapter describes a technique for representing the system security with emphasis on voltage stability in the deregulated electricity market. The OPF problem is formulated such that it maximizes both the social welfare and the distance to collapse point [62]. A method to include $\mathrm{N}-1$ contingency criterion is also discussed. However the cost to produce reactive power is not considered in that model. The inclusion of reactive power marginal prices gives incentives for both operators and customers to install VAR support and to reduce the reactive power usage respectively. Since the overall system stability can be closely associated with the voltage stability of the system, this chapter presents an overview of voltage stability and some analysis techniques.

\subsubsection{Voltage Stability}

Several voltage collapse events throughout the world show that power systems are being operated close to their stability limits. The problem can only be exacerbated by the application of open market principles to the operation of power systems, as stability margins are being reduced even further to respond to market pressures. In the restructured electricity industry, 
it is now very essential for the power systems to operate securely, under different operating conditions and especially, during contingencies. Voltage stability is one of the important phenomenons and in view of voltage collapses in recent past, lot of work has been especially devoted to it. Voltage stability is mainly concerned with maintaining acceptable voltage profile under all operating conditions.

Voltage stability is defined as [52] "the ability of power system to maintain acceptable voltage at all buses in the system after being subjected to a disturbance from a given initial operating condition". Voltage collapse generally is a consequence of load increase in systems characterized by heavy loading conditions and/or when a change occurs in the system, such as a line outage. The result is typically that the current operating point, which is stable, disappears and the following system transient leads to a fast, unrecoverable, voltage decrease. Voltage stability is inherently a dynamic problem. But, since time domain simulations are time consuming and also they do not readily provide the sensitivity information or the degree of stability. For these reasons generally for bulk system studies the static analysis is preferred in order to provide more insight into the voltage and reactive power problem.

\subsection{Bifurcation Analysis and Methods}

Nonlinear phenomena, especially bifurcations, have been shown to be responsible for a variety of stability problems in power systems. In particular the lack of post contingency stability equilibirum points, typically associate with saddle-node and limit-induced bifurcations, have been shown to be one of the main reasons for voltage collapse problems in power systems [20]. Bifurcation points can be defined as "equilibrium points where changes in "quantity" and/or "quality" of the equilibria associated with a nonlinear set of dynamic equations occur with respect to slow varying parameters in the system [84]". Since power systems are modeled by sets of nonlinear differential equations, various types of bifurcations are generally encountered as certain system parameters vary.

Two traditional methods to analyze bifurcations are the continuation and the direct methods (DMs) [84], [2]. Continuation methods systematically increase the loading level or bifurcation parameter, until a bifurcation is detected. Therefore, not only is the bifurcation or the point of collapse determined, but also the set of equilibrium points the system goes through to arrive the bifurcation point. The continuation method can be used to detect any type of 
bifurcation without great difficulties [2], [15], [25]. Direct, methods on the other hand, solve the set of algebraic equations used to define the bifurcation point, directly solving for the point at which the system collapses. Direct methods have been succesfully applied to determine the exact location of saddle-node in power systems [15], [4]. However, these methods present serious difficulties when used to locate other types of bifurcations. For both methods it is assumed that the bifurcation parameter is a scalar, which typically corresponds to a given direction of load increases in power system models.

\subsubsection{Direct Methods}

Directs methods, also known as point of collapse methods [84] were developed to directly determine the singular bifurcation points of nonlinear systems. It can be used to determine [15] the loading margin to collapse $\Delta \lambda=\lambda^{*}-\lambda$, at any given operating point $\lambda$.

The method consists of solving the following equations to directly compute the collapse point $\left(x^{*}, \lambda^{*}\right)$.

$$
\begin{aligned}
f(x, \lambda) & =0 \\
D_{x} f(x, \lambda)^{T} w & =0 \\
\|w\|_{\infty} & =1
\end{aligned}
$$

or

$$
\begin{aligned}
f(x, \lambda) & =0 \\
D_{x} f(x, \lambda) v & =0 \\
\|v\|_{\infty} & =1
\end{aligned}
$$

where

- $f(x, \lambda)=0$ represents bifurcation manifold ${ }^{1}$

- $D_{x} f(x, \lambda) v=0$ or $D_{x} f(x, \lambda)^{T} w=0$ is the singularity condition of the jacobian $D_{x} f(x, \lambda)$

- $\|w\|$ and $\|v\|$ are non-zero left and right eigenvectors norm respectively of the power flow jacobian.

\footnotetext{
${ }^{1}$ In this part f represents a column vector.
} 
The nonsingular equations (4.1) and (4.2) correspond to the system's steady state equations, the singularity condition at collapse point and nonzero eigenvector requirement for any given system. Since $J$ is singular at bifurcation point, a nonsingular eigenvector $v$ or $w$ must be guaranteed. The loading margin has been observed to exhibit a linear and smooth behavior $[20]$.

The disadvantage of this approach is the high computational cost as the number of equations doubles with respect to the steady state equations. The other disadvantage of the direct method as discussed in [15] and [68] is its inadequateness in predicting the collapse point when limits such as generator reactive power limits may come into effect and henceforth. Also, the requirement of good initial conditions for the eigenvectors, and the convergence problems as the system approaches the collapse point due to significant change in eigenvalues and eigenvectors. Another major disadvantage of direct method is its limitation of only detecting system singularities (bifurcation). The continuation methods overcome these difficulties as explained in the following section. Direct Methods which are implemented in PSAT allow to compute the value of the loading parameter $\lambda$ for at Saddle-Node Bifurcation points and at Limit-Induced Bifurcation points. In PSAT, DMs can perform only "static" bifurcation analysis.

\subsubsection{Continuation Methods}

The Continuation method is used to find the bifurcations of the nonlinear equations similar to the direct methods. The advantage of this method is its ability to not only find the bifurcation point but also to trace the bifurcation manifold accurately. Consequently the voltage behavior at all the system buses can be determined. Since, voltage profiles or PV nose curves are used in some utilities to determine the proximity to voltage collapse, tracing their behavior over different loading levels is an important observation.

The basic idea behind the continuation power flow technique is to use successive power flow solutions to compute the voltage profile up to and beyond the collapse point. But, continuation methods overcome the difficulties of successive power flow solution methods as they are based on an augmented system model through parameterization. This allows to trace complete voltage profile or bifurcation manifold without any problem, as parameter $\lambda$ is varied.

The technique implemented in the continuation is illustrated in Fig. 4.1, where a given 


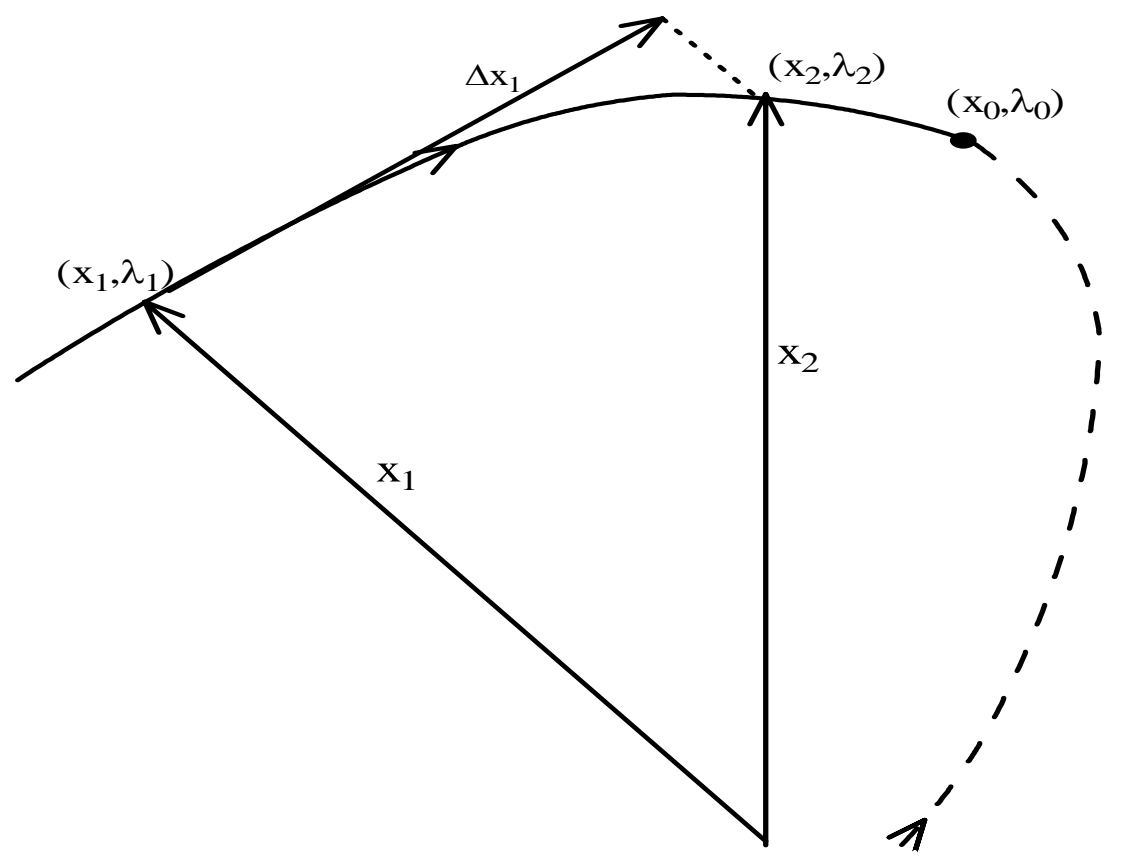

Figure 4.1: One Step of the Continuation method

equilibrium point $\left(x_{1}, \lambda_{1}\right)$ is used to compute the direction vector $\Delta x_{1}$ and the change in parameter $\Delta \lambda$ of the system. There are two steps involved in the process

1. Predictor and Parameterization : This step is known as the predictor, since it generates an initial guess $\left(x_{1}+\Delta x_{1}, \lambda_{1}+\Delta \lambda_{1}\right)$, which is then used to compute the new equilibrium point $\left(x_{2}, \lambda_{2}\right)$ in the corrector step.

Assuming the initial operating point $\left(x_{1}, \lambda_{1}\right)$ is known and holds, taking partial

$$
f\left(x_{1}, \lambda_{1}\right)=0
$$

derivatives yields,

$$
\left.\frac{d f}{d \lambda}\right|_{\left(x_{1}, \lambda_{1}\right)}=\left.D_{x} f\left(x_{1}, \lambda_{1}\right) \frac{d x}{d \lambda}\right|_{x=x_{1}}+\left.\frac{\partial f(x, \lambda)}{\partial \lambda}\right|_{x=x_{1}}=0 .
$$

The tangent vector at that point is given by

$$
\tau=\left.\frac{d x}{d \lambda}\right|_{x=x_{1}}=-\left.D_{x}^{-1} f\left(x_{1}, \lambda_{1}\right) \frac{\partial f(x, \lambda)}{\partial \lambda}\right|_{x=x_{1}}
$$


where $D_{x} f\left(x_{1}, \lambda_{1}\right)$ represents power flow Jacobian. As the system approaches the bifurcation or collapse point, the system Jacobian becomes ill-conditioned and at the bifurcation the Jacobian is singular, and hence in order to ensure that the tangent vector $\tau$ and numerical solution of the equations is well defined we need parameterization of the predictor and corrector steps.

\section{A. Step Length Control}

The parameter step and the direction vector are found from the normalization of the tangent vector found in the equation (4.5). The step generated by the predictor is given by

$$
\frac{\Delta x_{1}}{\Delta \lambda_{1}}=t_{1}
$$

Hence, one can choose

$$
\begin{aligned}
\Delta \lambda_{1} & =\frac{k}{\left\|t_{1}\right\|} \\
\Delta x_{1} & =k \frac{t}{\left\|t_{1}\right\|}
\end{aligned}
$$

where $k$ is a scalar positive constant that controls the size of the predictor step. This normalization results in the reduction of the step size as the system approaches the bifurcation point since the magnitude of tangent vector increases as the system gets closer to this point. Therefore, steeper the curve, smaller is the step length. The optimal values of step size $k$ have been investigated by using the tangent vectors [30].

\section{B. Parameterization}

One of the simple technique used in [2], [15] is local parameterization, which consists of interchanging the parameter $\lambda$ with the system variable $x_{i} \in x$ that has the largest normalized entry in the tangent vector, so that $\lambda$ becomes part of the equations, whereas $x_{i}$ becomes the new parameter $\mathrm{p}$, i.e.,

$$
p=\max _{i}\left\{\left|\frac{\Delta x_{i}}{x_{i}}\right|,\left|\frac{\Delta \lambda}{\lambda}\right|\right\}
$$

Detailed information regarding the predictors and parameterization techniques is given in $[20]$.

2. Corrector Step : The corrector step finds the actual point of solution $\left(x_{2}, \lambda_{2}\right)$, generated from the predictor step point $\left(x_{1}+\Delta x_{1}, \lambda_{1}+\Delta \lambda_{1}\right)$ with or without parameterization. 


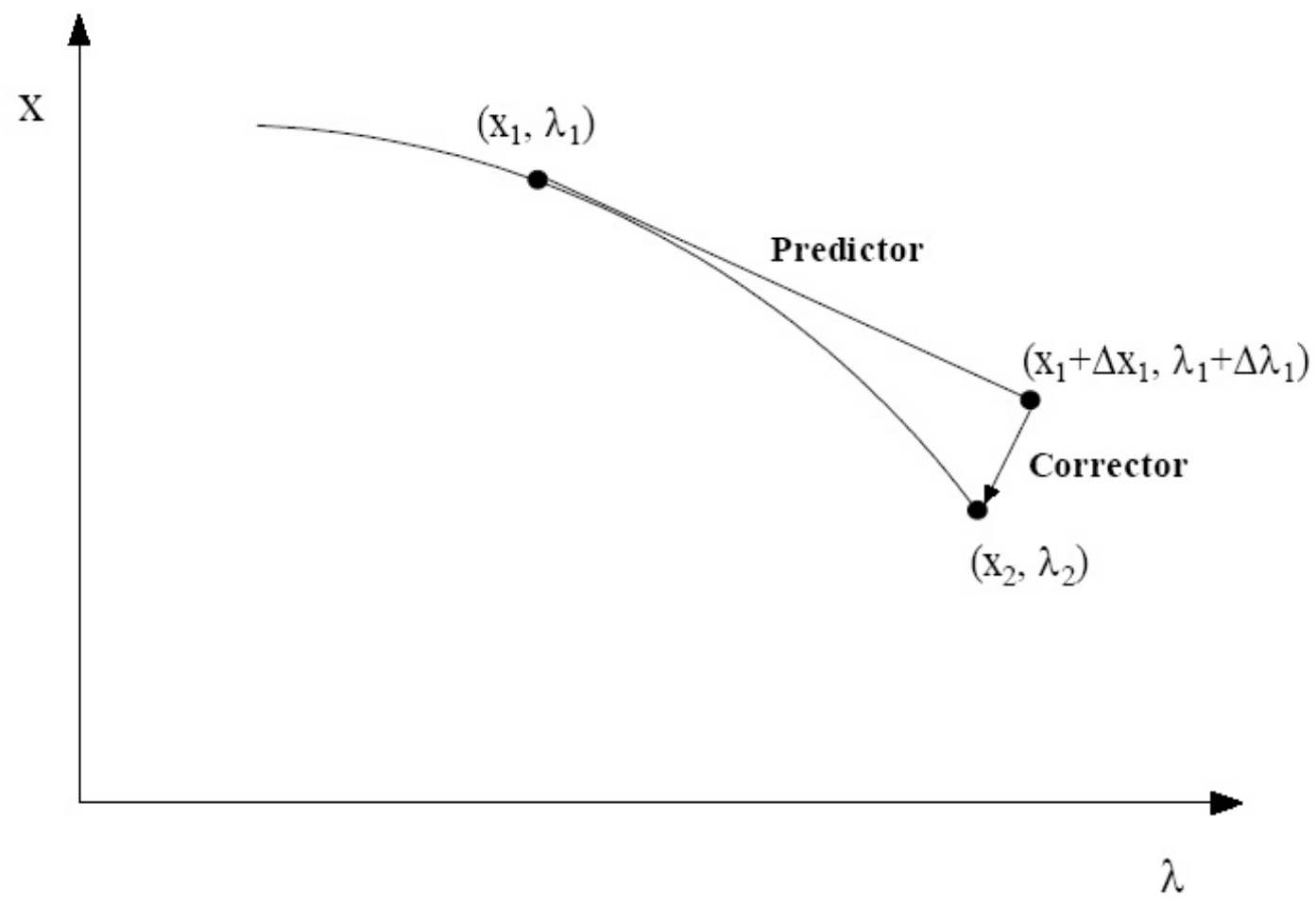

Figure 4.2: Predictor and Corrector Steps in Continuation power flow

This solution can be obtained by solving the following set of equations for $x$ and $\lambda$

$$
\begin{aligned}
& f(x, \lambda)=0 \\
& \rho(x, \lambda)=0
\end{aligned}
$$

From the Fig. 4.2, using a vector perpendicular to the tangent vector, we have

$$
\rho(x, \lambda)=\left[\begin{array}{c}
\Delta x_{1} \\
\Delta \lambda_{1}
\end{array}\right]^{T}\left[\begin{array}{c}
x_{2}-x_{1}-\Delta x_{1} \\
\lambda_{2}-\lambda_{1}-\Delta \lambda_{1}
\end{array}\right]=0
$$

which can be written as,

$$
\rho(x, \lambda)=\Delta x_{1}^{T}\left(x_{2}-x_{1}-\Delta x_{1}\right)+\Delta \lambda_{1}\left(\lambda_{2}-\lambda_{2}-\Delta \lambda_{1}\right)=0
$$

As shown in the Fig.(4.2), starting from point $\left(x_{1}, \lambda_{1}\right)$ the above equations converge to solution $\left(x_{2}, \lambda_{2}\right)$ 


\subsection{Multi Objective VSC-OPF Market model}

The following optimization problem has been used in this work to represent an OPF based market model with the inclusion of reactive power costs that helps investors and customers in the establishment of reactive power market. The market model is designed in such a way that system security is modeled through the use of voltage stability conditions.

Min. $F=-p_{1}\left(\sum_{j \in \mathcal{J}} B_{P_{j}}\left(P_{D_{j}}\right)+B_{Q_{j}}\left(P_{D_{j}} \tan \left(\phi_{D_{j}}\right)\right)-\sum_{i \in \mathcal{I}} C_{P_{i}}\left(P_{S_{i}}\right)-C_{Q_{i}}\left(Q_{G_{i}}\right)\right)-p_{2} \lambda_{c}$

$$
\begin{gathered}
f\left(V, \theta, Q_{G}, Q_{D}, P_{S}, P_{D}\right)=0 \rightarrow \text { PF equations } \\
f_{c}\left(V_{c}, \theta_{c}, Q_{G_{c}}, \lambda_{c}, Q_{D}, P_{S}, P_{D}\right)=0 \rightarrow \text { Max load PF equations } \\
\lambda_{c_{\text {min }}} \leq \lambda_{c} \leq \lambda_{c_{\max }} \rightarrow \text { Loading margin } \\
P_{S_{\min }} \leq P_{S} \leq P_{S_{\max }} \rightarrow \text { Supply bid blocks } \\
P_{D_{\min } \leq P_{D} \leq P_{D_{\max }}} \rightarrow \text { Demand bid blocks } \\
I_{h k}(\theta, V) \leq I_{h k_{\max }} \rightarrow \text { Thermal limits } \\
I_{k h}(\theta, V) \leq I_{k h_{\max }} \\
I_{h k}\left(\theta_{c}, V_{c}\right) \leq I_{h k_{\max }} \\
I_{k h}\left(\theta_{c}, V_{c}\right) \leq I_{k h_{\max }} \\
\leq Q_{G} \leq Q_{G_{\max }} \rightarrow \text { Generator Q limits } \\
Q_{G_{\min }} \leq Q_{G_{c}} \leq Q_{G_{\max }} \\
Q_{G_{\min }} \leq V_{\max } \rightarrow V_{\text {oltage }} \text { "security" limits } \\
V_{\min } \leq V_{c} \leq V_{\max }
\end{gathered}
$$

A second set of power flow equations and constraints with a subscript $c$ is introduced to represent the system at the limit or "critical" conditions associated with the loading margin $\lambda_{c}$ in p.u., where $\lambda$ is the parameter that drives the system to its maximum loading condition. The maximum or critical loading point could be either associated with a thermal or bus voltage limit or a voltage stability limit (collapse point) corresponding to a system singularity (saddlenode bifurcation) or system controller limits like generator reactive power limits (limit-induced bifurcation). 
Weighting factors $p 1$ and $p 2$ determine the influence of two terms in the objective and it is obvious that the total sum of two terms is equal to 1 and the two terms $p 1$ and $p 2$ should be $>0$ so that both the social welfare and the "distance" between the market solution and the critical point is maximized. If either of the terms is 0 , this wouldnot necessarily correspond either to a market representation or the maximum loading condition. Notice that the two terms of the objective function are expressed in different units, since the social welfare would be typically in $\$ / \mathrm{h}$, whereas the "security" term would be in p.u., which will basically affect the chosen values of $p 1$ and $p^{2}$ (typically $p 1>>p 2$ ). However, it is possible to assume that $p 1=(1-p)$ and $p 2=p$, with proper scaled values of $p$ for each system under study $(0<p<1)$, as this simplifies the optimization problem without losing generality.

Limits for the loading margin $\lambda_{c}$ have been included in 4.14 based on practical considerations. Thus the minimum limit $\lambda_{c_{m i n}}$ is introduced in order to ensure a minimum level of security in any operating condition and for any value of $p$, where the maximum value $\lambda_{c_{\max }}$ imposes a maximum required security level. These conditions ensure that the loading parameter remains within certain limits to avoid soultions by either low security levels or low supply and demand levels which would be unacceptable.

\section{Power Directions:}

The current and maximum loading conditions of load and the generator power directions are defined by (4.14):

$$
\begin{aligned}
P_{G} & =P_{G_{0}}+P_{S} \\
P_{L} & =P_{L_{0}}+P_{D} \\
P_{G_{c}} & =\left(1+\lambda_{c}+k_{G_{c}}\right) P_{G} \\
P_{L_{c}} & =\left(1+\lambda_{c}\right) P_{L}
\end{aligned}
$$

where, $P_{G_{0}}$ and $P_{L_{0}}$ stand for generator and load powers which are not part of market bidding, and $k_{G_{c}}$ represents a scalar variable used to distribute the system losses associated only with the solution of the power flow equations $f_{c}$ proportionally to the power injections obtained in the solution process, i.e. a standard distributed slack bus model is used. It is assumed that the losses associated with the loading level defined by $\lambda_{c}$ in 4.14 are distributed among all generators. 


\subsubsection{Spot Pricing and Nodal Congestion Pricing}

Spot Pricing

The Lagrangian multipliers associated with 4.14 correspond to the standard definition of LMPs only when $p=0$, i.e., for a pure market model. Lagrangian multipliers for $p>0$ would lead to unrealistic results, since they decrease almost linearly with respect to increases in $p$.

Consider the following vector objective function:

$$
\bar{F}=\left[\begin{array}{c}
-\left(B_{P}^{T} P_{D}+B_{Q}^{T} P_{D} \tan \left(\phi_{D}\right)-C_{P}^{T} P_{S}-C_{Q}^{T} Q_{G}\right) \\
-\lambda_{c}
\end{array}\right]
$$

From a fundamental theorem of multi-objective optimization an optimal solution of 4.14 is also a Pareto optimal point for the minimization problem constituted by the objective function 4.15 plus the constraints defined in 4.14 Thus, an optimal solution point of 4.14 has the property of independently minimizing both terms of the objective function 4.15. Based on this premise, for a given value of the weighting factor, say $p^{*}$, an optimization method is first used to minimize the following Lagrangian function of 4.14 


$$
\begin{aligned}
& \text { Min. } \mathcal{L}=F-\rho^{T} f\left(\theta, V, Q_{G}, Q_{D}, P_{S}, P_{D}\right) \\
& \text { - } \rho^{T} f_{c}\left(\theta_{c}, V_{c}, Q_{G_{c}}, \lambda_{c}, Q_{D}, P_{S}, P_{D}\right) \\
& -\mu_{\lambda_{c_{\max }}}\left(\lambda_{c_{\max }}-\lambda_{c}\right) \\
& -\mu_{\lambda_{c_{m i n}}}\left(\lambda_{c}-\lambda_{c_{\text {min }}}\right) \\
& -\mu_{P_{S_{\max }}^{T}}^{T}\left(P_{S_{\max }}-P_{S}\right) \\
& \text { - } \mu_{P_{S_{\text {min }}}^{T}}^{T}\left(P_{S}-P_{S_{\text {min }}}\right) \\
& \text { - } \mu_{P_{D_{\max }}^{T}}^{T}\left(P_{D_{\max }}-P_{D}\right) \\
& -\mu_{P_{D_{\min }}}^{T}\left(P_{D}-P_{D_{\text {min }}}\right) \\
& \text { - } \mu_{I_{\text {hkmax }}}^{T}\left(I_{\max }-I_{h k}\right) \\
& \text { - } \mu_{I_{\text {khmax }}}^{T}\left(I_{\max }-I_{k h}\right) \\
& \text { - } \mu_{I_{h k c \max }^{T}}^{T}\left(I_{\max }-I_{h k c}\right) \\
& \text { - } \mu_{I_{k h c \max }^{T}}^{T}\left(I_{\max }-I_{k h c}\right) \\
& \text { - } \mu_{Q_{\text {Gmax }}}^{T}\left(Q_{G_{\max }}-Q_{G}\right) \\
& \text { - } \mu_{Q_{G_{m i n}}^{T}}^{T}\left(Q_{G}-Q_{G_{m i n}}\right) \\
& \text { - } \mu_{Q_{G_{c} \max }^{T}}^{T}\left(Q_{G_{\max }}-Q_{G_{c}}\right) \\
& \text { - } \mu_{Q_{G_{c} \text { min }}^{T}}^{T}\left(Q_{G_{c}}-Q_{G_{m i n}}\right) \\
& \text { - } \mu_{V_{\max }}^{T}\left(V_{\max }-V\right) \\
& \text { - } \mu_{V_{\text {min }}}^{T}\left(V-V_{\text {min }}\right) \\
& \text { - } \mu_{V_{c} \max }^{T}\left(V_{\max }-V_{c}\right) \\
& \text { - } \mu_{V_{c} \text { min }}^{T}\left(V_{c}-V_{\text {min }}\right)
\end{aligned}
$$

Observe that the value of $\lambda_{c}$ cannot be obtained by the mere solution of $S_{w}$, as its value is basically defined by the value of $p$ in the multi-objective problem 4.14. As a result, the weighting factor $p$, although it affects the solution and the dual variables of it does not explicitly appear in the equations. The solution provides the value of $\lambda_{c}^{*}$ associated with $p^{*}$ along with all other system variables and market bids.

\section{Nodal Congestion Prices}

Using the decomposition formula given in 3.2 .2 , the real power congestion price at each bus 
can be rewritten as follows:

$$
\mathrm{NCP}=\left[D_{x} f\right]^{-1}\left[\frac{\partial I_{h k}}{\partial x}\left(\mu_{I_{h k m a x}}-\mu_{I_{h k \min }}\right)+\left(\begin{array}{c}
0 \\
\mu_{V_{\max }}-\mu_{V_{\min }}
\end{array}\right)\right]
$$

Observe that NCPs in 4.17 depends only on shadow prices of dual variables $\mu_{I_{h k m a x}}$ and $\mu_{I_{h k m i n}}$ associated with current thermal limits, since the VSC-OPF model 4.14 does not include real power flow limits as in 3.13. However, dependence on voltage security constraints given by the inclusion of the "critical" system $f_{c}$ and on the loading parameter $\lambda_{c}$ are implicit in 4.17.

\subsubsection{Maximum Transfer Capability and Available Transfer Capability}

The Available Transfer Capability (ATC) as defined by NERC, is a "measure of the transfer capability remaining in the physical transmission network for further commercial activity over and above already committed uses"[8]. This basic concept is typically associated with area interchange limits used, for example, in markets for transmission rights.

In the multi-objective OPF approach $\lambda_{c}$ represents the maximum loadability of the network and, hence, this value can be viewed as a measure of the congestion of the network. Observe that the maximum loading condition (MLC) or maximum transfer capability (MTC) and the available loading capability (ALC) or available transfer capability (ATC) can be obtained as a byproduct of the solution of 4.14 :

$$
\begin{aligned}
\mathrm{MLC} / \mathrm{MTC} & =\left(1+\lambda_{c}\right) \sum_{j \in \mathcal{J}} P_{L_{j}} \\
\mathrm{ALC} / \mathrm{ATC} & =\lambda_{c} \sum_{j \in \mathcal{J}} P_{L_{j}}=\lambda_{c} T T L
\end{aligned}
$$

Contingencies are considered when computing $\lambda_{c}$, MLC and ATC based on real power flow sensitivity analysis which is explained in next section.

\subsection{N-1 Contingency Criterion}

This section describes a technique for including in the Voltage Stability Constrained OPF presented in 4.3 a $\mathrm{N}-1$ contingency criterion. It is based on a sensitivity analysis of power flows in transmission lines. The available transfer capability, locational marginal prices, reactive power marginal prices and nodal congestion prices resulting from the solutions are compared with results obtained by means of a standard OPF technique. 


\subsubsection{VSC-OPF with Critical Line Contingency}

Contingencies are included in 4.14 by taking out the selected lines when formulating the "critical" power flow equations $f_{c}$, thus ensuring that the current solution of the VSC-OPF problem is feasible also for the given contingency. Thus, the VSC-OPF problem with N-1 contingency criterion is based on what has been proposed in [19], [61] and formulated as follows:

$$
\begin{aligned}
& \text { Min. } \mathcal{L}=F-\rho^{T} f\left(\theta, V, Q_{G}, Q_{D}, P_{S}, P_{D}\right) \\
& \text { - } \rho^{T} f_{c}^{N-1}\left(\theta_{c}, V_{c}, Q_{G_{c}}, \lambda_{c}, Q_{D}, P_{S}, P_{D}\right) \\
& \text { - } \mu_{\lambda_{c_{\max }}}\left(\lambda_{c_{\max }}-\lambda_{c}\right) \\
& -\mu_{\lambda_{c_{\text {min }}}}\left(\lambda_{c}-\lambda_{c_{\text {min }}}\right) \\
& -\mu_{P_{S_{\max }}^{T}}^{T}\left(P_{S_{\max }}-P_{S}\right) \\
& \text { - } \mu_{P_{S_{\text {min }}}^{T}}^{T}\left(P_{S}-P_{S_{\text {min }}}\right) \\
& \text { - } \mu_{P_{D_{\max }}^{T}}^{T}\left(P_{D_{\max }}-P_{D}\right) \\
& \text { - } \mu_{P_{D_{\text {min }}}^{T}}^{T}\left(P_{D}-P_{D_{\text {min }}}\right) \\
& \text { - } \mu_{I_{\text {hkmax }}}^{T}\left(I_{\max }-I_{h k}\right) \\
& \text { - } \mu_{I_{\text {khmax }}}^{T}\left(I_{\max }-I_{k h}\right) \\
& \text { - } \mu_{I_{h k \text { max }}}^{T}\left(I_{\max }-I_{h k c}\right) \\
& \text { - } \mu_{I_{\text {khcmax }}}^{T}\left(I_{\max }-I_{k h c}\right) \\
& \text { - } \mu_{Q_{\text {Gmax }}}^{T}\left(Q_{G_{\max }}-Q_{G}\right) \\
& \text { - } \mu_{Q_{G_{m i n}}^{T}}^{T}\left(Q_{G}-Q_{G_{\text {min }}}\right) \\
& \text { - } \mu_{Q_{G_{c} \max }^{T}}^{T}\left(Q_{G_{\max }}-Q_{G c}\right) \\
& \text { - } \mu_{Q_{G_{c} \text { min }}}^{T}\left(Q_{G c}-Q_{G_{m i n}}\right) \\
& \text { - } \mu_{V_{\max }}^{T}\left(V_{\max }-V\right) \\
& \text { - } \mu_{V_{\text {min }}}^{T}\left(V-V_{\text {min }}\right) \\
& \text { - } \mu_{V_{c} \max }^{T}\left(V_{\max }-V_{c}\right) \\
& \text { - } \mu_{V_{c \text { min }}}^{T}\left(V_{c}-V_{\text {min }}\right)
\end{aligned}
$$

where $f_{c}^{N-1}$ represent power flow equations for the system with under study with one line outage. The techniques used in this thesis address the problem of determining efficiently the 
contingencies which cause the worst effects on the system, i.e. the lowest loading margin $\lambda_{c}$ and $A T C^{N-1}$ (equation 4.20).

$$
\mathrm{ATC}^{\mathrm{N}-1}=\min _{h}\left(\lambda_{c_{h}}-1\right) T T L_{h}
$$

where $h$ indicates line outage.

\subsubsection{Contingency Ranking with VSC-OPF}

First, a basic VSC-OPF solution that does not consider contingencies is used for determining the sensitivity of power flows with respect to the loading parameter $\lambda_{c}$. Then, based on this solution and assuming a small variation $\in$ of the loading parameter and recomputing the power flows by solving $f_{c}$, normalized sensitivity factors can be approximately computed as follows:

$$
p_{h k}=P_{h k} \frac{\partial P_{h k}}{\partial \lambda_{c}} \approx P_{h k}\left(\lambda_{c}\right) \frac{P_{h k}\left(\lambda_{c}\right)-P_{h k}\left(\lambda_{c}-\epsilon\right)}{\epsilon}
$$

where $p_{h k}$ and $P_{h k}$ are the sensitivity factor and the power flows of line $h-k$ respectively. The scaling is introduced for properly evaluating the "weight" of each line in the system, and thus for considering only those lines characterized by both "significant" power transfers and the high sensitivities [17].

The first lines with the biggest sensitivity factors $p_{h k}$ are selected (from multiple tests, 5 lines appear to be a sufficient number), and a VSC-OPF for each one of these contingencies is solved (may be done in parallel). The VSC-OPF solution that presents the lowest $A T C^{N-1}$ is chosen as the final solution. Observe that not necessarily the outage of the line with the highest sensitivity factor will always produce the lowest $A T C^{N-1}$, because of the non-linear nature of the voltage stability constraints. Hence the need of solving more than one VSCOPF problem. However, ranking the sensitivity factors leads generally to determine a reduced number of critical areas; $A T C^{N-1}$ s associated with outages of high sensitivity lines within a certain area generally show only small differences. Thus, in practice, one needs to evaluate only one contingency constrained VSC-OPF for each critical area that was determined by the sensitivity analysis.

Observe that line outages that cause a separation in islands of the original grid have to be treated in a special way, since the VSC-OPF (4.3) may not converge. In order to solve this 
problem, the islanded market participants are not committed and the fixed power productions and/or absorptions eliminated. This solution appears to be reasonable especially for realistic transmission grids, which are typically well interconnected, as generally only very few buses result islanded as the consequence of a line outage.

\subsection{Summary}

In this chapter, a multi-objective optimization for managing and pricing voltage stability is explained. The multi-objective approach proposed by Milano [62] has been extended to include the cost of reactive power in the social benefit so that more accurate signals for ractive power pricing are obtained. The multi-objective OPF method allows market operators and participants to directly control the desired level of system security by controlling the weighting factors of the social welfare and loading margin, which is not possible in typical security constrained OPF-based market implementations. A method based on power flow sensitivities in the transmission lines to include N-1 contingency criterion is explained. The VSC-OPF with N-1 contingency is considered as the base case to compare the results with VAR support. 


\section{Chapter}

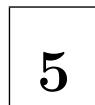

\section{VAR Support and Pricing}

\section{$5.1 \quad$ Introduction}

The transfer of real power can not be realized without reactive power/voltage support. Reactive power plays an important role in supporting the real power transfer. This support becomes especially important when an increasing number of transactions are utilizing the transmission system and voltages become a bottleneck in preventing additional power transfer. Establishing a price structure for reactive power and its support is important both operationally and financially. Considering the high costs of VAR support, it is important to find the optimal size and location of VAR support.

\subsection{SVC Investment Costs}

The following total investment cost analysis for static var compensator is based on information from Siemens AG database [39]. According to the data given, costs can be approximated by

$$
C_{S V C}=0.0003 s^{2}-0.3051 s+127.38(\mathrm{US} \$ / \mathrm{KVAr})
$$

where $C_{s v c}$ is in (US $\$ /$ KVAr) and $s$ is the operating range of the SVC in MVAR. The plot of the cost function against operating range upto 400 MVAR is shown in Fig. 5.1. 


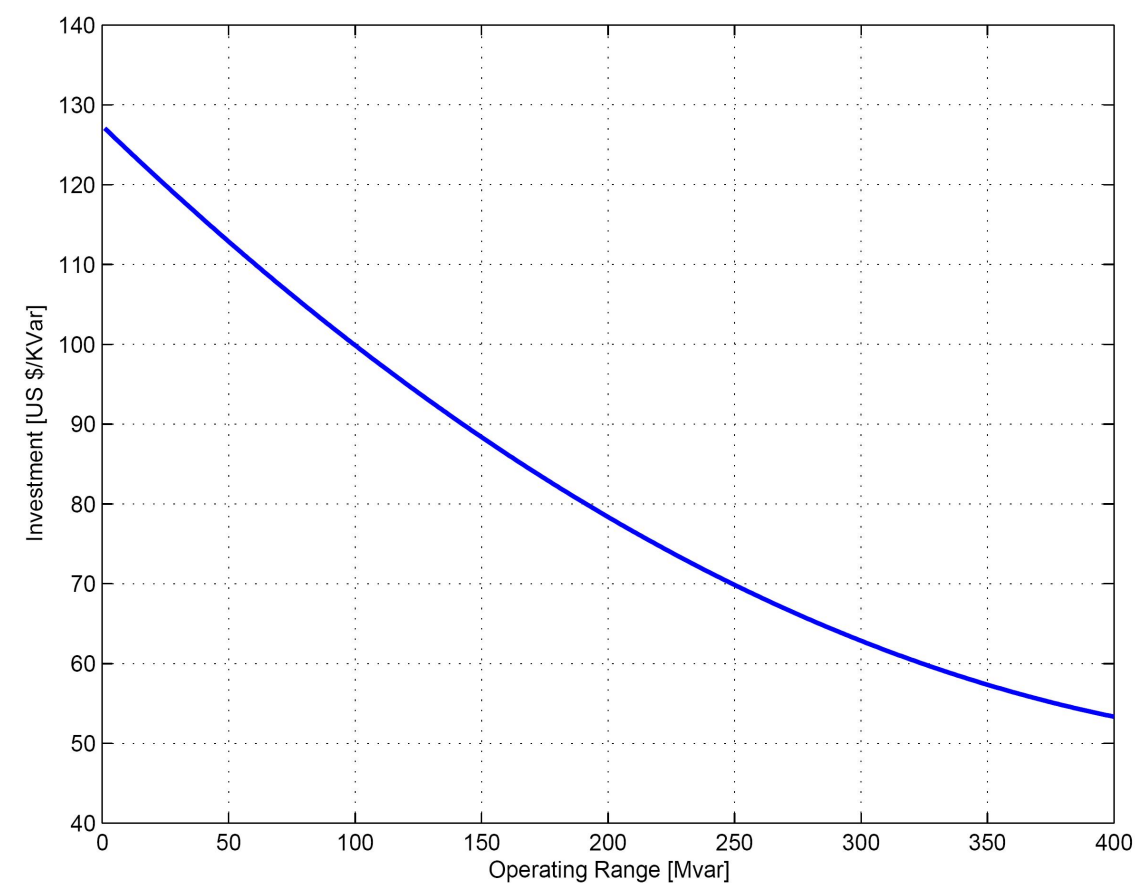

Figure 5.1: SVC Investment costs

\subsubsection{Equipment Costs and Infrastructure Costs}

As described in [39] the investment costs of FACTS devices can be split into two categories

1. Device equipment costs

2. Necessary Infrastructure costs

Equipment costs depend not only upon the installation rating but also upon special requirements such as:

- Redundancy of the control and protection systems

- Seismic conditions

- Ambient conditions (e.g. temperature, pollution level), and

- Communication requirements with the substation control system or the regional or national control center.

Infrastructure costs depend on the device's and costs include

- Land acquisition, if there is insufficient space in the existing substation, 
- Modifications to the existing substation,

- Construction of a building for indoor equipment,

- Yard civil works, and

- Communication infrastructure.

The typical range of investment costs is shown in Fig. 5.2, [39] with both the lower and upper limits of the cost areas. The lower limit of the cost area indicates the equipment costs and the upper limit indicates the total investment costs including the infrastructure costs. In this study, the total investment costs, corresponding to the upper limit of the Fig. 5.2 are used. The operating costs of SVC are generally negligible when compared to the total investment costs and can be safely ignored.

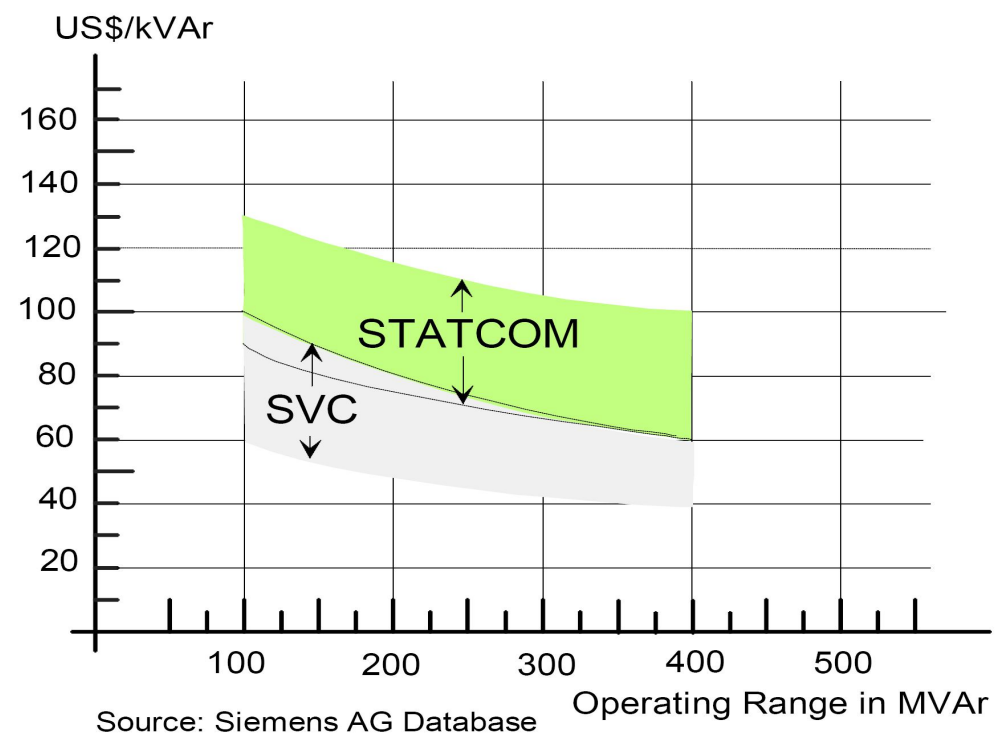

Figure 5.2: Typical Investemnt Costs for SVC / STATCOM [39]

Most of the FACTS devices are in service for many years [39] and only a part of their life time is employed in regulation of power flow [13]. Since SVC procurement requires a lot of capital cost, decision on investment needs to be based on the returns the device will allow. In this study, the annual cost of the device is calculated by assuming a uniform interest rate of $6 \%$ and 15 years of life expectancy. Hence, the annualized cost of the SVC as calculated from 
the model shown in Fig. 5.1 and from equation (5.1) is

$$
\begin{aligned}
\text { Annual } C_{\text {svc }} & =\frac{P \cdot r \cdot(1+r)^{n}}{(1+r)^{n}-1} \\
\text { Cost }_{\text {svc }} & =\frac{\text { Annual } C_{\text {svc }}}{8760}(U S \$ / h r)
\end{aligned}
$$

where $\mathrm{P}, \mathrm{r}$, and $\mathrm{n}$ denote principal value, interest rate per payment, and number of payments respectively. $C_{s v c}$ is the total investment costs of the SVC given from equation (5.1).

\subsection{Optimal Placement of VAR Support Devices}

According to engineering economics, whenever there are different investment schemes, technical and economic quantitative analysis should be performed and economic assessment should be provided in order to select the optimal scheme. The OPF solution will give the amount of reactive power support needed at each load bus. It is necessary to use cost-benefit analysis (CBA) to analyze whether the new VAR source would be cost-effective when it is actually installed.

\subsubsection{Cost Benefit Analysis}

For VAR planning purposes, costs and sites of reactive power sources must be determined. This thesis also presents a new method to select the reactive power source sites by the analytic hierarchy process (AHP). The proposed approach comprehensively considers the network topology, operation states and reactive power support service cost of each candidate VAR source site. Specifically it considers the social welfare benefit-to-cost ratio (SBCR), maximum loading condition benefit-to-cost ratio (MBCR) and congestion cost benefit-to-cost ratio (CBCR) based on a cost - benefit analysis. Due to their independent nature, results from these three BCRs are not necessarily the same. Of course, all BCRs reflect the improvement of the systems operation state after the VAR support service is provided.

Unfortunately, it is difficult to find a unified process for ranking these results. Moreover, all BCRs have not included other qualitative relationships for considering relative importance of different VAR source sites. AHP is a simple and convenient method to analyze a complicated problem (or a complex system). It is especially suitable for problems which are very difficult to be analyzed whole quantitatively, and is now widely used in various areas [83] including 
power systems. AHP can help to quantify the decision-makers thinking. Thus, it provides a useful means for considering myriad factors in the ranking and selection of VAR source locations. The method is explained in detail in the next section.

The aim of reactive power planning is to obtain optimal VAR placement scheme (location and sizing of SVC on the load buses) under the some load level and constraints. In this work, multi-objective OPF formulation is used along with the investment costs of SVC for this purpose. Considering the 'social welfare' objective function, somewhat higher losses would be incurred since cheaper generating sources, generally located away from load center, would be predominantly used to meet the demands. However, it might be worthwhile for the utility to bear this additional loss rather than switch generation to relatively expensive units located nearer to load center [24]. The OPF formulation as explained in the previous chapter is extended to include cost of VAR support/SVC is given in equation 5.4.

$$
\text { Min. } F=-p_{1} * \text { social welfare }-p_{2} * \lambda_{c}+C_{s v c} Q_{s v c}
$$

where $F$ is the sum of social welfare $(\$ / \mathrm{h})$, loading margin (p.u) and total investement cost of $\operatorname{SVC}(\$ / h)$.

In order to reflect the overall benefits after SVC is installed, three kinds of BCR were considered for the selection of optimal location.

(1) Social welfare benefit-to-cost ratio $(\mathrm{SBCR})(\$ / \mathrm{h})$

$$
\begin{aligned}
\mathrm{SBCR} & =\frac{\max \left(0, \sum_{t=1}^{24}\left(S_{w}\left(Q_{s v c i}\right)-S_{w}(0)\right)\right)}{C\left(Q_{s v c i}\right)} \\
\mathrm{or} & \mathrm{SBCR}^{t}=\frac{\max \left[0,\left(S_{w}^{t}\left(Q_{s v c i}\right)-S_{w}^{t}(0)\right)\right]}{C\left(Q_{\text {svci }}\right) / 24}
\end{aligned}
$$

where: $S_{w}^{t}(0)$, the social welfare at time $t$ before SVC at bus $i$ is installed; $S_{w}^{t}\left(Q_{s v c i}\right)$, the social welfare at time $t$ after SVC at bus $i$ is installed; $C\left(Q_{\text {svci }}\right)$, the equivalent daily investment cost of SVC at load node $i(\$ /$ day). Because of the chosen objective at some load buses the social welfare may decrease after the SVC is installed though the loading margin of the system increase. Since the social welfare being the main objective of the market opearator placement of SVC at such load buses is not desired. This means, $S_{w}^{t}(0)$ may be larger than $S_{w}^{t}\left(Q_{s v c i}\right)$, 
i.e. $\left(S_{w}^{t}\left(Q_{s v c i}\right)-S_{w}^{t}(0)\right)$ is negative. In other words no social welfare benefit is obtained in this case. Therefore, it is defined as $S B C R^{t}=0$ to reflect this case, i.e.

$$
\max \left[0,\left(S_{w}^{t}\left(Q_{s v c i}\right)-S_{w}^{t}(0)\right)\right]=0
$$

(2) Maximum loadability benefit-to-cost ratio $(\mathrm{MBCR})(\mathrm{MW} / \mathrm{h})$

$$
\begin{aligned}
\mathrm{MBCR} & =\frac{\left(\sum_{t=1}^{24}\left(M L\left(Q_{s v c i}\right)-M L(0)\right)\right)}{C\left(Q_{s v c i}\right)} \\
\text { or } & \\
\mathrm{MBCR}^{t} & =\frac{\left(M L^{t}\left(Q_{s v c i}\right)-M L^{t}(0)\right)}{C\left(Q_{s v c i}\right) / 24}
\end{aligned}
$$

where: $M L(0)$ is the loading margin or maximum loadability of the system at time $t$ before SVC at bus $i$ is installed and $M L\left(Q_{s v c i}\right)$ is the loading margin at time $t$ after SVC at bus $i$ is installed. MBCR provides the increase in maximum loading condition with the installation of SVC

(3) Congestion cost benefit-to-cost ratio (CBCR) $(\$ / \mathrm{h})$

$$
\begin{aligned}
\mathrm{CBCR} & =\frac{\max \left(0, \sum_{t=1}^{24}\left(C C(0)-C C\left(Q_{\text {svci }}\right)\right)\right)}{C\left(Q_{\text {svci }}\right)} \\
\text { or } & \\
\mathrm{CBCR}^{t} & =\frac{\max \left[0,\left(C C^{t}(0)-C C^{t}\left(Q_{\text {svci }}\right)\right)\right]}{C\left(Q_{\text {svci }}\right) / 24}
\end{aligned}
$$

where: $C C^{t}(0)$ is the congestion cost at time $t$ before SVC at bus $i$ is installed and $C C^{t}\left(Q_{\text {svci }}\right)$ is the congestion cost at time $t$ after SVC at bus $i$ is installed; $C\left(Q_{s v c i}\right)$, the equivalent daily investment cost of SVC at load node $i(\$ /$ day).

Obviously, all BCRs reflect the improvement of the system operation state after the VAR support service is provided. However, the ranking results from these three BCRs might not be same due to their independent nature. The relative importance of each factor over other is represented as weighting factor which is found through analytic hierarchy process.

The index for optimal placement of VAR support is formulated as:

$$
\widetilde{J}=\max _{i \in N L} J^{i}=w_{1} \widehat{J}_{1}^{i}+w_{2}{\widehat{J_{2}}}^{i}+w_{3} \widehat{J}_{3}^{i}
$$


where all the factors are evaluated at each optimal location $i$ for a selected critical line contingency found through sensitivity analysis.

$$
\begin{aligned}
\widetilde{J} & =\text { Index to be maximized } \\
\widehat{J_{1}} & =\text { Normalized value of SBCRs } \\
\widehat{J}_{2} & =\text { Normalized value of MBCRs } \\
\widehat{J_{3}} & =\text { Normalized value of CBCRs } \\
N L & =\text { Total number of load buses } \\
w_{1}+w_{2}+w_{3} & =1
\end{aligned}
$$

The bus corresponding to the maximum value of index $\widehat{J}$ is the optimal site for installing SVC. First compute the VSC-OPF solution by reading the network topology and market data - Identify the critical line such that the system's overall available transfer capability (ATC) reaches minimum with the line outage. This index is suitable for the systems which are capable of maintaining minimum level of security after critical line outage. The new benefits with SVC are obtained at each load bus over a period of 24 hours and all the three BCRs can be calculated from equations 5.6, 5.9, and 5.11. The importance of each factor over other factor is calculated by setting up an AHP model for source selection.

If the system cannot be loaded to the minimum desired security level i.e. $110 \%$ of system base load, it is considered as the market solution is not feasible i.e base case solution is not existing and it is a necessity for the system to install additional VAR support to make system realiable, secure and stable. For such systems the index for optimal VAR source site is given in 5.13. Considering the three factors social welfare, maximum loading condition and congestion cost for all the load buses. The index is given below,

$$
\widetilde{J}=\max _{i \in N L} J^{i}=w_{1}{\widehat{J_{1}}}^{i}+w_{2}{\widehat{J_{2}}}^{i}-w_{3}{\widehat{J_{3}}}^{i}
$$

where, the Social welfare is obtained from:

$$
\begin{aligned}
\mathrm{J}_{1} & =\frac{\sum_{t=1}^{24} S_{w}\left(Q_{s v c i}\right)}{C\left(Q_{s v c i}\right)} \\
\text { or } & \\
\mathrm{J}_{1}{ }^{t} & =\frac{S_{w}^{t}\left(Q_{s v c i}\right)}{C\left(Q_{s v c i}\right) / 24}
\end{aligned}
$$


Maximum loading condition or system loadability:

$$
\begin{aligned}
\mathrm{J}_{2} & =\frac{\sum_{t=1}^{24} M L\left(Q_{\text {svci }}\right)}{C\left(Q_{\text {svci }}\right)} \\
\text { or } & \\
\mathrm{J}_{2}{ }^{t} & =\frac{M L^{t}\left(Q_{\text {svci }}\right)}{C\left(Q_{\text {svci }}\right) / 24}
\end{aligned}
$$

Congestion cost:

$$
\begin{aligned}
\mathrm{J}_{3} & =\frac{\sum_{t=1}^{24} C C\left(Q_{s v c i}\right)}{C\left(Q_{s v c i}\right)} \\
\text { or } & \\
\mathrm{J}_{3}{ }^{t} & =\frac{C C^{t}\left(Q_{s v c i}\right)}{C\left(Q_{s v c i}\right) / 24}
\end{aligned}
$$

Setting up an AHP model and ranking the source sites can be performed similar to previous case. The maximum social welfare, MLC \& CC with SVC at load buses can be obtained from equations 5.15, 5.17 and 5.19 respectively. The bus corresponding to the maximum value of $\widetilde{J}$ is chosen as the optimal location.

In the equations 5.15, 5.17and CC 5.19, the final values are then obtained through normalization by dividing all the values with the maximum.

$$
\begin{aligned}
\widetilde{J} & =\text { Index to be maximized } \\
\widehat{J}_{1} & =\text { Normalized value of } \mathrm{J}_{1} \\
\widehat{J}_{2} & =\text { Normalized value of } \mathrm{J}_{2} \\
\widehat{J}_{3} & =\text { Normalized value of } \mathrm{J}_{3} \\
N L & =\text { Total number of load buses } \\
w_{1}+w_{2}+w_{3} & =1
\end{aligned}
$$

The sum of total weights is equal to 1 , so the resultant weights have values ranging from 0 to 1 .

\subsubsection{Analytic Hierarchy Process}

The principle of the analytic hierarchy process is that first a structural model of the analytic hierarchy is established through analysis of the complex system, then the complex problem 
is transformed into the problem of rank calculation within the hierarchy structure. In the ranking computation, the ranking in each hierarchy can also be converted into the judgment and comparison of a series of pairs of factors. This implies that a judgment matrix is needed to reflect these judgments and comparisons. The judgment matrix can be formed according to the quantified judgment of pairs of factors using some ratio scale method. Consequently, the value of the weighting coefficients of all factors can be obtained through calculating the maximal eigenvalue and the corresponding eigenvector of the judgment matrix. Obviously, the purpose of ranking the elements of the eigenvector corresponding to the maximal eigenvalue is simply to obtain the weight of each factor among the different kinds of factors.

The steps of the AHP algorithm may be written as follows:

1. Set up a hierarchy model.

2. Form a judgment matrix.

The value of elements in the judgment matrix reflects the users knowledge about the relative importance between every pair of factors.

3. Calculate the maximal eigenvalue and the corresponding eigenvector of the judgment matrix.

4. Perform hierarchy ranking and consistency checking of results.

We can perform the hierarchy ranking according to the value of elements in the eigenvector, which represents the relative importance of the corresponding factor. The consistency index (CI) of a hierarchy ranking is defined as

$$
C I=\frac{\left(\lambda_{\max }-n\right)}{(n-1)}
$$

where $\lambda_{\max }$ is the maximal eigenvalue of the judgment matrix and $n$ is the dimension of the judgment matrix.

The stochastic consistency ratio is defined as

$$
C R=\frac{C I}{R I}
$$

where $R I$ is a set of given average stochastic consistency indices. 


\begin{tabular}{c|c|c|c|c|c|c|c|c}
\hline $\mathrm{n}=1$ & $\mathrm{n}=2$ & $\mathrm{n}=3$ & $\mathrm{n}=4$ & $\mathrm{n}=5$ & $\mathrm{n}=6$ & $\mathrm{n}=7$ & $\mathrm{n}=8$ & $\mathrm{n}=9$ \\
\hline 0.00 & 0.00 & 0.58 & 0.90 & 1.12 & 1.24 & 1.32 & 1.41 & 1.45 \\
\hline
\end{tabular}

Table 5.1: Set of average stochastic consistency indices RI

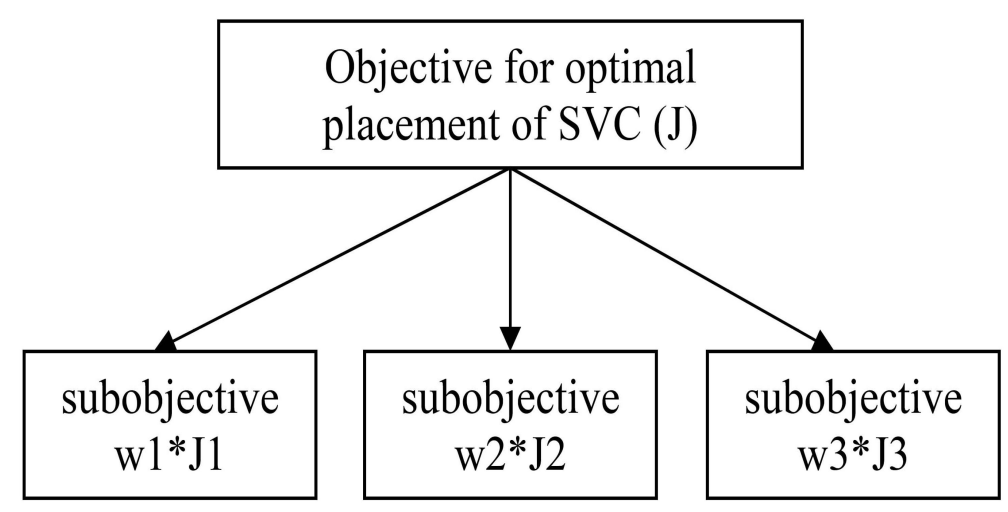

Figure 5.3: Hierarchy model for optimal placement of SVC

For any judgment matrix of dimension 1 to 9 , the average stochastic consistency indices $R I$, given in Table 5.1, can be obtained according to statistical calculations. A satisfactory hierarchy ranking has been obtained when the stochastic consistency ratio $C R<0.1$.

Hierarchy model of VAR placement

The hierarchy model for the VAR placement is simple. It consists of only a two-level hierarchy as shown in Fig. 5.3. In this way, the calculation of the weighting coefficients in the objective for VAR location is changed into ranking calculation in the hierarchy model. Thus, it is necessary to form a judgement matrix $A$ for ranking computation. According to the principle of AHP mentioned above, the judgement matrix is formed as below 5.22.

$$
A=\left[\begin{array}{lll}
W 1 / W 1 & W 1 / W 2 & W 1 / W 3 \\
W 2 / W 1 & W 2 / W 2 & W 2 / W 3 \\
W 3 / W 1 & W 3 / W 2 & W 3 / W 3
\end{array}\right]
$$

where $W_{i}$ is the weighting coefficient of the $i$ th subobjective in the hierarchy model. Of course $W_{i}$, which is just what we need, is unknown.

$W_{i} / W_{j}$ can be obtained according to the experiences of electrical engineers using some ratio scale methods. The weights usually consist of numbers on a scale of '1-9', as illustrated in Table [5.2]. For example, if $J_{2}$ as compared to $J_{1}$ is "clearly more important", corresponding 


\begin{tabular}{l|c}
\hline Importance of Any Factor in & \\
Comparison with Any Other Factor & Scale \\
\hline Equally important & 1 \\
A little more important & 3 \\
Clearly more important & 5 \\
Much more important & 7 \\
Most important & 9 \\
\hline
\end{tabular}

Table 5.2: Weighting Scale for "More Important Than"

\begin{tabular}{l|c}
\hline Importance of Any Factor in & \\
Comparison with Any Other Factor & Scale \\
\hline Equally important & 1 \\
A little less important & $1 / 3$ \\
Clearly less important & $1 / 5$ \\
Much less important & $1 / 7$ \\
Least important & $1 / 9$ \\
\hline
\end{tabular}

Table 5.3: Weighting Scale for "Less Important Than"

value in the matrix is taken as ' 5 '.

Conversely, the relative importance of $J_{1}$ as compared to $J_{2}$ is the reciprocal of ' 5 ', that is ' $1 / 5$ '. This suggests a second table, such as Table [5.3]. The numbers, '2', '4', '6' and '8' can be used to reduce the gap between "importance" in ratings. Thus, '8' might be assigned to a rating of "very much more important," lying half way between "much more important" and "most important". When the judgment matrix $A$ is formed, the maximal eigenvalue and the corresponding eigenvector can be computed by matrix theory.

It is possible to precisely calculate the eigenvalue and the corresponding eigenvector of a matrix, but this would be time-consuming. Moreover, it is not necessary to precisely compute the eigenvalue and the corresponding eigenvector of the judgment matrix. The reason is that the judgment matrix, which is formed by the subjective judgment of the user, itself has some range of error. Therefore, an approximate approach to compute the maximal eigenvalue and the corresponding eigenvector has been used. 
Sum Method:

(i) Normalize every column in the judgement matrix:

$$
X_{i j}^{*}=\frac{X_{i j}}{\sum_{k} X_{k j}} i, j, k=1,2, \ldots, n
$$

Now, the judgment matrix $A$ is changed into a new matrix $A^{*}$, in which each column has been normalised.

(ii) Add all the elements of each row in matrix $A^{*}$ :

$$
W_{i}^{*}=\sum_{j} X_{i j} i, j, k=1,2, \ldots, n
$$

(iii) Normalize the vector $W^{*}$, which equals $\left[W_{1}^{*}, W_{2}^{*}, \ldots, W_{n}^{*}\right]^{T}$

$$
W_{i}=\frac{W_{i}^{*}}{\sum_{j} W_{j}^{*}} \quad i, j, k=1,2, \ldots, n
$$

Hence, we obtain the eigenvector of the judgment matrix $A$ :

$$
\mathbf{W}=\left[W_{1}, W_{2}, \ldots, W_{n}\right]^{T}
$$

(iv) Calculate the maximal eigenvalue of the judgment matrix $\lambda_{\max }$ :

$$
\lambda_{\max }=\sum_{i}\left[\frac{(A \mathbf{W})_{i}}{n W_{i}}\right] \quad i=1,2, \ldots, n
$$

where $(A \mathbf{W})_{i}$ represents the $i$ th element in vector $A \mathbf{W}$.

\subsubsection{Pricing VAR Support Services}

FACTS devices are being used in many places to relieve congestion, to improve system loadability and there is a potential price reduction upon its usage. A pricing scheme for FACTS devices which are used in congestion relief and increase in social welfare, so that new construction can be efficiently simulated, is still missing. The effects of FACTS devices are not constrained to the location where they are installed and are hard to measure by the power flowing through them. Since the costs associated with FACTS controllers are high, pricing methodologies for the services provided by these controllers should be developed. 
The pricing methods are based on a comparison of congestion costs and social welfare. The congestion costs are defined as:

$$
C C=\sum\left(L M P_{i} P_{d_{i}}+R M P_{i} P_{d_{i}} \tan \left(\phi_{d_{i}}\right)\right)-\sum\left(L M P_{j} P_{s_{j}}+R M P_{j} Q_{g_{j}}\right)
$$

where $C C$ is the congestion cost in $\$ / \mathrm{h}, \mathrm{LMP}$ is the locational marginal price for demand bus $i$ or supply bus $j$ in $\$ / \mathrm{MWh}$, and $P_{d_{i}} \& P_{s_{j}}$ are the demand and supply powers in MW. Thus any reduction in CC due to the application of FACTS is considered to be a profit which cannot exist without these devices. Consequently, the difference between the $C C$ with and without the FACTS devices is used to price the reactive services of the device.

$$
F P=\left.C C\right|_{w o f}-\left.C C\right|_{w f}
$$

where $F P$ is FACTS pricing in $\$ / \mathrm{h}$, and $\left.C C\right|_{\text {wof }}$ and $\left.C C\right|_{w f}$ are the congestion costs without and with FACTS device in service respectively. The value of $F P$ is not considerable if the system is not heavily loaded.

The social welfare $S_{w}$ can also be used as a tool for pricing the FACTS service. It is defined as:

$$
S P=\left.S P\right|_{w f}-\left.S P\right|_{w o f}
$$

where $S P$ is the social welfare price in $\$ / \mathrm{h}$ and $\left.S P\right|_{\text {wof }}$ and $\left.S P\right|_{w f}$ are the social welfare without and with FACTS device in service respectively. Similar to $F P$, the value of $S P$ is not considerable if the system is not heavily loaded.

\subsubsection{Analysis of Reactive Power Pricing}

Developing an accurate and feasible method for reactive power pricing is important in the electricity market, Such reactive power price cannot be obtained by conventional optimal power flow models because the production cost of reactive power is ignored in these models. It is realized that establishing an accurate pricing structure of reactive power can not only recover the costs of reactive power providers, but also provide economic information for real-time operations. In this thesis, a social welfare objective function with both supply and demand reactive power costs are considered. Tests under different system operating conditions help to observe how those conditions influence reactive power prices. 
Reactive power production cost can be represented as the opportunity cost of generator. According to the loading capability diagram of a generator, reactive power output may reduce active power output capacity of generators which can at least serve as spinning reserve, therefore causes implicit financial loss to generators. Actually, opportunity cost depends on the real time balance between demand and supply in the market, so it is difficult to determine the real value. The opportunity cost (5.31) in general is approximated as:

$$
C_{p g i}\left(Q_{G i}\right)=\left[C_{p g i}\left(S_{G i, \max }\right)-\sqrt{C_{p g i}\left(S_{G i, \max }\right)^{2}-Q_{G i}^{2}}\right] \cdot k
$$

where $S_{G i \text { max }}$ is the nominal apparent power of the generator at bus $i$; $Q_{G i}$ is the reactive power output of the generator at bus $i ; k$ is the profit rate of of active power generation, usually between $5 \%$ and $10 \%$.

Since, there is no similar model for the reactive power procurement cost on the demand side and in addition to make the calculations simple, the cost to produce and consume reactive power is taken as a percentage of its respective real power bid price without losing any generality.

\subsection{VSC-OPF with SVC and N-1 contingency criterion}

The important objective of this thesis work is to study the effect of SVC on spot pricing in a VSC-OPF based market model. The multi-objective includes maximization of social welfare, maximum distance to collapse and the cost of SVC in $\$ / \mathrm{h}$. While calculating the loading margin the $\mathrm{N}-1$ contingency criterion is considered.

\section{Static VAR Compensator (SVC):}

SVC is used for voltage control applications in transmission systems. The placement of SVC has been considered at load bus only but not in the middle of the line, since the benefits rendered by SVC in the network go in vain with the line outage. Reactive power output of an SVC $\left(Q_{S V C}\right)$ lies within limits set by available inductive and capacitive susceptances $\left(B_{\text {ind }}\right.$ and $B_{\text {cap }}$ respectively) as follows:

$$
\begin{array}{r}
Q_{\text {ind }}=B_{\text {ind }} V_{\text {ref }}^{2} \\
Q_{\text {cap }}=B_{\text {cap }} V_{\text {ref }}^{2} \\
Q_{\text {min }} \leq Q_{S V C} \leq Q_{\max }
\end{array}
$$


Where $V_{\text {ref }}$ is the reference voltage magnitude at SVC node. In the OPF formulation, steady state model of SVC has been taken as a PV generator with $P=0$ and supply reactive power with the above set reactive power limits. The investment costs of SVC are given in section 5.2

\subsection{Summary}

An index to place the VAR support in the network considering both technical and economical factors is proposed based on CBA. Various factors such as social welfare, maximum loading condition and congestion cost are computed in a voltage-stability constrained OPF. AHP method is used to find the quantitative relationship between the three BCRs taking into account the complete network topology. A simple method to price VAR support to recover the investment cost is proposed. 


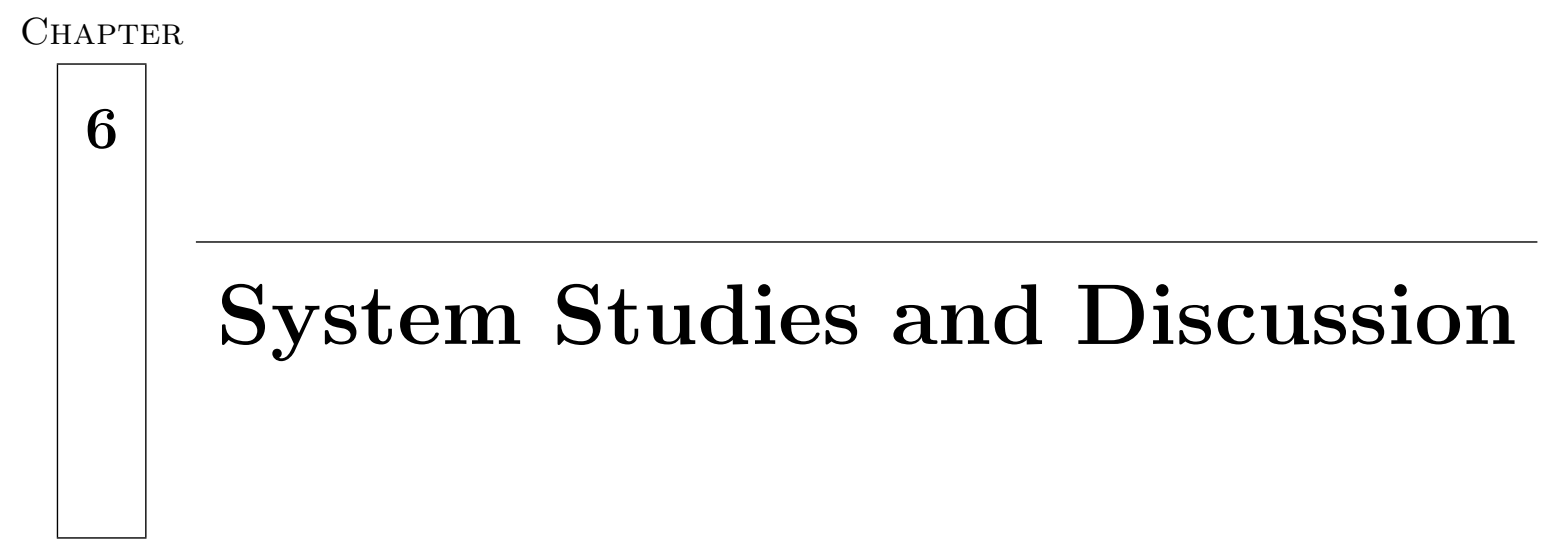

\subsection{Test Systems Description}

This chapter describes two case studies, the first case maintains minimum level of security after N-1 contingency and the second system fails to maintain minimum level of security.

1. Six-Bus Test System: Fig. 6.1 depicts the six-bus test system single-line diagram, which is extracted from [85].

2. IEEE 14-Bus Test System: A single-line diagram of the IEEE 14-bus test system is depicted in Fig. 6.10 which represents a portion of the American Electric Power System (in the Midwestern US) obtained from [94]

In sections 6.2 and 6.3 , the OPF problem for 3.13 and 4.3 are applied to the two test systems and compared the effect of system security on power dispatch and electricity prices. The power flow limits needed in 3.13 were obtained "offline" by means of a continuation power flow technique [20]. For both test systems, bid load and generator powers were used as the direction needed to obtain a maximum loading point and the associated power flows in the lines, ignoring contingencies so that proper comparisons can be made. The limits of the 
loading parameter were assumed to be $\lambda_{c_{\min }}=0.1$ and $\lambda_{c_{\max }}=0.8$ (i.e., for any value of $p$, it is assumed that the system can be securely loaded to an MLC between $110 \%$ and $180 \%$ of the total transaction level of the given solution). To allow for adequate comparisons, the actual power flow limits used in 3.13 were reduced by $10 \%$ with respect to the values obtained from the offline continuation power flow analysis to emulate the $\lambda_{c}=0.1$ limit.

VSC-OPF is extended to include $\mathrm{N}-1$ contingency criterion and the critical line is identified through power transfer sensitivity analysis. Optimal scheme for placing VAR support explained in section 5.3 is implemented by performing AHP analysis to find the appropriate weights for economical and technical terms. The results are then compared with Standard OPF and VSC-OPF with N-1 contingency and no VAR support. Transmission prices before and after the VAR support are compared for 6-bus test system as the system can be securely loaded and stable after crtical line failure. The effect of weighting factor $p$ on the total transaction level, congestion costs and the maximum loading margin $\lambda_{c}$ for the system with SVC is observed.

The IEEE 14-bus test system is not stable with critical line failure and therefore it needs VAR support to avoid voltage collapse and increase loading margin in this particular case. The index given in 5.13 is used for optimal placement of VAR support. The effect of SVC on power dispatch and electricity prices are compared with standard OPF, the case without SVC and without N-1 contingency criterion. The transmission prices are calculated using wheeling charges method. Reactive power marginal prices are effected because of the inclusion of cost for both suppliers and consumers. Though, there is some debate regarding the viability of reactive power prices, any pricing scheme will likely to be based on spot pricing technique. The impact of load power factor on reactive power marginal prices is analysed.

\subsection{6-Bus Test System}

The system represents three generation companies (GENCOs) and three energy supply companies (ESCOs) that provide supply and demand bids. The complete data set for this system is provided in the Appendix A.1.2, so that the results discussed here may be readily reproduced. 
Bus 3

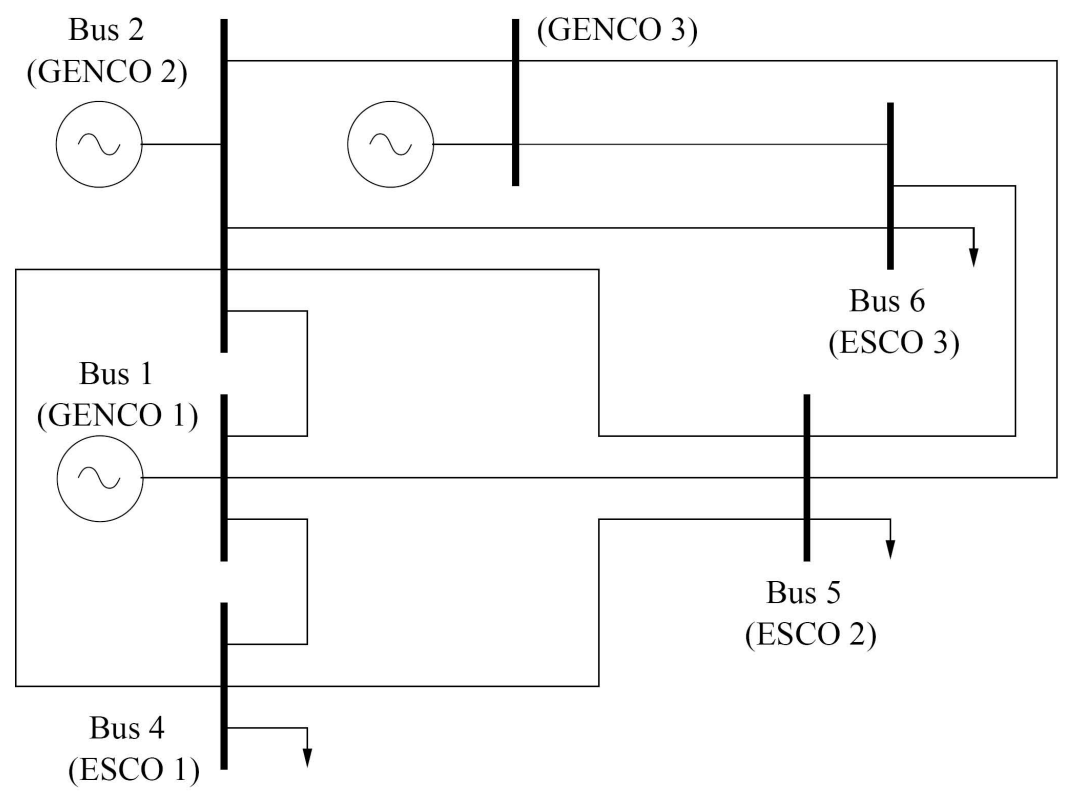

Figure 6.1: 6-bus test system [85] 


\begin{tabular}{c|ccccccc}
\hline Pariticipant & $\begin{array}{c}\mathrm{V} \\
{[\mathrm{p} . \mathrm{u} .]}\end{array}$ & $\begin{array}{c}\mathrm{LMP} \\
{[\$ / \mathrm{MWh}]}\end{array}$ & $\begin{array}{c}\mathrm{RMP} \\
{[\$ / \mathrm{MVArh}]}\end{array}$ & $\begin{array}{c}\mathrm{NCP} \\
{[\$ / \mathrm{MWh}]}\end{array}$ & $\begin{array}{c}P_{B I D} \\
{[\mathrm{MW}]}\end{array}$ & $\begin{array}{c}P_{0} \\
{[\mathrm{MW}]}\end{array}$ & $\begin{array}{c}\text { Pay } \\
{[\$ / \mathrm{h}]}\end{array}$ \\
\hline \hline GENCO1 & 1.089 & 9.70 & 0.97 & 1.24 & 14.5 & 90 & -811 \\
GENCO2 & 1.091 & 8.42 & 0.88 & 0.00 & 0.0 & 140 & -907 \\
GENCO3 & 1.100 & 7.00 & 0.70 & -1.03 & 20.5 & 60 & -496 \\
ESCO4 & 1.034 & 11.91 & 1.38 & 3.41 & 25.3 & 90 & 1184 \\
ESCO5 & 1.037 & 10.45 & 1.15 & 1.09 & 2.3 & 100 & 870 \\
ESCO6 & 1.055 & 9.57 & 0.81 & 1.79 & 6.4 & 90 & 746 \\
\hline \hline Totals & \multicolumn{2}{|l}{$\mathrm{T}=243.98 \mathrm{MW}$} & Congestion Cost $=584.85 \$ / \mathrm{h}$ & & & \\
& \multicolumn{2}{l}{ Losses $=6.23 \mathrm{MW}$} & & & & & \\
\hline
\end{tabular}

Table 6.1: Six-bus test system: OPF with offline power flow limits

\subsubsection{Results and Discussion}

The results for the standard OPF formulation (3.13) are reported in Table 6.1. The results depict that the system is having low transaction level ' $\mathrm{T}$ ' and heterogeneous LMPs, RMPs and NCPs, indicating that the system constraints, and in particular active power flow limits, negatively affect the market solution. Table 6.1 shows also the total losses and the payment given to the Independent Market Operator (referred to as PayIMO) or Congestion Cost (CC), which is computed as the difference between demand and supply payments.

Table 6.2 illustrates the initial solution of the VSC-OPF problem 4.3. The weighting factor $p$ in the objective function of VSC-OPF used for maximizing the loading parameter, was set to $p=10^{-3}$ as this was determined to be a value that does not significantly affect the market solution, since the distance to the maximum loading point is not being really "optimized," with mostly the social welfare being considered in the objective function. Observe that, as expected, the absence of active power flow limits and contingencies makes possible a higher total transaction level ' $\mathrm{T}$ ' and more homogeneous LMPs, RMPs and lower NCPs. For both solutions, generator voltages are almost at their maximum limits, as expected, since this condition generally provides higher transactions levels.

The improved LMPs result also in a lower total price paid to the independent market operator (Pay losses are higher which is expected, as ' $\mathrm{T}$ ' is higher. This demonstrates that offline power flow 


\begin{tabular}{|c|c|c|c|c|c|c|c|}
\hline Pariticipant & $\begin{array}{c}\mathrm{V} \\
\text { [p.u.] }\end{array}$ & $\begin{array}{c}\text { LMP } \\
{[\$ / M W h]}\end{array}$ & $\begin{array}{c}\text { RMP } \\
\text { [\$/MVArh] }\end{array}$ & $\begin{array}{c}\mathrm{NCP} \\
{[\$ / \mathrm{MWh}]}\end{array}$ & $\begin{array}{l}P_{B I D} \\
{[\mathrm{MW}]}\end{array}$ & $\begin{array}{c}P_{0} \\
{[\mathrm{MW}]}\end{array}$ & $\begin{array}{l}\text { Pay } \\
{[\$ / \mathrm{h}]}\end{array}$ \\
\hline GENCO1 & 1.096 & 9.20 & 0.97 & 0.01 & 0.0 & 90 & -650 \\
\hline GENCO2 & 1.100 & 9.08 & 0.88 & 0.00 & 37.5 & 140 & -1324 \\
\hline GENCO3 & 1.100 & 9.15 & 0.70 & 0.01 & 30.0 & 60 & -721 \\
\hline ESCO4 & 1.033 & 9.76 & 1.29 & 0.28 & 37.5 & 90 & 1106 \\
\hline ESCO5 & 1.033 & 9.76 & 1.21 & 0.31 & 15.0 & 100 & 951 \\
\hline $\mathrm{ESCO} 6$ & 1.054 & 9.48 & 0.99 & 0.19 & 12.2 & 90 & 806 \\
\hline Totals & \multicolumn{2}{|c|}{$\begin{array}{l}\mathrm{T}=274.72 \mathrm{MW} \\
\text { Losses }=7.93 \mathrm{MW} \\
\mathrm{MLC}=474.16 \mathrm{MW}\end{array}$} & \multicolumn{5}{|c|}{$\begin{array}{l}\text { Congestion Cost }=168.96 \$ / \mathrm{h} \\
\text { Loading Margin }=0.73\end{array}$} \\
\hline
\end{tabular}

Table 6.2: Six-bus test system: VSC-OPF w/o contingencies

\begin{tabular}{|c|c|c|c|c|}
\hline Line \# & Line $h-k$ & $\mathrm{P}_{\mathrm{hk}}(\lambda)$ (p.u.) & $p_{h k}=\mathrm{P}_{h k}{ }^{*} \mathrm{dP}_{h k} / \mathrm{d} \lambda\left(10^{6}\right)$ & $\mathrm{ATC}^{\mathrm{N}-1}(\mathrm{MW})$ \\
\hline \hline 1 & $2-3$ & 0.127 & 0.0025 & 184.71 \\
\hline 2 & $3-6$ & 0.932 & 0.1897 & 77.85 \\
\hline 3 & $4-5$ & 0.032 & 0.0008 & 184.38 \\
\hline 4 & $3-5$ & 0.530 & 0.0419 & 155.09 \\
\hline 5 & $5-6$ & 0.098 & 0.0009 & 179.25 \\
\hline 6 & $\mathbf{2 - 4}$ & $\mathbf{1 . 3 2 4}$ & $\mathbf{0 . 2 5 3 1}$ & $\mathbf{2 7 . 4 7}$ \\
\hline 7 & $1-2$ & 0.043 & 0.0117 & 191.71 \\
\hline 8 & $1-4$ & 0.655 & 0.1073 & 42.61 \\
\hline 9 & $1-5$ & 0.506 & 0.0318 & 174.17 \\
\hline 10 & $2-6$ & 0.599 & 0.1189 & 132.58 \\
\hline 11 & $2-5$ & 0.491 & 0.0581 & 151.02 \\
\hline
\end{tabular}

Table 6.3: Six-bus test system: Sensitivity coefficients Phk and ATC (N-1)

limits are not adequate constraints for representing the actual system congestion and not a very good reprentation of stability.

Table 6.3 shows the coefficients $p_{h k}$ used for sensitivity analysis. As mentioned in section 4.4, the line which produces lowest $\mathrm{ATC}^{\mathrm{N}-1}$ is chosen as the critical line. For the six-bus test system failure of 'line 6' i.e. line connecting from bus 2 - bus 4 produces the lowest ATC. 


\begin{tabular}{|c|c|c|c|c|c|c|c|}
\hline Pariticipant & $\begin{array}{c}\mathrm{V} \\
\text { [p.u.] }\end{array}$ & $\begin{array}{c}\mathrm{LMP} \\
{[\$ / \mathrm{MWh}]}\end{array}$ & $\begin{array}{c}\text { RMP } \\
\text { [\$/MVArh] }\end{array}$ & $\begin{array}{c}\mathrm{NCP} \\
{[\$ / \mathrm{MWh}]}\end{array}$ & $\begin{array}{l}P_{B I D} \\
{[\mathrm{MW}]}\end{array}$ & $\begin{array}{c}P_{0} \\
{[\mathrm{MW}]}\end{array}$ & $\begin{array}{l}\text { Pay } \\
{[\$ / \mathrm{h}]}\end{array}$ \\
\hline GENCO1 & 1.096 & 9.20 & 0.97 & 0.01 & 0.0 & 90 & -650 \\
\hline GENCO2 & 1.100 & 9.08 & 0.88 & 0.00 & 37.5 & 140 & -1324 \\
\hline GENCO3 & 1.100 & 9.15 & 0.70 & 0.01 & 30.0 & 60 & -721 \\
\hline ESCO4 & 1.033 & 9.76 & 1.29 & 0.28 & 37.5 & 90 & 1106 \\
\hline ESCO5 & 1.033 & 9.76 & 1.21 & 0.31 & 15.0 & 100 & 951 \\
\hline $\mathrm{ESCO} 6$ & 1.054 & 9.48 & 0.99 & 0.19 & 12.2 & 90 & 806 \\
\hline Totals & \multicolumn{2}{|c|}{$\begin{array}{l}\mathrm{T}=274.72 \mathrm{MW} \\
\text { Losses }=7.93 \mathrm{MW} \\
\mathrm{MLC}=315.36 \mathrm{MW}\end{array}$} & \multicolumn{5}{|c|}{$\begin{array}{l}\text { Congestion Cost }=168.96 \$ / \mathrm{h} \\
\text { Loading Margin }=0.148\end{array}$} \\
\hline
\end{tabular}

Table 6.4: Six-bus test system: VSC-OPF w/ contingency on line 2-4

Table 6.4 depicts the VSC-OPF results with the critical line 2-4 outage. This solution presents practically the same total transaction level as provided by the solution without contingencies in Table 6.2. If the system maintains just the minimum level of security, the OPF solution might get affected and therefore a slight decrease in LMPs, RMPs and NCPs is possible.

The $A T C^{N-1}$ in Table 6.4 corresponds to a $\lambda_{c_{m i n}}=0.1$, i.e. $110 \%$ of the total transaction level, indicating that the current solution has the minimum required security level $\left(\lambda_{c}=\right.$ 0.148). Because of the rescheduling of bids and by including more precise security constraints there is significant reduction in the congestion cost or Pay-IMO value compared to Standard OPF problem 3.13.

Optimal Placement of VAR Support based on CBA

As explained in the section 5.3.1 and from index 5.12, the optimal location for SVC is found through a cost-benefit analysis. First the AHP algorithm is solved to find the weights to three different BCRs. The criterion for chosing weights are:

1. Social welfare is "clearly more important" compared to maximum loading condition and "much more important" compared to congestion cost benefit-to-cost ratio.

2. Maximum loading condition BCR is taken as "little more important" compared to congestion cost BCR. 
Therefore, the judgement matrix $\mathbf{A}$ is as follows:

$$
A=\left[\begin{array}{ccc}
1 & 5 & 7 \\
1 / 5 & 1 & 3 \\
1 / 7 & 1 / 3 & 1
\end{array}\right]
$$

From the judgement matrix further analysis is performed. The Consistency Ratio (CR) is obtained as 0.057 which is acceptable for this size problem. The corresponding weights obtained are:

$$
\begin{array}{|l||l||l|}
\hline \mathrm{w}_{1}=0.724 & \mathrm{w}_{2}=0.193 & \mathrm{w}_{3}=0.083 \\
\hline
\end{array}
$$

Table 6.5: Weighting factors for six-bus test system

The Cost benefit analysis should be performed for a period of 24 hours with different loading conditions. Inorder to make calculations simple and at the same time not to lose the generality, four load serving factors (LSFs) are considered that reflect the change in loads. The LSFs considered for CBA study are 0.8, 1.0, 1.2, 1.4. This means the system is loaded with $80 \%, 100 \%, 120 \%$ and $140 \%$ of total load. Mean of the four values is calculated as explained in equations 5.6, 5.9 and 5.11.

Based on the index proposed in this thesis, the optimal location for VAR support is found for the six-bus test system. The weak bus ranking for VAR support is listed in Table 6.6.

\begin{tabular}{|c||c|}
\hline Bus No & $\mathrm{J}_{\max }$ \\
\hline \hline $\mathbf{4}$ & $\mathbf{0 . 9 7 2 6}$ \\
\hline 5 & 0.1241 \\
\hline 6 & 0.0479 \\
\hline
\end{tabular}

Table 6.6: Weak bus ranking for six-bus test system using CBA

In order to estimate the most appropriate capacity of the VAR support, a relationship between the loading factor and the corresponding capacity of the device was found through evaluating information regarding how much support the device can provide against voltage collapse. The loading factor is the factor by which real and reactive power loads are increased to calculate the maximum loading point. This relationship is shown in the Fig. 6.2. Based on this relationship, the optimal rating of the SVC was determined to be 130 MVar but, 
considering the high investment cost associated with it and keeping in mind of increase in demand in the future, a bigger size of SVC i.e. 200MVAR is taken in this study.

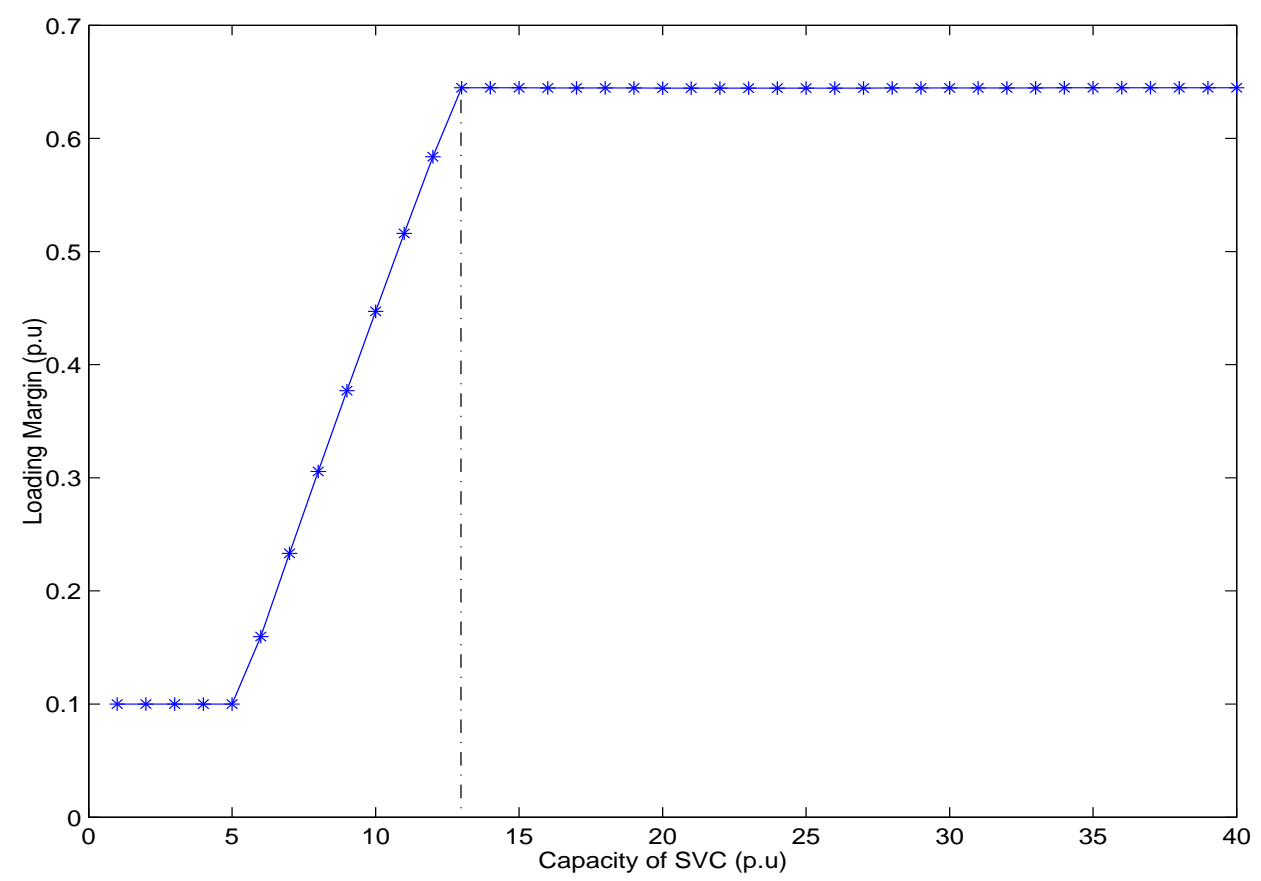

Figure 6.2: Loading Margin Vs SVC Capacity for six-bus test system

Table 6.7 depicts the results of VSC-OPF with SVC for a six-bus test system. We can observe that the system loading margin is increased and can now be loaded until $164 \%$ of its base load.

The voltages at all buses after installing the SVC are close to the reference value which is highly desired to restrict voltage limit violations. The three factors Social welfare, loading capability and congestion cost benefits are given below:

Though we cannot draw any mathematical relationship between change in locational prices with installation of SVC, but since the system loadability is being increased, the congestion cost should decrease compared to base case. Reactive power marginal prices decreased with the installation of SVC which is a desired incentive for new ventures.

Pricing VAR Support:

According to the pricing scheme explained in 5.28, Congestion cost decrease obtained due to installation of SVC should be socialized or should be used for using the FACTS service. 


\begin{tabular}{|c|c|c|c|c|c|c|c|}
\hline Pariticipant & $\begin{array}{c}\mathrm{V} \\
\text { [p.u.] }\end{array}$ & $\begin{array}{c}\mathrm{LMP} \\
{[\$ / \mathrm{MWh}]}\end{array}$ & $\begin{array}{c}\text { RMP } \\
{[\$ / M V A r h]}\end{array}$ & $\begin{array}{c}\mathrm{NCP} \\
{[\$ / \mathrm{MWh}]}\end{array}$ & $\begin{array}{l}P_{B I D} \\
{[\mathrm{MW}]}\end{array}$ & $\begin{array}{c}P_{0} \\
{[\mathrm{MW}]}\end{array}$ & $\begin{array}{l}\text { Pay } \\
{[\$ / \mathrm{h}]}\end{array}$ \\
\hline GENCO1 & 1.035 & 9.09 & 0.97 & -0.03 & 0.0 & 90 & -616 \\
\hline GENCO2 & 1.047 & 9.01 & 0.88 & 0.00 & 37.5 & 140 & -1271 \\
\hline GENCO3 & 1.084 & 9.16 & 0.70 & 0.08 & 30.0 & 60 & -751 \\
\hline $\mathrm{ESCO} 4$ & 1.000 & 9.63 & 0.92 & 0.20 & 37.5 & 90 & 1070 \\
\hline ESCO5 & 0.991 & 9.74 & 1.20 & 0.34 & 15.0 & 100 & 949 \\
\hline ESCO6 & 1.022 & 9.48 & 0.98 & 0.27 & 11.9 & 90 & 803 \\
\hline Totals & \multicolumn{2}{|c|}{$\begin{array}{l}\mathrm{T}=274.37 \mathrm{MW} \\
\text { Losses }=8.28 \mathrm{MW} \\
\mathrm{MLC}=451.20 \mathrm{MW}\end{array}$} & \multicolumn{5}{|c|}{$\begin{array}{l}\text { Congestion Cost }=145.64 \$ / \mathrm{h} \\
\text { Loading Margin }=0.644\end{array}$} \\
\hline
\end{tabular}

Table 6.7: Six-bus test system: VSC-OPF $w /$ contingency on line 2-4 and with SVC at bus 4

\begin{tabular}{|c|c|c|}
\hline Factor & Base Case & SVC at bus \# 4 \\
\hline Social Welfare & $103.85 \$ / \mathrm{h}$ & $108.45 \$ / \mathrm{h}$ \\
\hline Maximum Loading Condition & $315.36 \mathrm{MW}$ & $451.20 \mathrm{MW}$ \\
\hline Congestion Cost & $168.96 \$ / \mathrm{h}$ & $145.64 \mathrm{MW}$ \\
\hline
\end{tabular}

Table 6.8: Benefit factors before and after $S V C$ is installed 


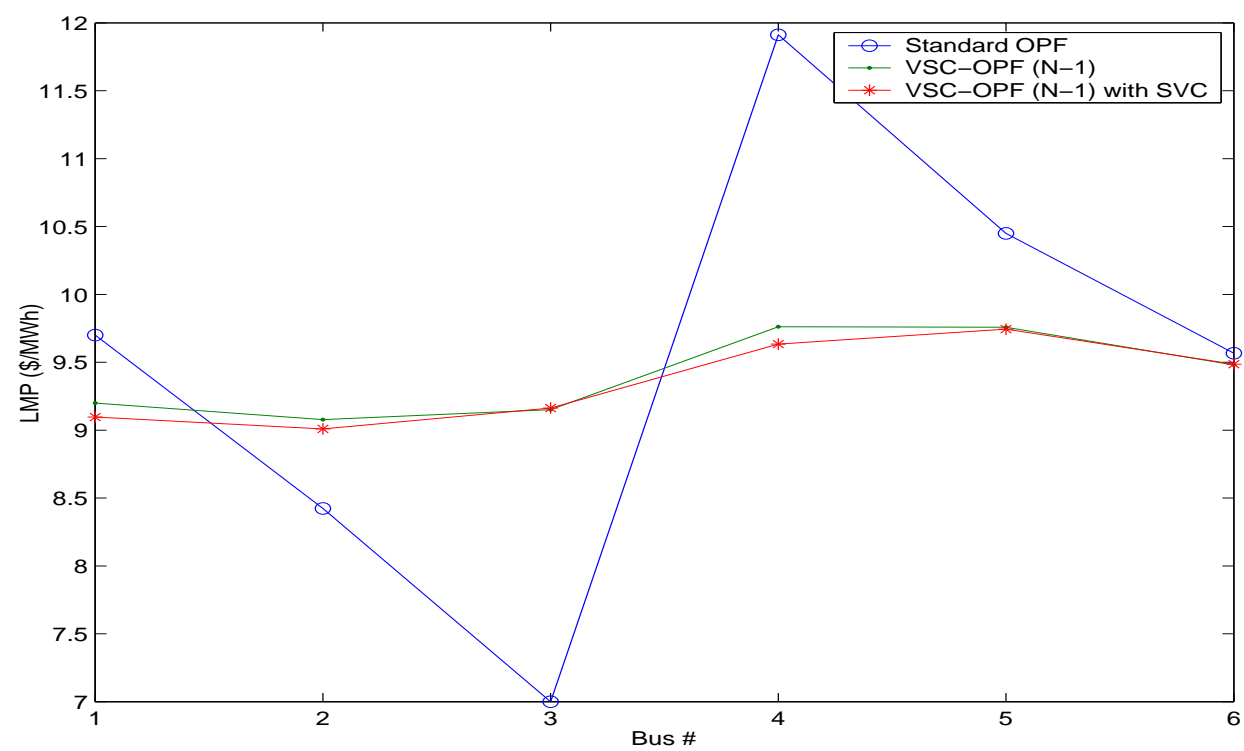

Figure 6.3: LMPs for the six-bus system

Therefore, from 5.29,

$$
\begin{array}{r}
C C_{w o f}=168.96 ; \\
C C_{w f}=145.64 ; \\
F P=\left.C C\right|_{w o f}-\left.C C\right|_{w f}
\end{array}
$$

$F P=\mathbf{2 3 . 3 2} \$ / \mathbf{h}$ and this amount can be used to recover the investment cost of SVC.

The Fig. 6.3, Fig. 6.4, and Fig. 6.5, it is clearly shown that the marginal prices are effected by placing VAR support. Compared to Standard OPF model, the prices obtained through VSC-OPF are more homogeneous and decreased. The Fig. 6.6 and Fig. 6.7 shows the effect of weighting factor $p$ on the total transaction level ' $\mathrm{T}$ ' and the maximum loading margin $\lambda_{c}$

Observe that as expected the more the weight of loading margin, the higher the level of security $\lambda_{c}$, but at the same time the lower the Transaction level ' $T$ '. This is due to the power bids being free to vary so that, as $p$ increases, congestion is minimized (security is maximized) by both increasing $\lambda_{c}$ and reducing ' $\mathrm{T}$ '. The impact of SVC on the two factors is quite obvious that by installing SVC the total transfer capability of the system increased there by the system security increased. System is now stable at higher weighting factors providing 


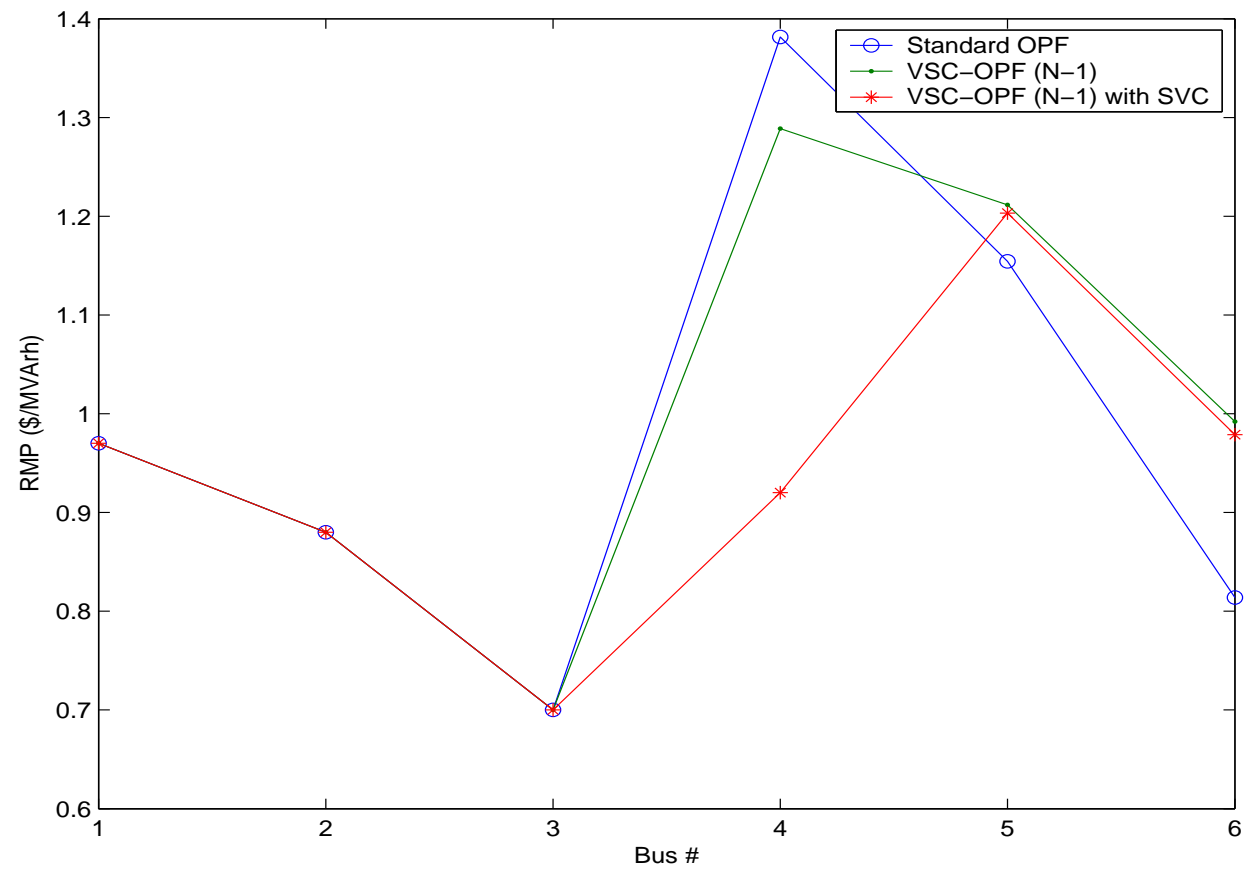

Figure 6.4: RMPs for the six-bus system

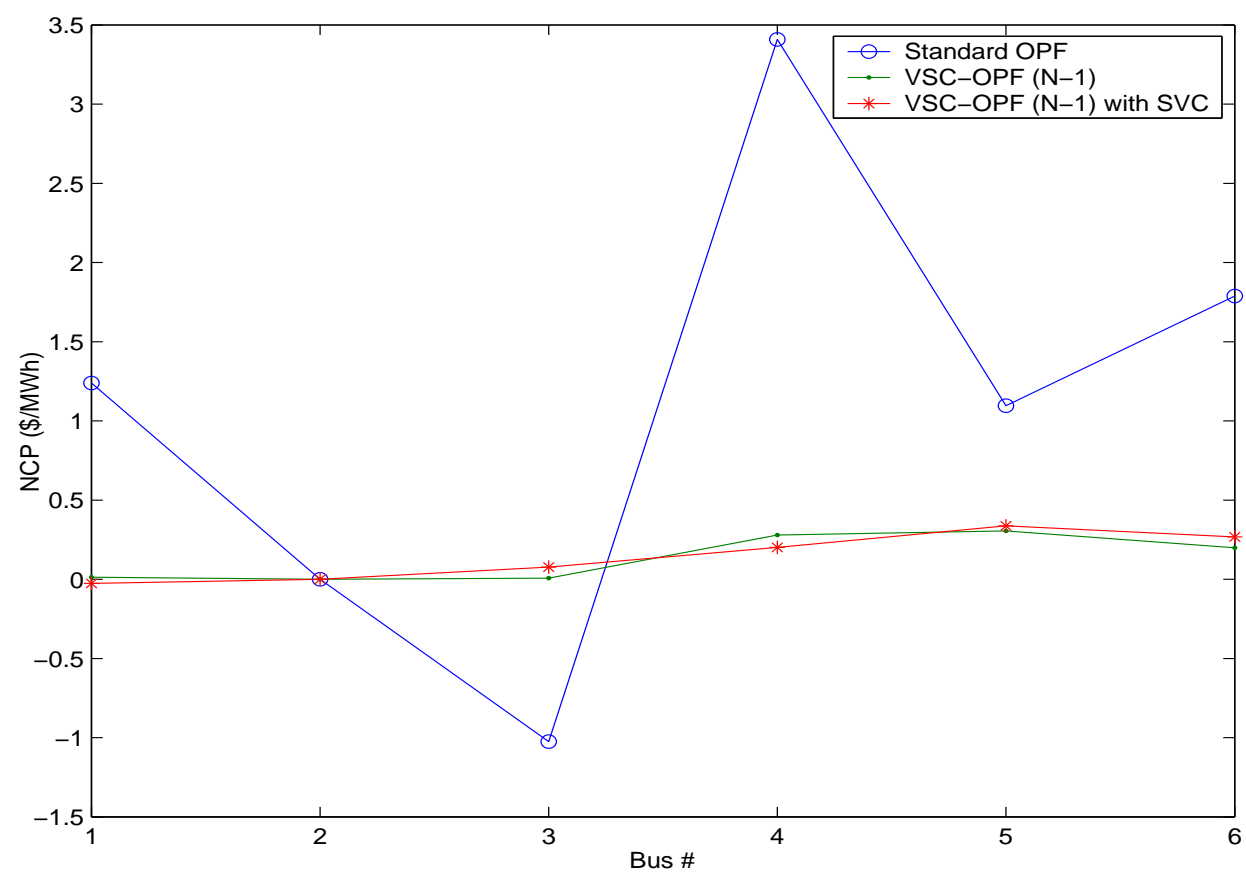

Figure 6.5: NCPs for the six-bus system 


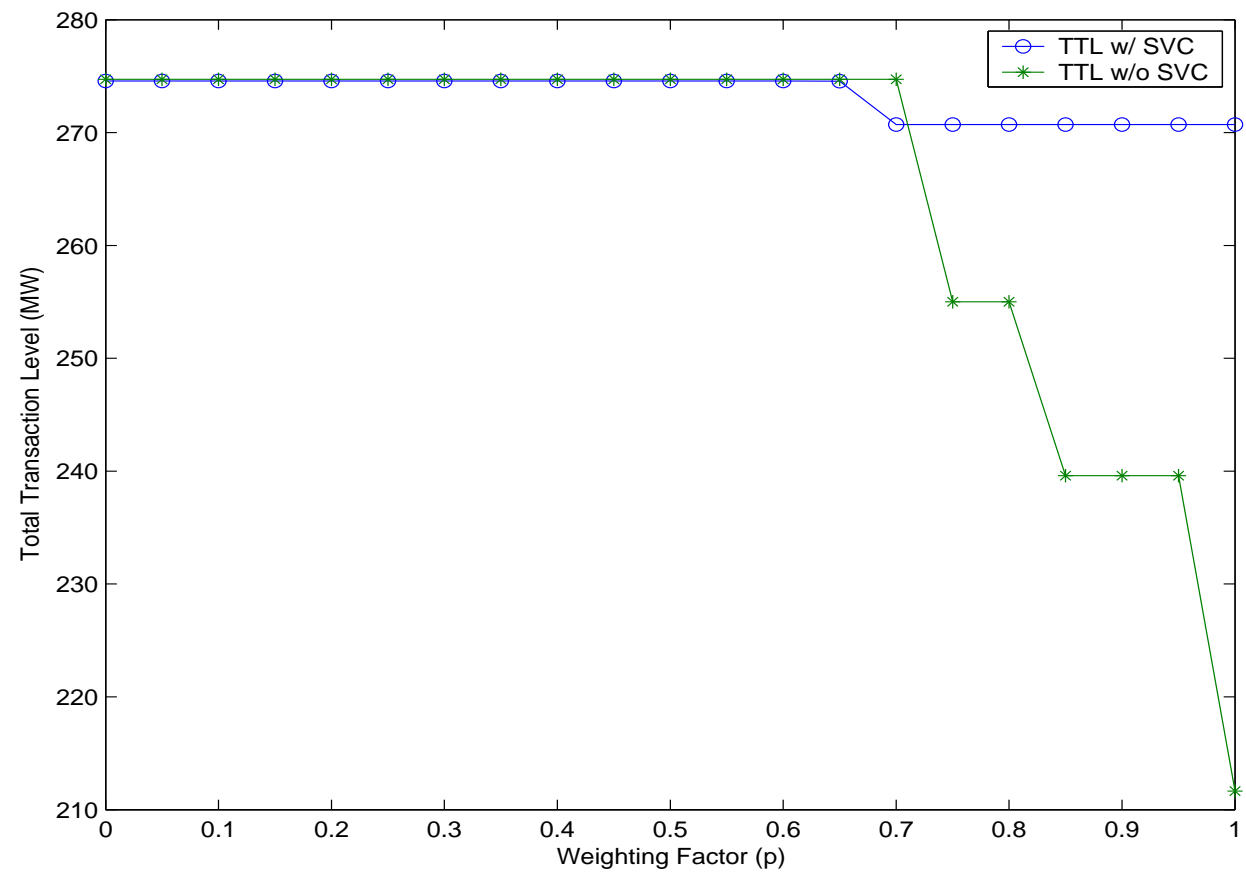

Figure 6.6: Total transaction level for the six-bus system

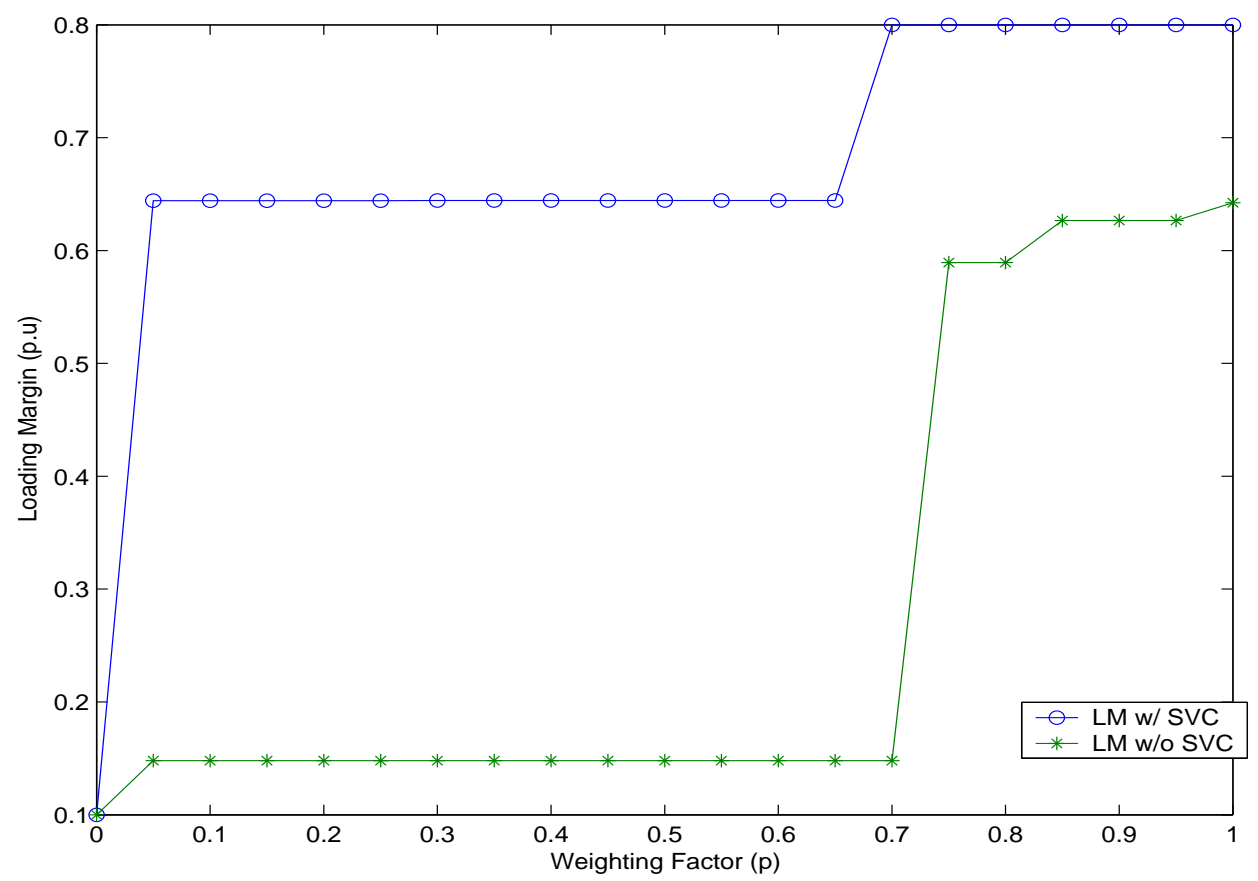

Figure 6.7: Loading margin for the six-bus system 


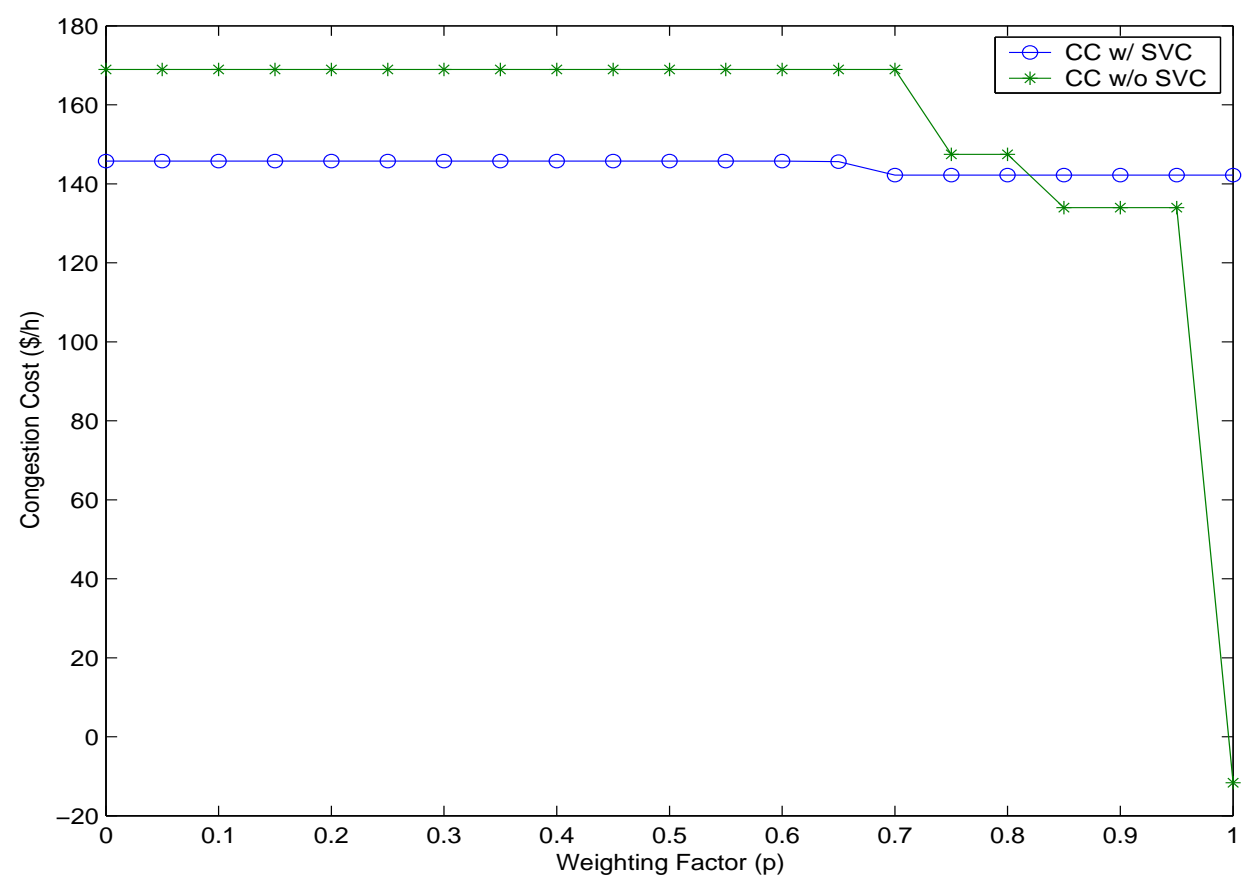

Figure 6.8: Congestion Cost for the six-bus system

constant transaction levels. In the Fig. 6.8 the impact of weighting factors on the congestion cost is shown with and without SVC. The plot shows that the behavior of CC is same as ' $\mathrm{T}$ ' as expected. At higher security, system is still able to maintain transaction levels and hence the congestion cost exist. At lower security levels, we can observe that the congestion cost decreased with SVC.

Fig. 6.9 depicts LMPs as $p$ varies, illustrating the transition from an OPF market problem to an OPF security problem as $\lambda_{c}$ approaches its maximum imposed value of $\lambda_{c_{\max }}=0.8$. LMPs decrease as the security levels increase, since the auction solutions move away from the security limits (i.e., the system is less congested). Furthermore, even though the LMPs and the overall total transaction level decrease, local bids may increase or decrease, accordingly to the power schedule which better matches the obtained loading margin.

\section{Wheeling Rates}

The transmission prices are calculated based on wheeling charges method presented in section 3.3. Table 6.9 gives the comparison of wheeling rates for a few selected buses with and without SVC. The base case refers to the VSC-OPF with no critical line outage and no VAR 


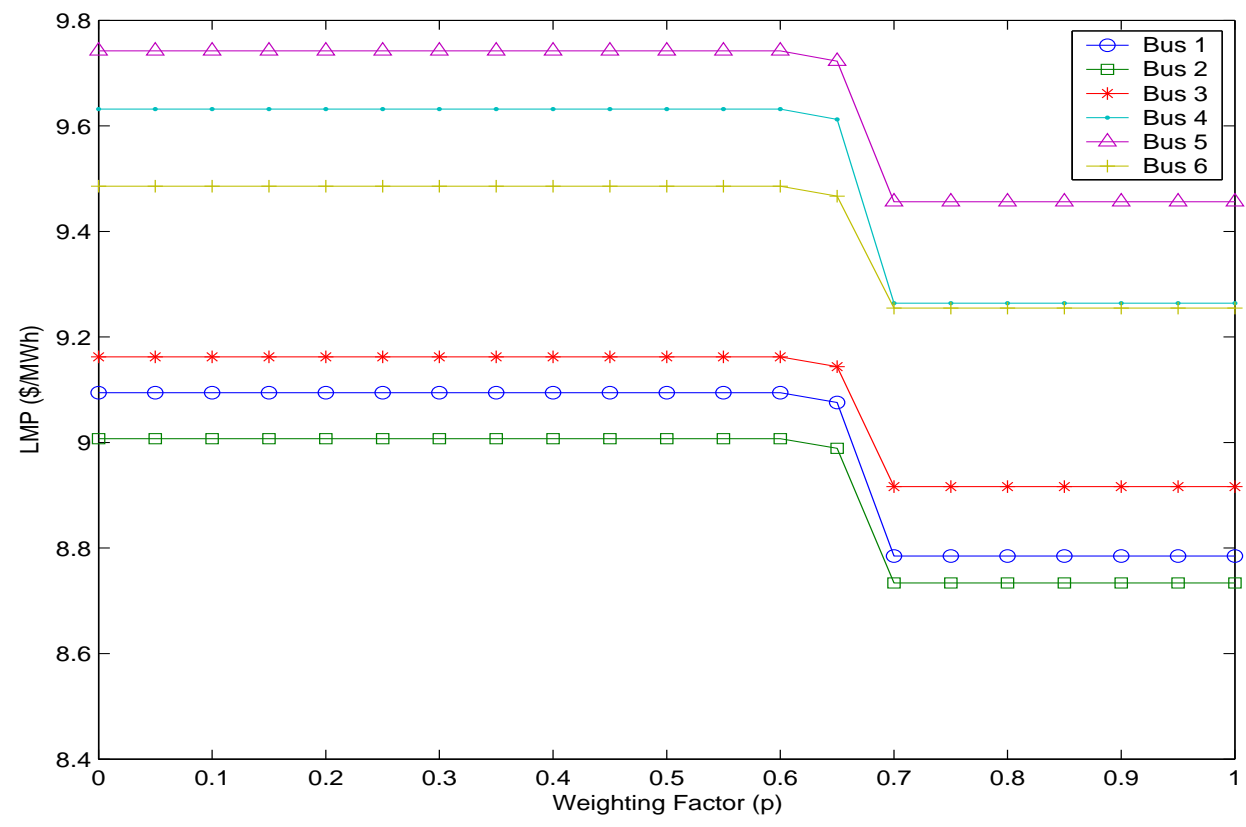

Figure 6.9: LMPs for the six-bus system

\begin{tabular}{|c|c|c|}
\hline Gen Bus - Load Bus & Base Case & SVC at bus \# 4 \\
\hline \hline $1-4$ & 0.562 & 0.537 \\
\hline $1-5$ & 0.559 & 0.647 \\
\hline $2-4$ & 0.684 & 0.625 \\
\hline $2-5$ & 0.681 & 0.735 \\
\hline $2-6$ & 0.402 & 0.478 \\
\hline $3-5$ & 0.608 & 0.580 \\
\hline $3-6$ & 0.329 & 0.323 \\
\hline
\end{tabular}

Table 6.9: Wheeling rates for a few selected buses w.r.t. generator buses ( $\$ / M W h)$ 
support. The table shows that the FACTS devices are capable to impact transmission prices. As in the case of LMPs, the wheeling rates increase at few buses and decrease at few buses.

\subsection{IEEE 14-Bus Test System}

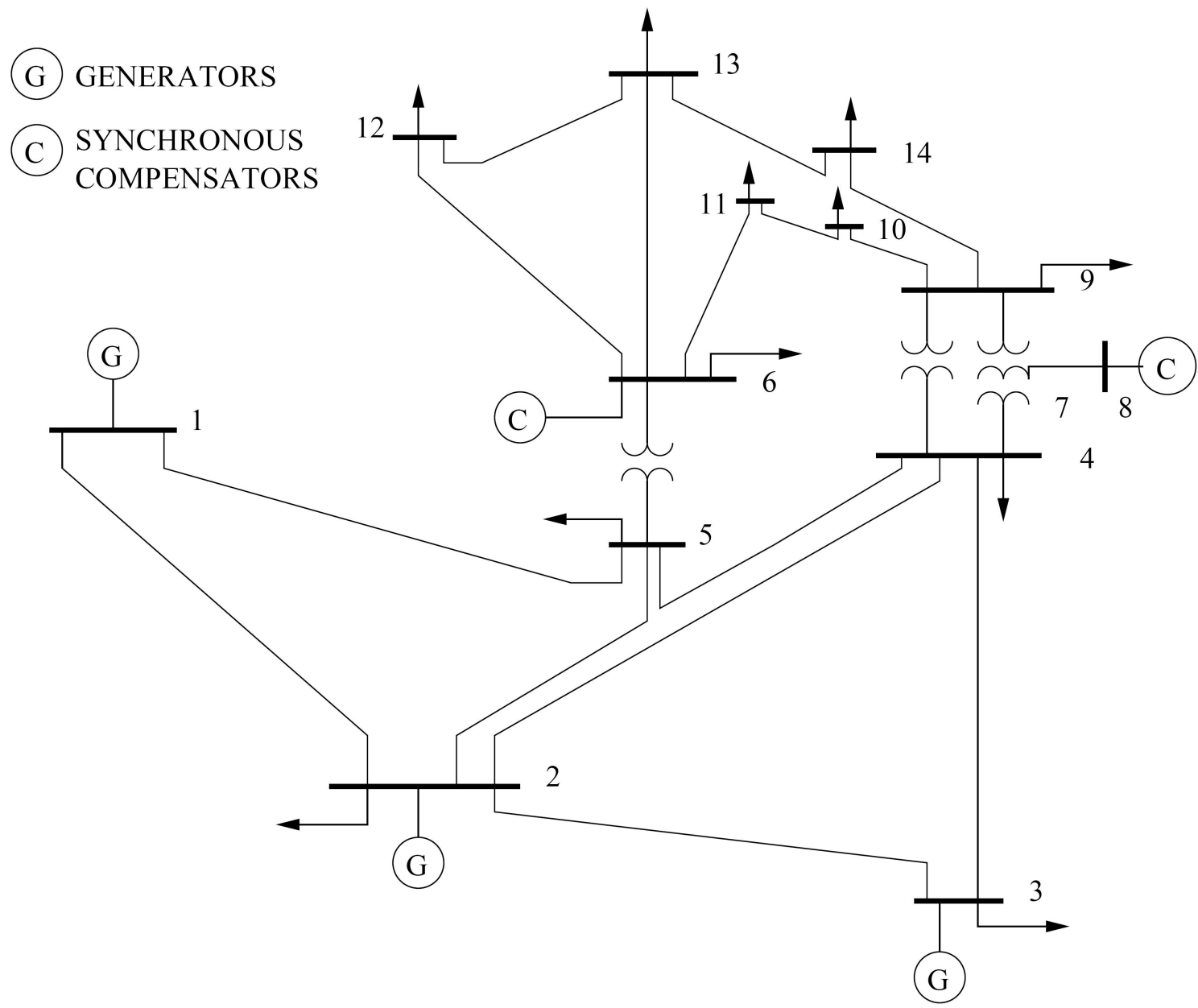

Figure 6.10: Single-line daiagram of the IEEE 14-bus test system [94]

The IEEE 14-bus test system represents a portion of the American Electric Power System and hence can be considered a realistic example. The system has enough generation and load to simulate an electricity market, and thus, produce significant results for examining the algorithm and prices. The system consists of five synchronous machines two of which 
are synchronous compensators for reactive power support. There are 11 loads in the system, totalling 259 MW and 81.3 MVAr. The data for the system, generators are illustrated in Appendix A.1.3, together with the market bidding data.

\subsubsection{Results and Discussion}

The results for standard security constrained OPF for IEEE 14-bus system with offline power flow limits found through CPF and N-1 contingency analysis are presented in Table 6.10. As demonstrated above for the six-bus test case, the LMPs and RMPs are more heterogeneous and the NCPs being very high. The table also provides the payments recieved by suppliers and paid by consumers.

\begin{tabular}{c|cccccc}
\hline $\begin{array}{c}\text { Bus } \\
\#\end{array}$ & $\begin{array}{c}\text { V } \\
{[\mathrm{p} . \mathrm{u} .]}\end{array}$ & $\begin{array}{c}\text { LMP } \\
{[\$ / \mathrm{MWh}]}\end{array}$ & $\begin{array}{c}\text { RMP } \\
{[\$ / \text { MVArh }]}\end{array}$ & $\begin{array}{c}\text { NCP } \\
{[\$ / \mathrm{MWh}]}\end{array}$ & $\begin{array}{c}\text { PayS } \\
{[\$ / \mathrm{h}]}\end{array}$ & $\begin{array}{c}\text { PayD } \\
{[\$ / \mathrm{h}]}\end{array}$ \\
\hline \hline 1 & 1.045 & 10.20 & 1.02 & 0.00 & -4 & 0 \\
2 & 1.059 & 9.52 & 0.95 & -0.54 & -1950 & 302 \\
3 & 1.015 & 11.30 & 1.22 & 0.75 & -918 & 1559 \\
4 & 1.025 & 12.19 & 1.01 & 1.53 & 0 & 150 \\
5 & 1.027 & 12.72 & 0.98 & 2.08 & 0 & 0 \\
6 & 1.083 & 12.47 & 0.69 & 2.32 & -17 & 178 \\
7 & 1.062 & 13.15 & 0.92 & 2.06 & 0 & 0 \\
8 & 1.100 & 13.15 & 0.54 & 2.06 & -13 & 0 \\
9 & 1.047 & 13.66 & 1.09 & 2.34 & 0 & 495 \\
10 & 1.046 & 14.83 & 1.07 & 2.55 & 0 & 158 \\
11 & 1.061 & 13.86 & 0.91 & 2.53 & 0 & 63 \\
12 & 1.065 & 15.15 & 0.21 & 2.94 & 0 & 95 \\
13 & 1.059 & 14.35 & 1.11 & 2.61 & 0 & 200 \\
14 & 1.029 & 14.52 & 1.28 & 2.63 & 0 & 253 \\
\hline \hline Totals & T $=274.46 \mathrm{MW}$ & Congestion Cost $=551.79 \$ / \mathrm{h}$ & & \\
& Losses $=4.866 \mathrm{MW}$ & & & & \\
\hline
\end{tabular}

Table 6.10: IEEE 14-bus test system: OPF with offline power flow limits

Table 6.11 provides the market outcomes of VSC-OPF without any contingencies. We can 
observe that the LMPs and RMPs are more homogeneous. The change in LMPs resulted in decrease of congestion cost.

\begin{tabular}{c|cccccc}
\hline $\begin{array}{c}\text { Bus } \\
\#\end{array}$ & $\begin{array}{c}\mathrm{V} \\
{[\mathrm{p} . \mathrm{u} .]}\end{array}$ & $\begin{array}{c}\text { LMP } \\
{[\$ / \mathrm{MWh}]}\end{array}$ & $\begin{array}{c}\text { RMP } \\
{[\$ / \text { MVArh }]}\end{array}$ & $\begin{array}{c}\text { NCP } \\
{[\$ / \mathrm{MWh}]}\end{array}$ & $\begin{array}{c}\text { PayS } \\
{[\$ / \mathrm{h}]}\end{array}$ & $\begin{array}{c}\text { PayD } \\
{[\$ / \mathrm{h}]}\end{array}$ \\
\hline \hline 1 & 1.100 & 10.20 & 1.02 & 0 & -967 & 0 \\
2 & 1.084 & 10.36 & 1.28 & 0.13 & -2136 & 331 \\
3 & 1.023 & 11.30 & 1.65 & 0.78 & -998 & 1583 \\
4 & 1.011 & 11.54 & 1.72 & 0.88 & 0 & 821 \\
5 & 1.023 & 11.32 & 1.63 & 0.74 & 0 & 128 \\
6 & 1.061 & 11.76 & 1.68 & 1.54 & -40 & 196 \\
7 & 1.040 & 11.82 & 1.83 & 1.36 & 0 & 0 \\
8 & 1.079 & 11.82 & 1.70 & 1.36 & -41 & 0 \\
9 & 1.021 & 11.98 & 1.96 & 1.63 & 0 & 529 \\
10 & 1.019 & 12.08 & 1.97 & 1.69 & 0 & 163 \\
11 & 1.036 & 11.99 & 1.87 & 1.65 & 0 & 63 \\
12 & 1.036 & 12.12 & 1.85 & 1.73 & 0 & 110 \\
13 & 1.029 & 12.22 & 1.92 & 1.77 & 0 & 246 \\
14 & 0.995 & 12.59 & 2.18 & 1.96 & 0 & 282 \\
\hline \hline Totals & T = 362.62 MW & Congestion Cost $=268.94 \$ / \mathrm{h}$ & Losses = $10.753 \mathrm{MW}$ \\
& Loading Margin =0.172 & MLC $=424.97$ MW & & \\
\hline
\end{tabular}

Table 6.11: IEEE 14-bus test system: VSC-OPF w/o contingencies

Table 6.12 gives the sensitivity co-efficients and the ATC values. Observe that not all the lines that carry high powers or that have sensitivity co-efficients will be the worst outage. Here it is evident that line $1-2$ is the most sensitive line in the system and with the outage of this line, the system collapses and there is no solution for VSC-OPF. This is a situation where the installation of VAR support/SVC is desired to make the system N-1 secure and stable. Though the system looks stable without any failure, with the critical line failure, the system doesnt have enough resources to avoid the collapse. The optimal placement of SVC is performed according to the algorithm proposed in 5.13

Optimal Placement of SVC: 


\begin{tabular}{|c|c|c|c|c|}
\hline Line \# & Line $h-k$ & $\mathrm{P}_{\mathrm{hk}}(\lambda)$ (p.u.) & $p_{h k}=\mathrm{P}_{h k}{ }^{*} \mathrm{dP}$ \\
$h k$ & $\mathrm{~d} \lambda\left(10^{6}\right)$ & $\mathrm{ATC}^{\mathrm{N}-1}(\mathrm{MW})$ \\
\hline \hline $\mathbf{1 1}$ & $\mathbf{1 - 2}$ & $\mathbf{1 . 6 8 6}$ & $\mathbf{0 . 1 9 2 6}$ & - \\
\hline 12 & $3-2$ & 0.680 & 0.0345 & 52.47 \\
\hline 14 & $1-5$ & 0.900 & 0.0280 & 49.04 \\
\hline 15 & $5-4$ & 0.566 & 0.0174 & 52.19 \\
\hline 16 & $2-4$ & 0.710 & 0.0074 & 51.27 \\
\hline 13 & $3-4$ & 0.086 & 0.0034 & 52.76 \\
\hline 1 & $2-5$ & 0.577 & 0.0012 & 51.83 \\
\hline 4 & $6-13$ & 0.273 & 0.0003 & 51.73 \\
\hline 17 & $5-6$ & 0.647 & 0.0002 & 42.55 \\
\hline 7 & $9-10$ & 0.182 & 0.0001 & 52.97 \\
\hline
\end{tabular}

Table 6.12: IEEE 14-bus test system: Sensitivity coefficients Phk and ATC (N-1) 
The approach explained in 6.2.1 for the six-bus system to find the weights for the three BCRs is adopted for this test case. Since, the base case solution with critical line outage has no solution the index proposed in 5.12 has been used to rank the VAR source location sites. The tables for judgement matrix (Table 6.3) and weighting co-efficients (Table 6.13) are illustrated again below:

$$
A=\left[\begin{array}{ccc}
1 & 5 & 7 \\
1 / 5 & 1 & 3 \\
1 / 7 & 1 / 3 & 1
\end{array}\right]
$$

From the judgement matrix further analysis is performed. The Consistency Ratio (CR) is obtained as 0.057 which is acceptable for this size problem. The corresponding weights obtained are:

$$
\begin{array}{|l||l||l|}
\hline \mathrm{w}_{1}=0.724 & \mathrm{w}_{2}=0.193 & \mathrm{w}_{3}=0.083 \\
\hline
\end{array}
$$

Table 6.13: Weighting factors for IEEE 14-bus test system

The LSFs considered for this study are $0.8,1.0,1.2,1.4$. It means the system is loaded with $80 \%, 100 \%, 120 \%$ and $140 \%$ of total load. Mean of the four values is calculated as explained in equations 5.15, 5.17 and 5.19.

Based on the index explained in 5.12, the optimal location for VAR support is found for the IEEE 14-bus test system. The weak bus ranking for VAR support is listed in Table 6.14. From the table it is found that bus \# 4 is the optimal location for VAR support where the index $J$ is maximum. Table 6.15 gives the single hierarchical ranking of VAR support buses for IEEE 14-bus test system.

The single hierarchical ranking is defined as that ranking as obtained by using only one BCR for all elements in one hierarchical structure. It can be observed from Table 6.15 that the candidate VAR support buses selected by the three benefit-to-cost ratios (SBCR, MBCR and $\mathrm{CBCR}$ ) are different in ranking. Hence the need for calculating the weighting factors. In the ranking table, it is desired that both social welfare and maximum loadability ratios to be maximum where as the congestion cost ratio is to be minimum. Therefore, the negative sign for CBCR in index 5.13 minimizes the congestion cost. The approach to find optimal size of 


\begin{tabular}{|c||c|}
\hline Bus No & $J_{\max }$ \\
\hline \hline $\mathbf{4}$ & $\mathbf{0 . 9 9 7 0}$ \\
\hline 5 & 0.9755 \\
\hline 9 & 0.9464 \\
\hline 14 & 0.9387 \\
\hline 10 & 0.9375 \\
\hline 13 & 0.9290 \\
\hline 11 & 0.9279 \\
\hline 12 & 0.9241 \\
\hline
\end{tabular}

Table 6.14: Weak bus ranking for IEEE 14-bus test system

\begin{tabular}{|c||cc||cc||cc|}
\hline Bus \# & SBCR & Rank \# & MBCR & Rank \# & CBCR & Rank \# \\
\hline \hline 4 & 1.0000 & 1 & 1.0000 & 1 & 0.9644 & 6 \\
\hline 5 & 0.9938 & 2 & 0.8969 & 2 & 1.0000 & 8 \\
\hline 9 & 0.9791 & 4 & 0.8114 & 3 & 0.9762 & 7 \\
\hline 10 & 0.9783 & 5 & 0.7745 & 4 & 0.9614 & 5 \\
\hline 11 & 0.9729 & 8 & 0.7459 & 8 & 0.9591 & 4 \\
\hline 12 & 0.9734 & 7 & 0.7459 & 7 & 0.9096 & 1 \\
\hline 13 & 0.9751 & 6 & 0.7465 & 6 & 0.9516 & 3 \\
\hline 14 & 0.9864 & 3 & 0.7605 & 5 & 0.9376 & 2 \\
\hline
\end{tabular}

Table 6.15: Single hierarchical ranking of VAR support buses for IEEE 14-bus test system 
SVC for this system is chosen in a similar way to six-bus test case. Fig. 6.11 depicts the plot between loading margin and reactive power output of SVC.

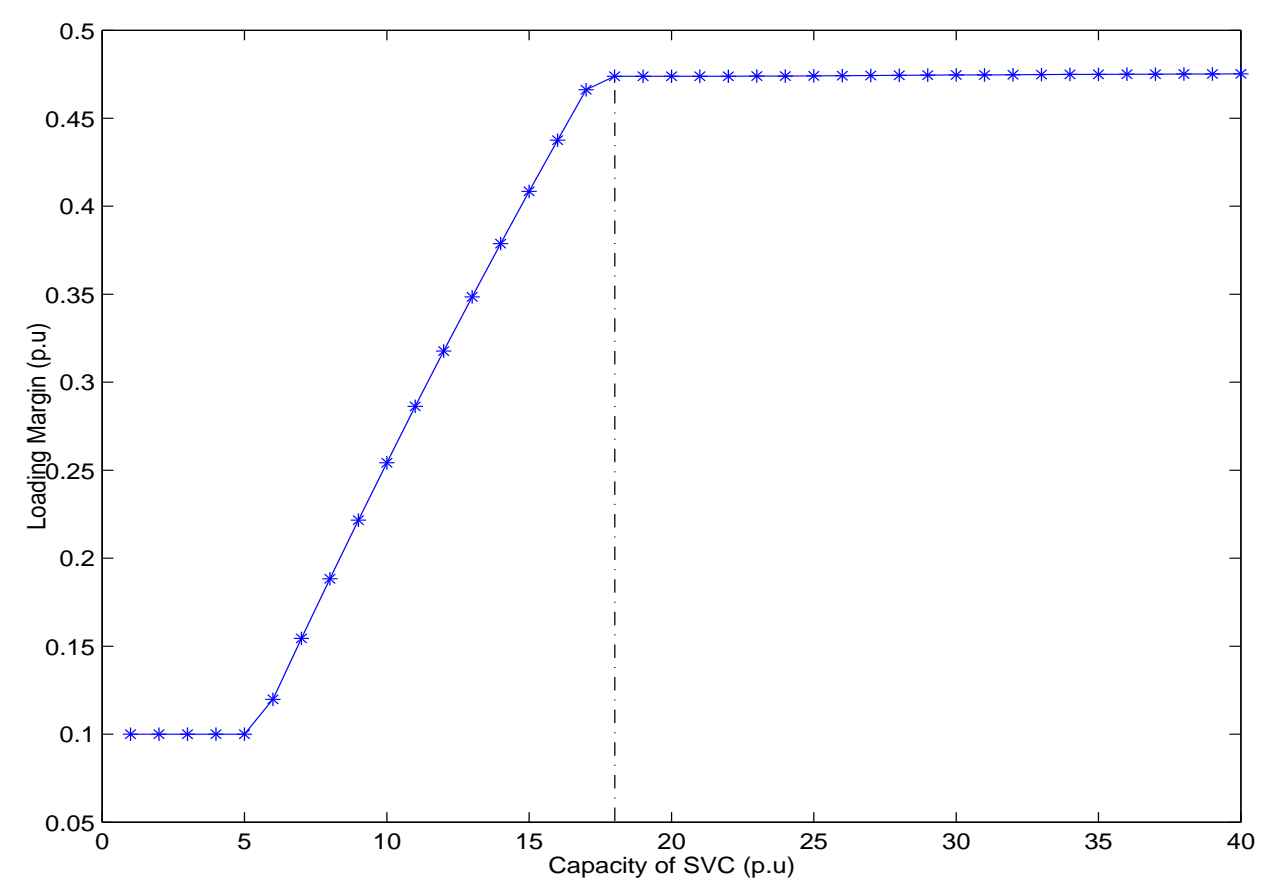

Figure 6.11: Loading Margin Vs SVC Capacity for IEEE 14-bus test system

From the plot, it is clear that the system loading margin reaches its maximum and stables at $Q_{S V C}=1.8 p . u$. Considering the high cost involved in the investment of SVC, a device of capacity 2.5 p.u. is taken in this study for this system. Table 6.16 illustrates the spot prices and the benefits obtained by installing SVC at the optimal location. Also observe that the bus voltages in the three cases, the system with SVC at bus \# 4 has got the voltages close to 1.0 which is desired at higher loading levels inorder to avoid voltage collapses.

The system which was prone to collapse and failed to maintain minimum level of security with the critical line outage is now able to withstand the failure of line with the installation of VAR support. The system with SVC is stable in all aspects. The congestion cost decreased compared to standard OPF where as losses are increased which is expected because of the increase in the transaction level. The loading margin which is less then 0.1 with no SVC has been increased to 0.475 i.e. the system can be loaded safely upto $140 \%$ of base load by maintaining minimum level of security. 


\begin{tabular}{c|cccccc}
\hline $\begin{array}{c}\text { Bus } \\
\#\end{array}$ & $\begin{array}{c}\mathrm{V} \\
{[\mathrm{p} . \mathrm{u} .]}\end{array}$ & $\begin{array}{c}\text { LMP } \\
{[\$ / \mathrm{MWh}]}\end{array}$ & $\begin{array}{c}\text { RMP } \\
{[\$ / \text { MVArh }]}\end{array}$ & $\begin{array}{c}\text { NCP } \\
{[\$ / \mathrm{MWh}]}\end{array}$ & $\begin{array}{c}\text { PayS } \\
{[\$ / \mathrm{h}]}\end{array}$ & $\begin{array}{c}\text { PayD } \\
{[\$ / \mathrm{h}]}\end{array}$ \\
\hline \hline 1 & 1.029 & 10.20 & 1.02 & 0.00 & -991 & 0 \\
2 & 1.031 & 10.35 & 0.95 & 0.10 & -2108 & 327 \\
3 & 0.976 & 11.30 & 1.13 & 0.71 & -883 & 1554 \\
4 & 1.000 & 11.41 & 0.74 & 0.71 & -63 & 785 \\
5 & 0.996 & 11.23 & 0.89 & 0.62 & 0 & 124 \\
6 & 1.038 & 11.46 & 0.84 & 1.26 & -20 & 185 \\
7 & 1.024 & 11.55 & 0.86 & 1.09 & 0 & 0 \\
8 & 1.064 & 11.55 & 0.80 & 1.09 & -19 & 0 \\
9 & 1.003 & 11.63 & 0.96 & 1.31 & 0 & 497 \\
10 & 1.001 & 11.72 & 0.99 & 1.36 & 0 & 153 \\
11 & 1.014 & 11.65 & 0.95 & 1.34 & 0 & 59 \\
12 & 1.013 & 11.78 & 0.99 & 1.43 & 0 & 104 \\
13 & 1.006 & 11.87 & 1.04 & 1.45 & 0 & 233 \\
14 & 0.975 & 12.19 & Congestion & Cost $=200.35 \$ / \mathrm{h}$ & Losses $=11.64 \mathrm{MW}$ \\
\hline \hline Totals & T $=362.62$ MW & Loading Margin $=0.475$ & MLC = 534.7 MW & & \\
\hline
\end{tabular}

Table 6.16: IEEE 14-bus test system: VSC-OPF w/ contingency on line 1-2 and SVC on bus 4 


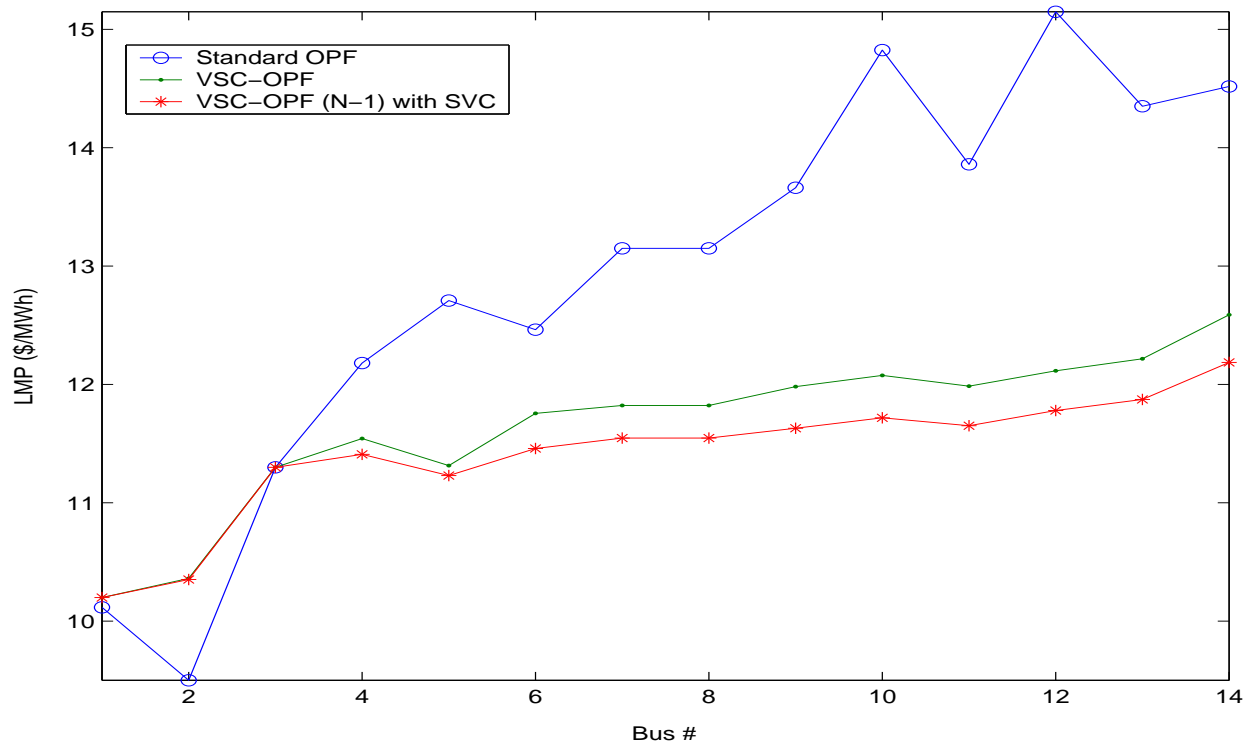

Figure 6.12: LMPs for the IEEE 14-bus system 


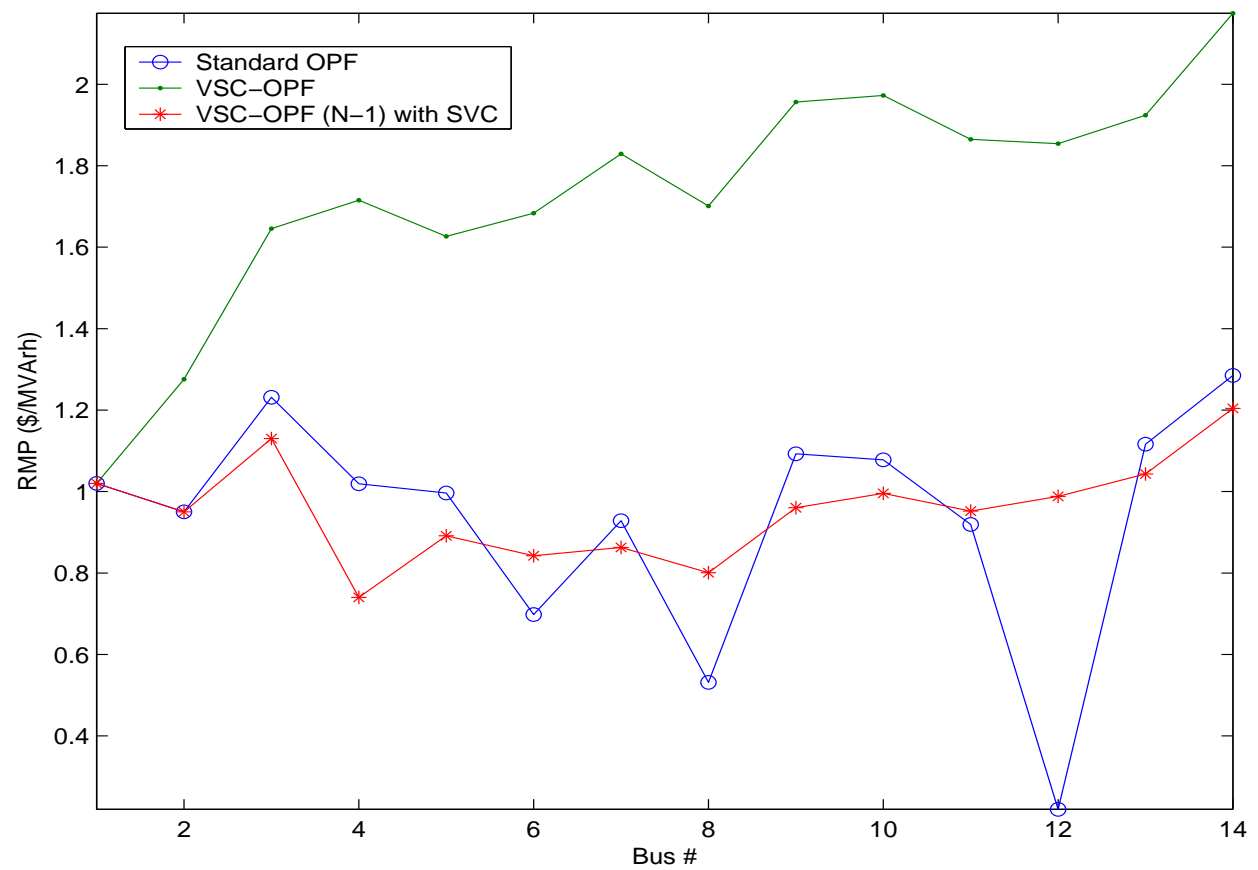

Figure 6.13: RMPs for the IEEE 14-bus system

From Fig. 6.12 depicts the LMPs at all the buses. We can observe that the LMPs decreased with the case without any contingency. Observe that the LMPs obtained for standard OPF with offline power flow limits are heterogeneous and very high compared to the other two cases. The improvement in the LMPs and change in power bids help to decrease congestion cost and to increase transaction levels.

The reactive power marginal prices in Fig. 6.13 obtained by placing SVC are more homogeneous and are lesser compared to standard OPF and with VSC-OPF with no contingency. The loads are required to maintain a constant power factor of 0.92 and this high power factor leads to lower RMPs. Observe that from Fig. 6.14 the nodal congestion prices (NCPs) reduced compared to both standard OPF and voltage stability OPF.

Wheeling Rates The wheeling charges calculated for few selected load buses w.r.t generator buses are shown in Table 6.17. The base case refers to the VSC-OPF with no contingencies as the system with critical line outage is not stable. It is evident that the wheeling charges decreased for the case with SVC at bus \# 4 compared to the one with no SVC.

Analysis of Reactive Power Pricing 


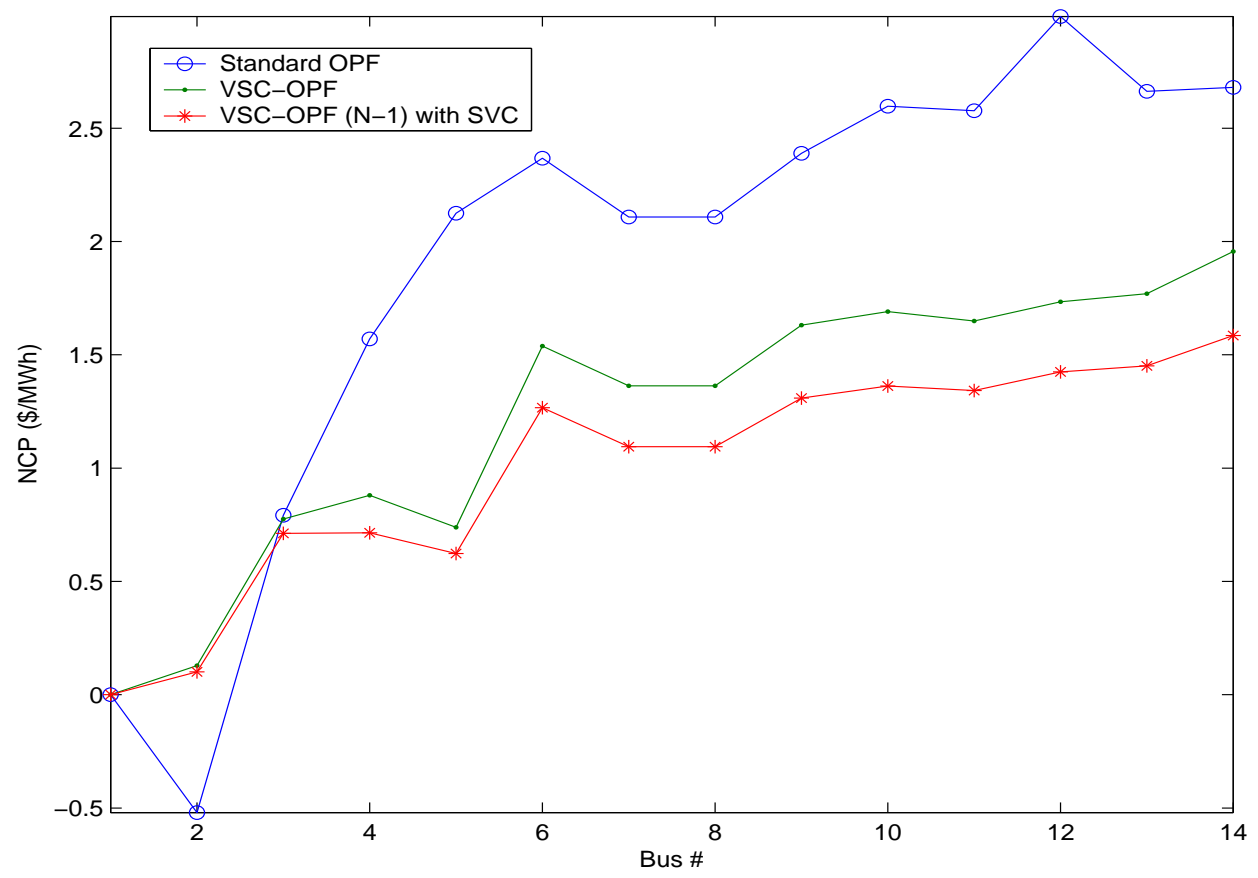

Figure 6.14: NCPs for the IEEE 14-bus system

\begin{tabular}{|c|c|c|}
\hline Gen Bus - Load Bus & Base Case & SVC at bus \# 4 \\
\hline \hline $1-5$ & 1.115 & 1.031 \\
\hline $2-4$ & 1.182 & 1.058 \\
\hline $2-5$ & 0.954 & 0.879 \\
\hline $3-4$ & 0.243 & 0.109 \\
\hline $6-11$ & 0.230 & 0.193 \\
\hline $6-12$ & 0.360 & 0.322 \\
\hline $6-13$ & 0.462 & 0.415 \\
\hline
\end{tabular}

Table 6.17: Wheeling rates for a few selected buses w.r.t. generator buses $(\$ / M W h)$ 


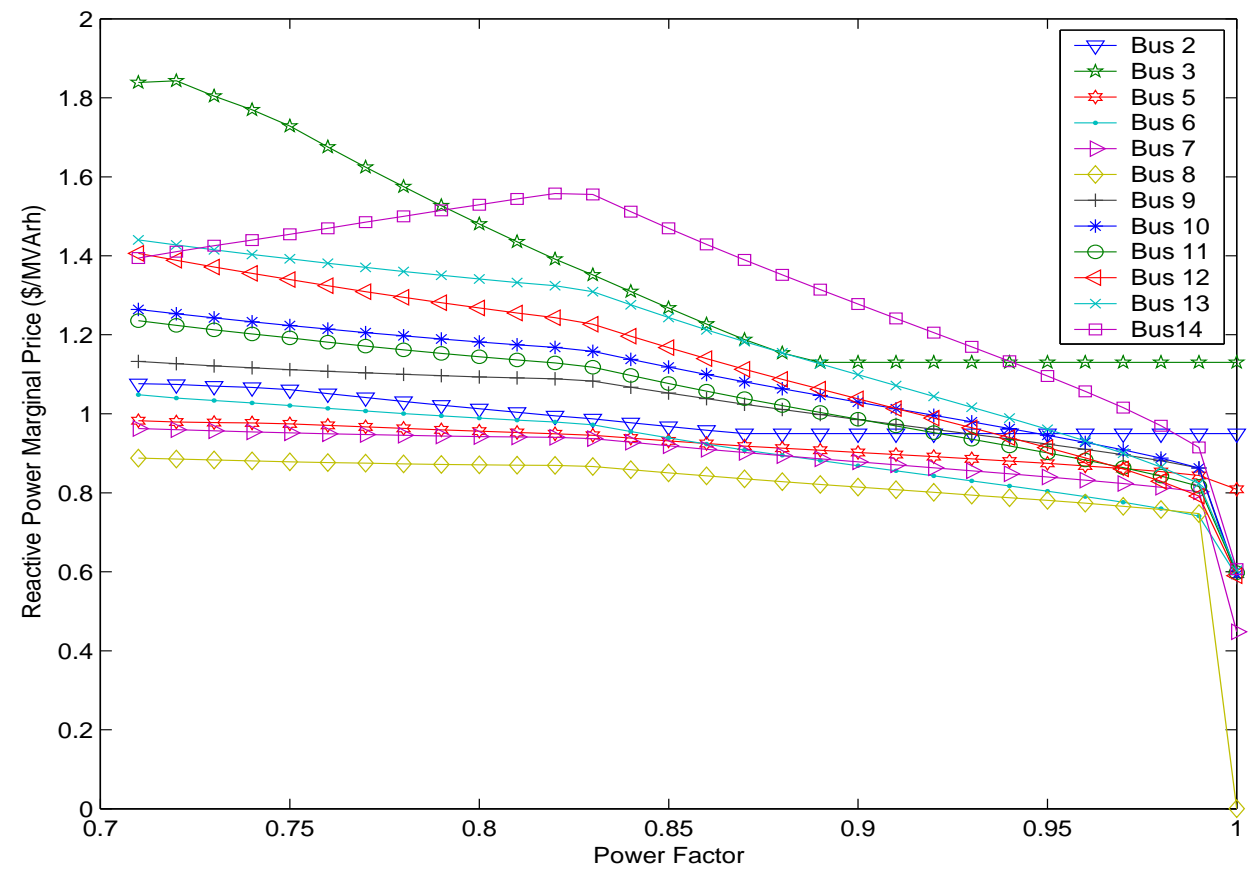

Figure 6.15: RMPs for the IEEE 14-bus system

In this case, the impact of load power factor on RMP is studied. From Fig. 6.15, 6.16, 6.17 we can see:

1. When the load power factor reduces from 1.0 to 0.7 , the RMP increases gradually. Therefore, the RMP can provide clear economic information to loads to improve their power factors.

2. In Fig. 6.16 when the power factor is close to 1, the reactive power output of the two generators becomes negative. This means that the system has surplus reactive power and the generators are asked to absorb excessive reactive power. The corresponding RMPs in 6.15 are also low or at their minimum.

3. When the voltage of bus 3 reduced with the decrease in power factor, the corresponding RMP increased rapidly.

4. The revenue of reactive power supply based on the marginal price will be much more than that based on the average price especially at lower power factors. Therefore some adjustment should be made if RMP is going to be used. 


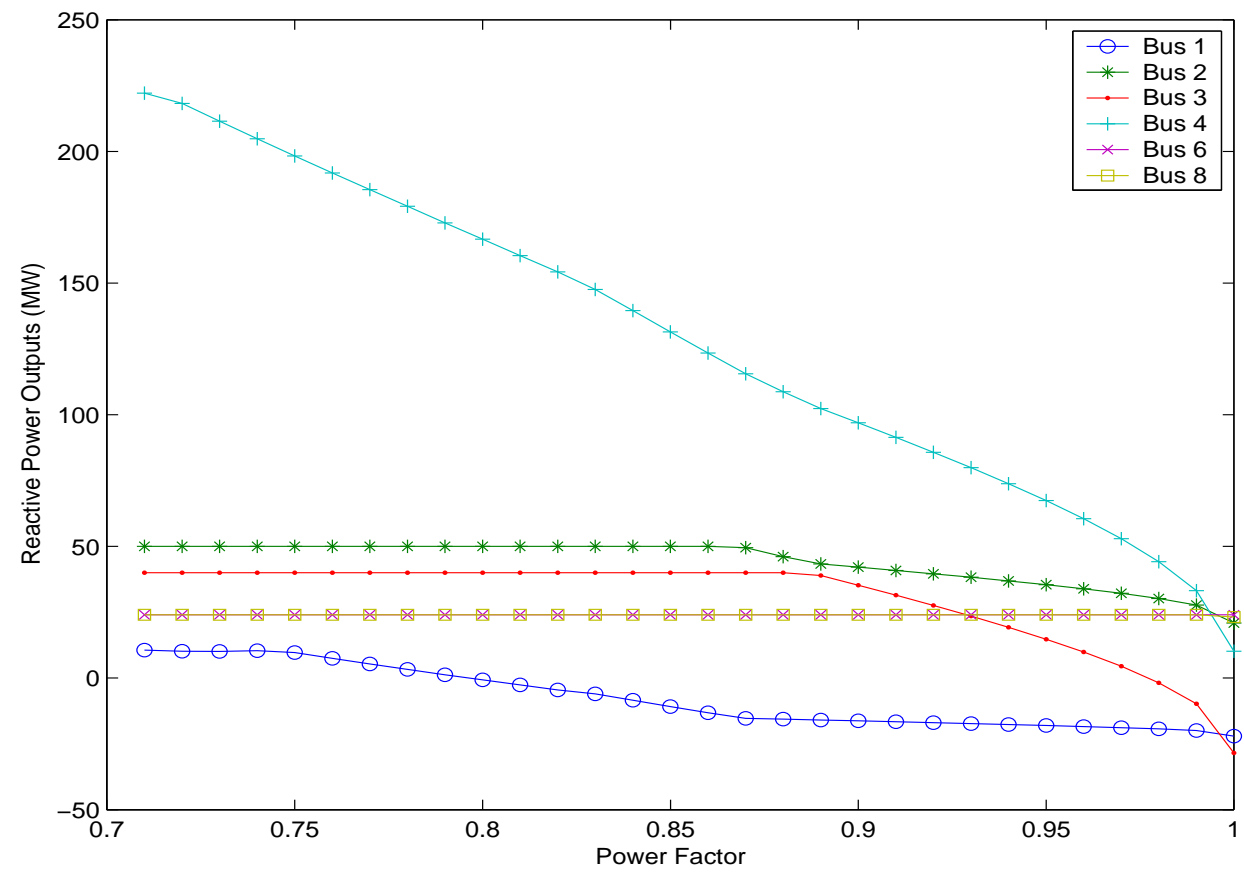

Figure 6.16: Reactive Power output of generators for IEEE 14-bus system

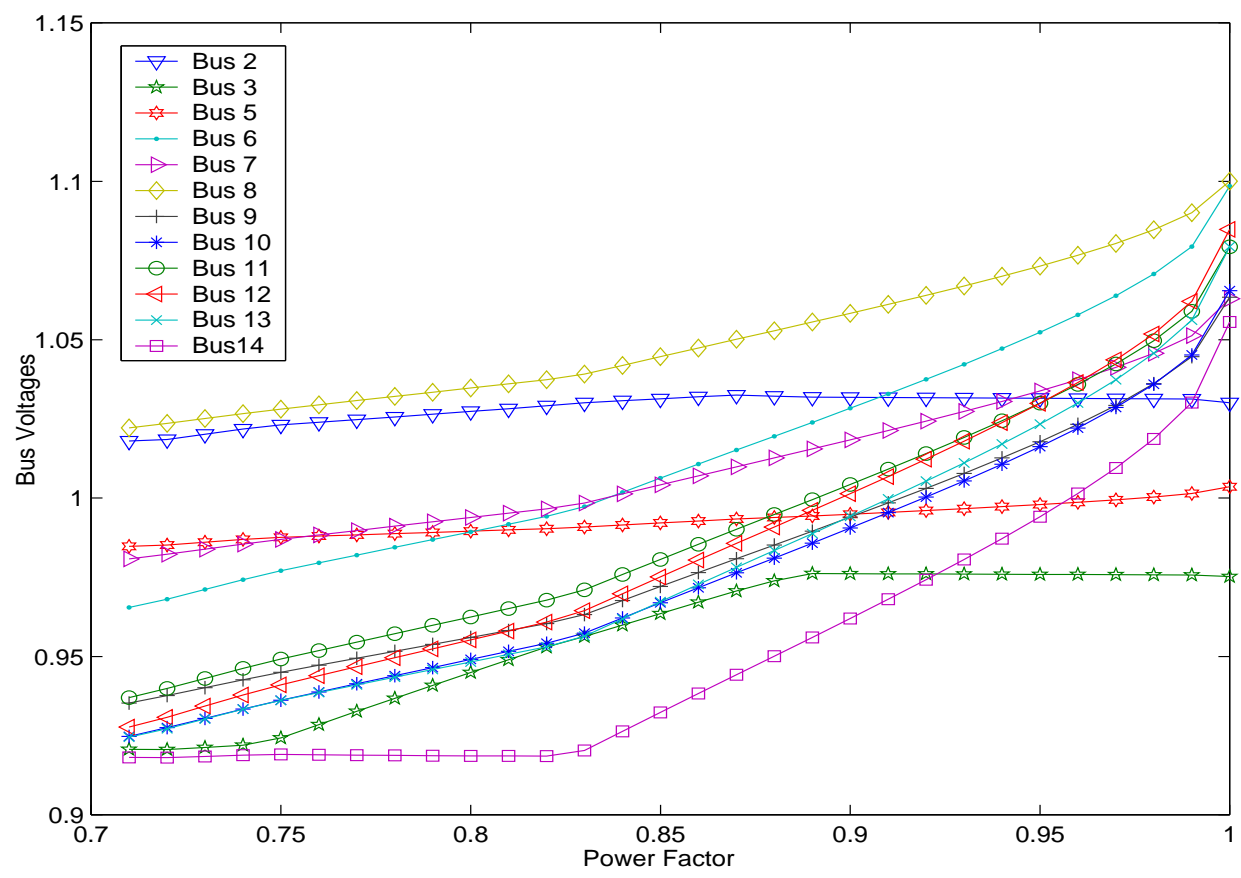

Figure 6.17: Bus Voltages for IEEE 14-bus system 


\subsection{Summary}

The impact of VAR support on the electricity market prices is studied. Electricity market is designed as a multi-objective OPF problem that maximizes social welfare and loading margin. The index to identify and rank candidate VAR source nodes is tested on a six-bus and a realistic IEEE 14-bus test system. 


\section{Chapter}

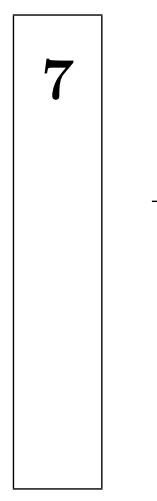

\section{Conclusions and Future Work}

\subsection{Principal Contributions}

An approach to study the impact of optimally placed VAR support on electrity spot pricing in the deregulated electricity market is proposed. The multi-objective OPF is modified to include the reactive power production and consumption costs which provides proper market signals to restrict the reactive power usage and maintain good power factor. An index to place VAR support such that the social welfare, maximum loading condition are improved and congestion costs are reduced based on a cost benefit analysis is proposed. Analytic Hierarchy Process which can be used to find weights for different terms which are not related qualitatively is extended to use in the complicated power systems to find appropriate weighting factors for different benefit-to-cost ratios but based on engineers knowledge of each of these terms.

This thesis has described a new approach of transmission pricing calculation taking VSCOPF based multi-objective maximization as the objective and has studied the impact of FACTS devices on it. A simple method to price VAR support such that the investment cost is recovered from the market solution is proposed according to congestion cost of the system. An analysis of reactive power pricing is performed such that the RMPs can provide clear economic information to loads to improve their power factors. 


\subsection{Possible Future Directions}

Some possible future directions for this work are:

1. The loads considered in this study are elastic, i.e. price sensitive. Studies with voltage dependent loads may help to better understand the impact of load voltages on market solutions.

2. Real market scenario can be replicated by the multi-agent systems. GENCOs, TRANSCOs DISCOs and ESCOs can all be different agents that communicate each other in real time operations.

3. The principal's of optimal location in transmission system can be extended to distribution system with the help of GIS. 


\section{APPENDIX}

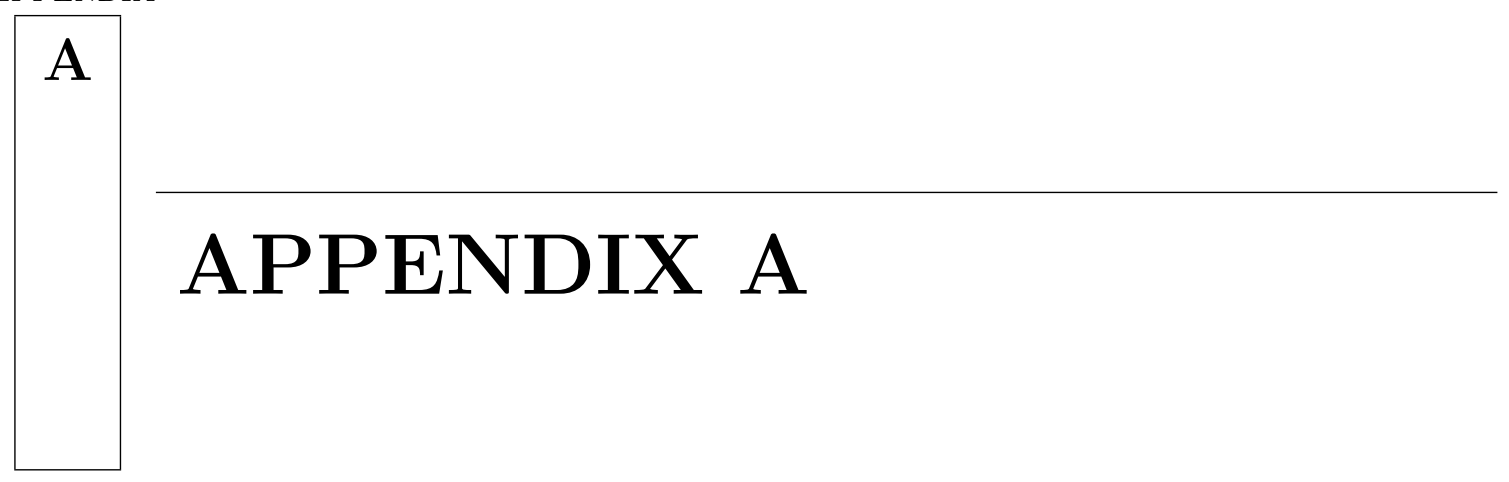

\section{A.1 Network and Market Data}

\section{A.1.1 PSAT Data Format}

The following tables ${ }^{1}$ illustrate the PSAT data structure.

Table A.1: Bus Data Format (Bus.con)

\begin{tabular}{c|l|c}
\hline Column & Description & Unit \\
\hline \hline 1 & Bus number & int \\
2 & Voltage base & $\mathrm{kV}$ \\
$\dagger 3$ & Voltage amplitude initial guess & $\mathrm{p.u.}$ \\
$\dagger 4$ & Voltage phase initial guess & $\mathrm{rad}$ \\
$\dagger 5$ & Area number (not used yet...) & int \\
$\dagger 6$ & Region number (not used yet...) & int \\
\hline
\end{tabular}

\footnotetext{
${ }^{1}$ In this table and remaining tables in this chapter, fields marked with $\dagger$ are optional
} 
Table A.2: $P Q$ Data Format (PQ.con)

\begin{tabular}{c|l|c}
\hline Column & Description & Unit \\
\hline \hline 1 & Bus number & int \\
2 & Power rating & MVA \\
3 & Voltage rating & $\mathrm{kV}$ \\
4 & Active power & p.u. \\
5 & Reactive power & p.u. \\
$\dagger 6$ & Maximum voltage & p.u. \\
$\dagger 7$ & Minimum voltage & p.u. \\
$\dagger 8$ & Allow conversion to impedance & boolean. \\
\hline
\end{tabular}

Table A.3: $P V$ Data Format (PV.con)

\begin{tabular}{c|l|c}
\hline Column & Description & Unit \\
\hline \hline 1 & Bus number & int \\
2 & Power rating & MVA \\
3 & Voltage rating & $\mathrm{kV}$ \\
4 & Active power & $\mathrm{p} . \mathrm{u}$. \\
5 & Voltage magnitude & $\mathrm{p} . \mathrm{u}$. \\
$\dagger 6$ & Maximum reactive power & $\mathrm{p} . \mathrm{u}$. \\
$\dagger 7$ & Minimum reactive power & $\mathrm{p} . \mathrm{u}$. \\
$\dagger 8$ & Maximum voltage & $\mathrm{p} . \mathrm{u}$. \\
$\dagger 9$ & Minimum voltage & $\mathrm{p} . \mathrm{u}$. \\
$\dagger 10$ & Loss participation coefficient & - \\
\hline
\end{tabular}

Table A.4: Shunt Data Format (Shunt.con)

\begin{tabular}{c|l|c}
\hline Column & Description & Unit \\
\hline \hline 1 & Bus number & int \\
2 & Power rating & $\mathrm{MVA}$ \\
3 & Voltage rating & $\mathrm{kV}$ \\
4 & Frequency rating & $\mathrm{Hz}$ \\
5 & Conductance & p.u. \\
6 & Susceptance & p.u. \\
\hline
\end{tabular}


Table A.5: $S W$ Data Format (SW.con)

\begin{tabular}{c|l|c}
\hline Column & Description & Unit \\
\hline \hline 1 & Bus number & int \\
2 & Power rating & MVA \\
3 & Voltage rating & $\mathrm{kV}$ \\
4 & Voltage magnitude & p.u. \\
5 & Reference angle & p.u. \\
$\dagger 6$ & Maximum reactive power & p.u. \\
$\dagger 7$ & Minimum reactive power & p.u. \\
$\dagger 8$ & Maximum voltage & p.u. \\
$\dagger 9$ & Minimum voltage & p.u. \\
$\dagger 10$ & Active power guess & p.u. \\
$\dagger 11$ & Loss participation coefficient & - \\
\hline
\end{tabular}

Table A.6: Line Data Format (Line.con)

\begin{tabular}{c|l|c}
\hline Column & Description & Unit \\
\hline \hline 1 & From Bus & int \\
2 & To Bus & int \\
3 & Power Rating & MVA \\
4 & Voltage Rating & $\mathrm{kV}$ \\
5 & Frequency Rating & $\mathrm{Hz}$ \\
6 & Line Length & $\mathrm{km}$ \\
7 & (not used yet...) & - \\
8 & Resistance & p.u. $(\Omega / \mathrm{km})$ \\
9 & Reactance & p.u. $(\mathrm{H} / \mathrm{km})$ \\
10 & Susceptance & p.u. $(\mathrm{F} / \mathrm{km})$ \\
$\dagger 11$ & (not used yet...) & - \\
$\dagger 12$ & (not used yet...) & - \\
$\dagger 13$ & Current limit & p.u. \\
$\dagger 14$ & Active power limit & p.u. \\
$\dagger 15$ & Apparent power limit & p.u. \\
\hline
\end{tabular}


Table A.7: Demand Data Format (Demand.con)

\begin{tabular}{c|l|c}
\hline Column & Description & Unit \\
\hline \hline 1 & Bus number & int \\
2 & Power Rating & MVA \\
3 & Forecasted active power & p.u. \\
4 & Forecasted reactive power & p.u. \\
5 & Maximum power bid & p.u. \\
6 & Minimum power bid & p.u. \\
7 & Actual power bid & p.u. \\
8 & Fixed cost(active power) & p.u. $(\$ / h)$ \\
9 & Proportional cost(active power) & p.u. $(\$ / M W h)$ \\
10 & Quadratic cost(active power) & p.u. $\left(\$ / M W^{2} h\right)$ \\
11 & Fixed cost(reactive power) & p.u. $(\$ / h)$ \\
12 & Proportional cost(reactive power) & p.u. $(\$ / M V A r h)$ \\
13 & Quadratic cost(active power) & p.u. $\left(\$ / M W^{2} h\right)$ \\
& \multicolumn{2}{|}{} \\
\hline
\end{tabular}

Table A.8: Supply Data Format (Supply.con)

\begin{tabular}{c|l|c}
\hline Column & Description & Unit \\
\hline \hline 1 & Bus number & int \\
2 & Power Rating & MVA \\
3 & Forecasted active power & p.u. \\
4 & Forecasted reactive power & p.u. \\
5 & Maximum power bid & p.u. \\
6 & Minimum power bid & p.u. \\
7 & Actual power bid & p.u. \\
8 & Fixed cost(active power) & p.u. $(\$ / h)$ \\
9 & Proportional cost(active power) & p.u. $(\$ / M W h)$ \\
10 & Quadratic cost(active power) & p.u. $\left(\$ / M W^{2} h\right)$ \\
11 & Fixed cost(reactive power) & p.u. $(\$ / h)$ \\
12 & Proportional cost(reactive power) & p.u. $(\$ / M V A r h)$ \\
13 & Quadratic cost(active power) & p.u. $\left(\$ / M W^{2} h\right)$ \\
& \multicolumn{2}{|}{} \\
\hline
\end{tabular}




\section{A.1.2 6-Bus Test System}

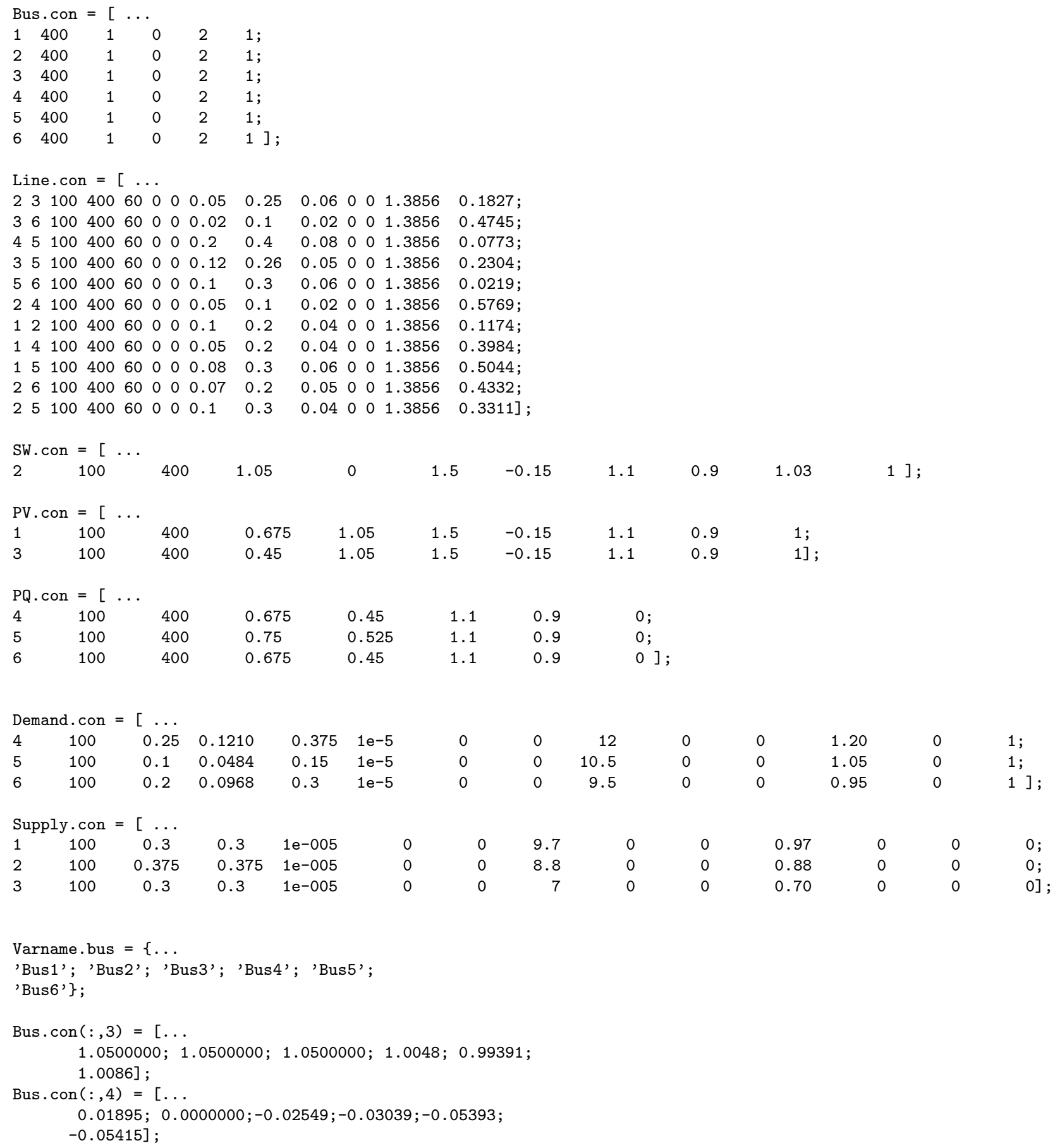

\section{A.1.3 IEEE 14-Bus Test System}

Bus.con $=[\ldots$ 


$\begin{array}{lllllllll}1 & 69 & 1 & 0 & 4 & 1 ; & & & \\ 2 & 69 & 1 & 0 & 4 & 1 ; & & & \\ 3 & 69 & 1 & 0 & 4 & 1 ; & & & \\ 4 & 69 & 1 & 0 & 4 & 1 ; & & & \\ 5 & 69 & 1 & 0 & 4 & 1 ; & & & \\ 6 & 13.8 & & 1 & & 0 & 2 & 1 ; \\ 7 & 13.8 & & 1 & & 0 & 2 & 1 ; \\ 8 & 18 & 1 & 0 & 3 & 1 ; & & & \\ 9 & 13.8 & & 1 & & 0 & 2 & 1 ; \\ 10 & 13.8 & & 1 & & 0 & 2 & 1 ; \\ 11 & 13.8 & & 1 & & 0 & 2 & 1 ; \\ 12 & 13.8 & & 1 & & 0 & 2 & 1 ; \\ 13 & 13.8 & & 1 & & 0 & 2 & 1 ; \\ 14 & 13.8 & & 1 & & 0 & 2 & 1] ;\end{array}$

\begin{tabular}{|c|c|c|c|c|c|c|c|c|c|c|c|c|c|c|}
\hline \multicolumn{15}{|c|}{ Line.con $=[$} \\
\hline 2 & 5 & 100 & 69 & 60 & 0 & 0 & 0.05695 & 0.17388 & 0.034 & 0 & 0 & 0 & 0 & 0 \\
\hline 6 & 12 & 100 & 13.8 & 60 & 0 & 0 & 0.12291 & 0.25581 & 0 & 0 & 0 & 0 & 0 & 0 \\
\hline 12 & 13 & 100 & 13.8 & 60 & 0 & 0 & 0.22092 & 0.19988 & 0 & 0 & 0 & 0 & 0 & 0 \\
\hline 6 & 13 & 100 & 13.8 & 60 & 0 & 0 & 0.06615 & 0.13027 & 0 & 0 & 0 & 0 & 0 & 0 \\
\hline 6 & 11 & 100 & 13.8 & 60 & 0 & 0 & 0.09498 & 0.1989 & 0 & 0 & 0 & 0 & 0 & 0 \\
\hline 11 & 10 & 100 & 13.8 & 60 & 0 & 0 & 0.08205 & 0.19207 & 0 & 0 & 0 & 0 & 0 & 0 \\
\hline 9 & 10 & 100 & 13.8 & 60 & 0 & 0 & 0.03181 & 0.0845 & 0 & 0 & 0 & 0 & 0 & 0 \\
\hline 9 & 14 & 100 & 13.8 & 60 & 0 & 0 & 0.12711 & 0.27038 & 0 & 0 & 0 & 0 & 0 & 0 \\
\hline 14 & 13 & 100 & 13.8 & 60 & 0 & 0 & 0.17093 & 0.34802 & 0 & 0 & 0 & 0 & 0 & 0 \\
\hline 7 & 9 & 100 & 13.8 & 60 & 0 & 0 & 0 & 0.11001 & 0 & 0 & 0 & 0 & 0 & 0 \\
\hline 1 & 2 & 100 & 69 & 60 & 0 & 0 & 0.01938 & 0.05917 & 0.0528 & 0 & 0 & 0 & 0 & 0 \\
\hline 3 & 2 & 100 & 69 & 60 & 0 & 0 & 0.04699 & 0.19797 & 0.0438 & 0 & 0 & 0 & 0 & 0 \\
\hline 3 & 4 & 100 & 69 & 60 & 0 & 0 & 0.06701 & 0.17103 & 0.0346 & 0 & 0 & 0 & 0 & $0 ;$ \\
\hline 1 & 5 & 100 & 69 & 60 & 0 & 0 & 0.05403 & 0.22304 & 0.0492 & 0 & 0 & 0 & 0 & 0 \\
\hline 5 & 4 & 100 & 69 & 60 & 0 & 0 & 0.01335 & 0.04211 & 0.0128 & 0 & 0 & 0 & 0 & 0 \\
\hline 2 & 4 & 100 & 69 & 60 & 0 & 0 & 0.05811 & 0.17632 & 0.0374 & 0 & 0 & 0 & 0 & 0 \\
\hline 5 & 6 & 100 & 69 & 60 & 0 & 5 & 0 & 0.25202 & 0 & 0.932 & 0 & 0 & 0 & 0 \\
\hline 4 & 9 & 100 & 69 & 60 & 0 & 5 & 0 & 0.55618 & 0 & 0.969 & 0 & 0 & 0 & 0 \\
\hline 4 & 7 & 100 & 69 & 60 & 0 & 5 & 0 & 0.20912 & 0 & 0.978 & 0 & 0 & 0 & 0 \\
\hline 8 & 7 & 100 & 18 & 60 & 0 & 1.30435 & 0 & 0.17615 & 0 & 0 & 0 & 0 & 0 & 0 \\
\hline
\end{tabular}

Line.con $(:, 13)=1.5498$

Line.con $(:, 14)=[0.49535 ; 0.09027 ; 0.01987 ; 0.21251 ; 0.08948 ; 0.03882 ; 0.07662 ; 0.12167 ; 0.07268 ; 0.38089 ; \ldots$ $1.9237 ; 0.89421 ; 0.24213 ; 0.89121 ; 0.78599 ; 0.6519 ; 0.54778 ; 0.21166 ; 0.38089 ; 0] * 0.9$;

SW. con $=[\ldots$

$\left.\begin{array}{lllllllllll}1 & 100 & 69 & 1.06 & 0 & 1.0 & -0.4 & 1.1 & 0.9 & 2.324 & 1\end{array}\right]$;

PV.con $=[\ldots$

$\begin{array}{ccclllllll}2 & 100 & 69 & 0.4 & 1.045 & 0.5 & -0.4 & 1.1 & 0.9 & 1 ; \\ 3 & 100 & 13.8 & 0 & 1.07 & 0.4 & -0.4 & 1.1 & 0.9 & 1 ; \\ 6 & 100 & 69 & 0 & 1.01 & 0.24 & -0.06 & 1.1 & 0.9 & 1 ; \\ 8 & 100 & 18 & 0 & 1.09 & 0.24 & -0.06 & 1.1 & 0.9 & 1] ; ;\end{array}$

$\begin{array}{lrrrrrrl}\text { PQ.con }=[\ldots & \ldots & & & & \\ 11 & 100 & 13.8 & 0.035 & 0.018 & 1.1 & 0.9 & 0 ; \\ 13 & 100 & 13.8 & 0.135 & 0.058 & 1.1 & 0.9 & 0 ; \\ 3 & 100 & 69 & 0.942 & 0.19 & 1.1 & 0.9 & 0 ; \\ 5 & 100 & 69 & 0.076 & 0.016 & 1.1 & 0.9 & 0 ; \\ 2 & 100 & 69 & 0.217 & 0.127 & 1.1 & 0.9 & 0 ; \\ 6 & 100 & 13.8 & 0.112 & 0.075 & 1.1 & 0.9 & 0 ; \\ 4 & 100 & 69 & 0.478 & 0.04 & 1.1 & 0.9 & 0 ; \\ 14 & 100 & 13.8 & 0.149 & 0.05 & 1.1 & 0.9 & 0 ; \\ 12 & 100 & 13.8 & 0.061 & 0.016 & 1.1 & 0.9 & 0 ; \\ 10 & 100 & 13.8 & 0.09 & 0.058 & 1.1 & 0.9 & 0 ; \\ 9 & 100 & 13.8 & 0.295 & 0.166 & 1.1 & 0.9 & 0] ;\end{array}$




\begin{tabular}{|c|c|c|c|c|c|c|c|c|c|c|c|c|}
\hline \multirow{3}{*}{$\begin{array}{l}\mathrm{Su} \\
1 \\
2\end{array}$} & $\begin{array}{c}y \cdot \text { con } \\
100\end{array}$ & $\begin{array}{l}\cdots \\
0.10\end{array}$ & 1.0 & $1 e-005$ & 0 & 0 & 10.2 & 0 & 0 & 1.02 & 0 & 0 \\
\hline & 100 & 0.10 & 2.0 & $1 e-005$ & 0 & 0 & 9.5 & 0 & 0 & 0.95 & 0 & 0 \\
\hline & 100 & 0.10 & 2.0 & $1 e-005$ & 0 & 0 & 11.3 & 0 & 0 & 1.13 & 0 & 0 \\
\hline
\end{tabular}

\begin{tabular}{|c|c|c|c|c|c|c|c|c|c|c|c|c|c|c|}
\hline \multicolumn{15}{|c|}{ Demand. con $=[\ldots$} \\
\hline 2 & 100 & 0.1519 & 0.0646 & 0.3038 & $1 e-5$ & 0 & 0 & 13 & 0 & 0 & 1.300 & 0 & 0 & 0 \\
\hline 3 & 100 & 0.6595 & 0.2803 & 1.319 & $1 e-5$ & 0 & 0 & 13.2 & 0 & 0 & 1.320 & 0 & 0 & 0 \\
\hline 4 & 100 & 0.3346 & 0.1422 & 0.6692 & $1 e-5$ & 0 & 0 & 12.1 & 0 & 0 & 1.210 & 0 & 0 & 0 \\
\hline 5 & 100 & 0.0532 & 0.0226 & 0.1064 & $1 e-5$ & 0 & 0 & 12.33 & 0 & 0 & 1.233 & 0 & 0 & 0 \\
\hline 6 & 100 & 0.0784 & 0.0333 & 0.1568 & $1 e-5$ & 0 & 0 & 12.24 & 0 & 0 & 1.224 & 0 & 0 & 0 \\
\hline 9 & 100 & 0.2065 & 0.0878 & 0.4130 & $1 e-5$ & 0 & 0 & 13.55 & 0 & 0 & 1.355 & 0 & 0 & $0 ;$ \\
\hline 10 & 100 & 0.063 & 0.0268 & 0.1260 & $1 e-5$ & 0 & 0 & 14.66 & 0 & 0 & 1.466 & 0 & 0 & 0 \\
\hline 11 & 100 & 0.0245 & 0.0104 & 0.0490 & $1 e-5$ & 0 & 0 & 13.67 & 0 & 0 & 1.367 & 0 & 0 & $0 ;$ \\
\hline 12 & 100 & 0.0427 & 0.0182 & 0.0854 & $1 e-5$ & 0 & 0 & 14.62 & 0 & 0 & 1.462 & 0 & 0 & $0 ;$ \\
\hline 13 & 100 & 0.0945 & 0.0402 & 0.1890 & $1 e-5$ & 0 & 0 & 14.22 & 0 & 0 & 1.422 & 0 & 0 & 0 \\
\hline 14 & 100 & 0.1043 & 0.0443 & 0.2086 & $1 e-5$ & 0 & 0 & 14.45 & 0 & 0 & 1.445 & 0 & 0 & 0] ; \\
\hline
\end{tabular}

Demand. $\operatorname{con}(:, 4)=$ Demand $\operatorname{con}(:, 3) * 0.425$;

Varname. bus $=\{\ldots$

'Bus 01'; 'Bus 02'; 'Bus 03'; 'Bus 04'; 'Bus 05';

'Bus 06'; 'Bus 07'; 'Bus 08'; 'Bus 09'; 'Bus 10';

'Bus 11'; 'Bus 12'; 'Bus 13'; 'Bus 14'\}; 


\section{References}

[1] Abdel-Moamen, M. A., Padhy, N. P., "Optimal power flow incorporating FACTS devices - bibliography and survey," IEEE PES Transmission and Distribution Conference and Exposition, Vol. 2, pp. 669-676, Sept. 2003.

[2] Ajjarapu, V., Christy, C., "The Continuation Power Flow: A Tool for Steady State Voltage Stability Analysis," IEEE Transactions on Power Systems, Vol. 7, no. 1, pp. 416-423, Feb. 1992.

[3] Alsac, O., Bright, J., Prais, M., Stott, M., "Further Developments in LP based Optimal Power Flow," IEEE Transactions on Power Systems, Vol. 5, no. 3, pp. 697-711, Aug. 1990.

[4] Alvarado, F. L., Jung, T. H., "Direct Detection of Voltage Collapse Conditions," Proc. Bulk Power System Voltage Phenomena-Voltage Stability and Security , EL-6183, EPRI, pp. 5.23-5.38, Jan. 1989.

[5] Ambriz-Perez, H., Acha, E., Fuerte-Esquivel, C. R., "Advanced SVC models for NewtonRaphson load flow and Newton optimal power flow studies," IEEE Transactions on Power Systems, Vol. 15, no. 1, pp. 129-136, Feb. 2000.

[6] Ambriz-Perez, H. et al., "Incorporation of a UPFC model in an optimal power flow using Newton's method," IEE Proceedings: Generation, Transmission and Distribution, Vol. 145, no. 3, pp. 336-344, May 1998.

[7] Arabi, S., Kundur, P., Adapa, R., "Innovative Techniques in Modeling UPFC for Power System Analysis," IEEE Transactions of Power Systems, Vol. 15, No. 1, pp. 336-341, Feb. 2000.

[8] Available Transfer Capability Definition and Determination, Tech. rep., NERC, USA (1996). 
[9] Barcelo, W. R., Lemmon, W. W., "Standardized Sensitivity Coeffcients for Power System Networks," IEEE Transactions on Power Systems, Vol. 3, no. 4, pp. 1591-1599, Nov. 1988.

[10] Baughman, M. L., Siddiqi, S. N., "Real Time Pricing of Reactive Power: Theory and Case Study Results," IEEE Transactions on Power Systems, Vol. 6, no. 1, pp. 23-29, Feb. 1993.

[11] Berizzi, A. et al., "Enhanced Security-Constrained OPF With FACTS Devices," IEEE Transactions on Power Systems, Vol. 20, no. 3, pp. 1597-1605, Aug. 2005.

[12] Brooke, A., Kendrick, D., Meeraus, A., Raman, R., Rosenthal, R. E., GAMS, a User's Guide, available at http://www.gams.com/.

[13] Cai, L. J., Erlich, I., Stamtsis, G. C., "Optimal choice and allocation of FACTS devices using genetic algorithms," IEEE PES Power Systems Conference and Exposition, Vol. 1, pp. 201-207, 2004.

[14] Californina Power Market, Online: http://www.caiso.com/.

[15] Cañizares, C. A., Alvarado, F. L., "Point of Collapse and Continuation Methods for Large AC/DC Systems," IEEE Transactions on Power Systems, Vol. 8, no. 1, pp. 1-8, Feb. 1993.

[16] Cañizares, C. A., "Applications of Optimization to Voltage Collapse Analysis," IEEEPES Summer Meeting, San Diego, USA, July 1998.

[17] Cañizares, C. A., Faur, Z. T., "Analysis of SVC and TCSC controllers in voltage collapse," IEEE Transactions on Power Systems, Vol. 14, no. 1, pp. 158-165, Feb. 1999.

[18] Cañizares, C. A., Rosehart, W., Quintana, V. H., "Costs of Voltage Security in Electricity Markets," Proc. 2001 IEEE-PES Summer Meeting, Seattle, WA, USA, July 2000.

[19] Cañizares, C. A., Chen, H., Rosehart, W., "Pricing System Security in Electricity Markets," Proceedings Bulk Power systems Dynamics and Control - V, Onomichi, Japan, September 2001.

[20] Cañizares, C. A., "Voltage Stability Assesment : Concepts Practices and Tools," IEEEPES Power System Stability Subcommittee Special Publication, SP101PSS, Technical Report, 2002.

[21] Cañizares, C. A., Kodsi, S. K. M., "Dynamic versus steady-state modeling of FACTS controllers in transmission congestion," IEEE Power Engineering Society General Meeting, June 2006.

[22] Carpentier, J., "Contribution a l'ètude du Dispatch Economique," Bulletin de la Société. Francaise des Electriciena, Series. 8, Vol. 3, August 1962.

[23] Cazzol, M. V. et al., "Unified power flow controller (UPFC) model in the framework of interior point based active and reactive OPF procedure," International Journal of Electrical Power and Energy Systems, Vol. 24, no. 6, pp. 431-437, August 2002.

[24] Chattopadhyay, D., Bhattacharya, K., Parikh, J., "Optimal reactive power planning and its spot-pricing: an integrated approach," IEEE Transactions on Power Systems, Vol. 10, no. 4, pp. 2014-2020, Nov. 1995. 
[25] Chiang, H. D., Flueck, A. J., Shah, K. S., Balu, N., "CPFLOW: A Pratical Tool for Tracing Power System Steady-State Stationary Behavior Due to Load and Generation Variations," IEEE Transactions on Power Systems, Vol. 10, no. 2, pp. 623-634, May 1995.

[26] Chen, A. H. L., Nwankpa, C. O., Kawatny, H. G. and ming Yu, X., "Voltage Stability Toolbox: An Introduction and Implementation," Proceedings of North American Power Symposium, MIT, 1996.

[27] Choi, J. Y., Rim, S. H., Park, J. K., "Optimal real time pricing of real and reactive powers," IEEE Transactions on Power Systems, Vol. 3, no. 4, pp. 1226-1231, Nov. 1998.

[28] Chow, J., "Power System Toolbox Version 2.0: Load Flow Tutorial and Functions," Cherry Tree Scientific Software, RR-5 Colborne, Ontario K0K 1S0, 1991-1999.

[29] Chung, T. S., Li, Y. Z., "A hybrid GA approach for OPF with consideration of FACTS devices," IEEE Power Engineering Review, Vol. 21, no. 2, pp. 47-50, Feb. 2001.

[30] De Souza, A. C. Z., Cañizares, C.A., Quintana, V. H., "New techniques to speed up voltage collapse computations using tangent vectors," IEEE Transactions on Power Systems, Vol. 12, No. 3, pp. 1380-1387, Aug. 1997.

[31] Einbom, M., Siddiqi, R., "Electricity Transmission Pricing and Technology," Kluwer Academic Publisher, Boston, MA, 1996.

[32] El-Keib, A. A., Ma, X., "Calculating of Short-run Marginal Costs of Active and Reactive Power Production," IEEE Transactions on Power Systems, Vol. 12, no. 1, pp. 559-565, May 1997.

[33] Feng, W., Shrestha, G. B., "Allocation of TCSC devices to optimize total transmission capacity in a competitive power market," Proceedings of the IEEE Power Engineering Society Transmission and Distribution Conference, Vol. 2, pp. 587-593, 2001.

[34] Feng, W., Shrestha, G. B., "Impacts of TCPAR on spot price power markets," Proceedings of Fifth International Power Engineering Conference (IPEC 2001), Vol. 2, Pt. 2, pp. 592-597, May 2001.

[35] Galiana, G. D., "Assessment and Control of the Impact of FACTS devices on Power System Performance," IEEE Transactions on Power Systems, Vol. 11, No. 4, pp. 19311936, November 1996.

[36] Gerbex, S., Cherkaoui, R., Germond, A. J., "Optimal location of multi-type FACTS devices in a power system by means of genetic algorithms," IEEE Transactions on Power Systems, Vol. 16, no. 3, pp.537-544, Aug. 2001.

[37] Gyugyi, L., "Power Electronics in Electrical Utilitis: Static Var Compensators," Proceedings of the IEEE, Vol. 76 No. 4, pp.483-494, April. 1988.

[38] Gyugi, L. et al., "The Unified power flow controller: a new approach to power transmission control," IEEE Transactions on Power Delivery, Vol. 10, no. 2, pp. 1085-1093, April 1995.

[39] Habur, K., and Oleary, D., "FACTS - Flexiable Alternating Current Transmission Systems, For cost effective and reliable transmission of electrical energy," Available Online : http://www.siemenstd.com/TransSys/pdf/CostEffectiveReliabTrans.pdf. 
[40] Hammons, T. J., Lim, S. K., "Flexible AC Transmission System(FACTS)," Electric Machines and Power Systems, Vol. 25, pp. 73-85, 1997.

[41] Hao, S., Papalexopoulos, A., "Reactive Power Pricing and Management," IEEE Transactions on Power Systems, Vol. 12, no. 1, pp. 95-104, Feb. 1997.

[42] Hasanovic, A., "Modelling and Control of Unified Power Flow Controller (UPFC), thesis, West Virginia University, 2000.

[43] Hingorani, N. G., "Power Electronics in Electrical utilities: Rule of Power Electronics in Future Power Systems," Proceedings of the IEEE, Vol. 76, No. 4, pp.481-482, April 1988.

[44] Hingorani, N. G., "High Power Electronics and Flexible AC Transmission System," IEEE Power Engineering Review, NO. 7, pp 3-4, July 1988.

[45] Hingorani, N. G., Gyugyi, L., "Understanding FACTS Concepts and Technology of Flexible AC Transmission System," IEEE Press, 2000.

[46] Huang,G. M., Yan, P., "TCSC and SVC as Re-dispatch Tools for Congestion Management and TTC Improvement," Proceedings of the IEEE Power Engineering Society Transmission and Distribution Conference, Vol. 1, pp. 660-665, 2002.

[47] Huang,G. M., Yan, P., "Establishing Pricing Schemes for FACTS Devices in Congestion Management," IEEE PES General Meeting, Vol.2, No.2, pp. 1025-30, July 2003.

[48] Huneault, M., Galiana, F. D., "A Survey of the Optimal Power Flow Literature," IEEE Transactions on Power Systems, Vol. 6, no. 2, pp. 762-770, May 1991.

[49] Irisarri, G, D., Wang, X., Tong, J., Mokhtari, S., "Maximum Loadability of Power Systems using Interior Point Nonlinear Optimization Method," IEEE Transactions on Power Systems, Vol. 12, no. 1, pp. 162-172, Feb. 1997.

[50] Kodsi, S. K. M., Accounting for the Effects of Power System Controllers and Stability on Power Dispatch and Electricity Market Prices, dissertation, University of Waterloo, Ontario, Canada, 2005.

[51] Kundur, P., "Power System Stability and Control," McGraw-Hill, 1994.

[52] Kundur, P., Paserba, J., Ajjarappu, V., et.al, "Definition and classification of power system stability IEEE/CIGRE joint task force on stability terms and definitions," IEEE Transactions on Power Systems, Vol. 19, no. 3, pp. 1387-1401, Aug. 2004.

[53] Lakkaraju, T., Feliachi, A., "Selection of Pilot buses for VAR Support Considering N-1 Contingency Criteria," IEEE Power Systems Conference and Exposition, Nov 2006.

[54] Lamont, J. W., Fu. J., "Cost Analysis of Reactive Power Support," IEEE Transactions on Power Systems, Vol. 14, no. 3, pp. 890-898, Aug. 1999

[55] Leung, H. C., Chung, T. S., "Optimal placement of FACTS controller in power system by a genetic-based algorithm," Proceedings of the IEEE 1999 International Conference on Power Electronics and Drive Systems. PEDS'99, Vol. 2, Pt. 2, pp. 833-836, 1999.

[56] Leung, H. C., Chung, T. S., "Optimal power flow with a versatile FACTS controller by genetic algorithm approach," IEEE Power Engineering Society Winter Meeting, Vol. 4, pp. 2806-2811, Jan. 2000. 
[57] Lie, T. T., Deng, W., "Optimal flexible AC transmission systems (FACTS) devices allocation," International Journal of Electical Power Energy Systems Vol. 19, no. 2, pp. 125-134, Feb. 1997.

[58] LMP tutorial, Available at: http://www.pjm.com/services/courses/downloads/lmp101-training.pdf.

[59] Lugtu, R., "Security Constrained Dispatch," IEEE Transactions on Power Apparatus and Systems, Vol. PAS-98, no. 1, pp. 270-274, 1979.

[60] Mahseredjian, J. and Alvarado, F., "Creating an Electromagnetic Transient Program in Matlab: MatEMTP," IEEE Transactions on Power Delivery, Vol. 12, no. 1, pp. 380 - 388, 1997.

[61] Milano, F., Cañizares, C. A., Invernizzi, M., "Multi-objective Optimization for Pricing System Security in Electricity Markets," IEEE Transactions on Power Systems, Vol. 18, no. 2, May 2003.

[62] Milano, F., Pricing System Security in Electricity Market Models with Inclusion of Voltage Stability Constraints, dissertation, University of Genova, 2003.

[63] Milano, F., Cañizares, C. A., Invernizzi, M., "Voltage stability constrained OPF market models considering N - 1 contingency criteria," Electric Power Systems Research, Vol. 74, no. 1, pp. 27-36, April 2005.

[64] Milano, F., "An Open Source Power System Analysis Toolbox," IEEE Transactions on Power Systems, Vol. 20, no. 3, pp. 1199-1206, Aug. 2005.

[65] Milano, F., Cañizares, C. A., Conejo, A. J., "Sensitivity-based security-constrained OPF market clearing model," IEEE Transactions on Power Systems, Vol. 20, no. 4, pp. 20512060, Nov. 2005.

[66] Momoh, J et al., "Challenges to Optimal Power Flow," IEEE Transactions on Power Systems, Vol. 12, no. 1, pp. 444-455, Feb. 1997.

[67] Mori, H., Goto, Y., "A parallel tabu search based method for determining optimal allocation of FACTS in power systems," International Conference on Power System Technology, Vol. 2, Pt.2, pp. 1077-1082, 2000.

[68] Morrison, G. K., Gao, B., Kundur, P, "Voltage stability analysis using static and dynamic approaches," IEEE Transactions on Power Systems, Vol. 8, No. 3, pp. 1159-1171, August 1993.

[69] Nordic Power Market, Online: http://www.nordpool.com/.

[70] Noroozian, M., Angquist, L., Ghandhari, M., Andersson, G., "Use of UPFC for Optimal Power Flow Control," IEEE Transactions on Power Delivery, Vol. 12, no. 4, pp. 16291634, Oct. 1997.

[71] Nyati, S et al., "Design issues for a single core transformer thyristor controlled phaseangle regulator," IEEE Transactions on Power Delivery, Vol. 10, no. 4, pp. 2013-2019, 1995.

[72] de Oliveira, E. J., Marangon Lima, J. W., Pereira, J. L. R., "Flexible AC transmission system devices: allocation and transmission pricing," International Journal of Electrical Power $\&$ Energy Systems, Vol. 21, no. 2, pp. 111-118, Feb. 1999. 
[73] Padhy, N. P., Abdel-Moamen, M. A., Kumar, B. J. P., "Optimal location and initial parameter settings of multiple TCSCs for reactive power planning using genetic algorithms," EEE Power Engineering Society General Meeting, Vol. 1, pp. 1110-1114, 2004.

[74] Palma-Behnke, R et al., "OPF with SVC and UPFC modeling for longitudinal systems," IEEE Transactions on Power Systems, Vol. 19, no. 4, pp. 1742-1753, Nov. 2004.

[75] Paterni, $\mathrm{P}$ et al., "Optimal location of phase shifters in the French network by genetic algorithm," IEEE Transactions on Power Systems, Vol. 14, no. 1, pp. 37-42, Feb. 1999.

[76] PJM Power Market, Online: http://www.pjm.com/index.jsp.

[77] Milano, Federico., PSAT : A Matlab based Power System Analysis Toolbox[Online] Available : http://www.power.uwaterloo.ca/ fmilano.

[78] Rivier, M., Perez-Arriaga, I. J., "Computation and Decomposition of Spot Price for Transmission Pricing," PSCC. Proceedings of the Eleventh Power Systems Computation Conference, Vol.1, pt. 1, pp. 371-378, 1993.

[79] Robak, S., Rasolomampionona, D., "Effectiveness of power system oscillation damping using TCPAR devices," 39th International Universities Power Engineering Conference (UPEC), Vol. 1, Pt. 1, pp. 270-273, Sep. 2004.

[80] Rosehart, W., Cañizares, C. A., Quintana, V. H., "Optimal Power Flow Incorporating Voltage Collapse Constraints, "textitProc. 1999 IEEE-PES Summer Meeting, Edmonton, Alberta, July 1999.

[81] Scheweppe,F. C., Caramanis,M. C., Tabors,R. D., Bohn,R. E., "Spot Pricing of Electricity," Kluwer Academic Publishers, 1988.

[82] Schoder, K., Hasanovic, A., Feliachi, A., "PAT: a power analysis toolbox for MATLAB/Simulink," IEEE Transactions on Power Systems, Vol. 18, no. 1, pp. 42-47, Feb. 2003.

[83] Saaty, T. L., "The Analytic Hierarchy Process," McGraw Hill, New York, 1980.

[84] Seydel, R., Practical Bifurcation and Stability Analysis - From Equilibrium to Chaos, Springer-Verlag, Newyork, second edition, 1994.

[85] Sheble, "Computational Auction Mechanism for Restructured Power Industry Operation," Kluwer Academic Publishers, Norwell, MA, 1998.

[86] Shayanfar, H. A., Kazemi, A., Aghaei, J., "Effective location of facts devices for optimal power flow in deregulated systems," WSEAS Transactions on Circuits and Systems, Vol. 4, no. 1, pp. 32-37, Jan. 2005.

[87] Shirmohammadi, D., Filho, X. V., Goresntin, B., Pereira, M. V. P., "Some fundamental technical concepts about cost based transmission pricing," IEEE Transactions on Power Systems, Vol. 11, no. 2, pp. 1002-1008.

[88] Shrestha, G. B., Feng, W., "Effects of Series Compensation on Spot Price Power Markets," International Journal of Electrical Power and Energy Systems, Vol. 27, No. 5-6, pp.428-436, June/July 2005.

[89] Singh, S. N., David, A. K., "A new approach for placement of FACTS devices in open power markets," IEEE Power Engineering Review, Vol. 21, no. 9, pp. 58-60, Sept. 2001. 
[90] Srivastava, S. C., Verma, R. K., "Impact of FACTS devices on transmission pricing in a deregulated electricity market," Proc. IEEE International Conference on Electric Utility Deregulation Restructuring Power Technologies, pp. 642-648, April 2000.

[91] Stott, B., Marino, J. L., Alsac, O., "Review of Linear Programming Applied to Power System Rescheduling," Proc. PICA IEEE International Conference, pp. 142-154, 1979.

[92] Sybille, G., "SimPowerSystems User's Guide, Version 4, published under sublicense from Hydro-Quebec, and The MathWorks, Inc.," Available at http://www.mathworks.com.

[93] UK Power Market, Online: http://www.elecpool.com/, http://electricity.org.uk/.

[94] UWEE., "Power system test case archive," Online: http://www.ee.washington.edu/research/pstca/

[95] Verma, K. S., Gupta, H. O., "Impact on real and reactive power pricing in open power market using unified power flow controller," IEEE Transactions on Power Systems, Vol. 21, no. 1, pp. 365-371, Feb. 2006.

[96] Vournas, C. D., Potamianakis, E. G., Moors, C. and Cutsem, T. V., " An Educational Simulation Tool for Power System Control and Stability, " IEEE Transactions on Power Systems, Vol. 19, no. 1,pp. 48-55, 2004.

[97] Xie, K. et al., "Decomposition Model and Interior Point Methods for Optimal Spot Pricing of Electricity in Deregulation Environments," IEEE Transactions on Power Systems, Vol. 15, no. 1, pp. 39-50, Feb. 2000.

[98] Online: http://en.wikipedia.org/wiki/Supply_and_demand.

[99] Zhao, J., Zhang, B., Chiang, H, D., "An optimal power flow model and approach with static voltage stability constraints," IEEE/PES Transmission and DistributionConference and Exhibition - Asia and Pacific, pp.15-18, Dalian, China, Aug 2005.

[100] Zimmerman, R. D. and Gan, D., " Matpower, Documentation for version 3.0.0," Power system engineering research center, Cornell University, 2006. Available at http://www.pserc.cornell.edu/matpower/matpower.html. 